JOINT TRANSPORTATION RESEARCH PROGRAM

FHWA/IN/JTRP-2009/7

Final Report

RISK MANAGEMENT AND ASSESSMENT

OF UPGRADING AND STANDARDIZING

GUARDRAIL

Karen Zhu

Shuo Li

December 2009 


\section{TECHNICAL Summary}

INDOT Research

Technology Transfer and Project Implementation Information

TRB Subject Code: 21-7 Safety Appurtenances Design and Placement

Publication No. FHWA/IN/JTRP-2009/7, SPR-3028

December 2009

Final Report

\section{RISK MANAGEMENT AND ASSESSMENT OF UPGRADING AND STANDARDIZING GUARDRAIL}

\section{Introduction}

The Indiana Department of Transportation (INDOT) has installed guardrail systems on interstate highways and other highways in accordance with a variety of standards throughout the years. Traffic volume has increased and the posted speeds have been raised on most INDOT's interstate highways. Consequently, the characteristics of run-off-the-road (ROR) crashes may have changed. In the meantime, material prices have increased considerably and the guardrail maintenance and crash repair costs have increased accordingly. There is no doubt all these changes will not only greatly affect the characteristics of ROR crashes, but also greatly affect the guardrail benefit/cost analysis.

This study examined the current use of roadside guardrails on INDOT roadways, conducted field visits to fatal ROR crash sites, analyzed 2-year ROR crash data, and investigated the characteristics of ROR crashes and main contribution factors. In addition, this study developed the probabilities for ROR crash predictions and identified the costs associated with guardrail crash repairs and maintenance for guardrail benefit/cost analysis.

\section{Findings}

Most guardrails on INDOT highways are Wbeam guardrails with strong posts at $1.905 \mathrm{~m}$ spacing. Some guardrails consist of a steel rubrail. $42.2 \%$ by total guardrail length is placed on interstates, $21.2 \%$ on US highways, and $36.6 \%$ on State highways. The guardrails adjoining bridge ends account for $37.7 \%$ of the total guardrails on interstates, $31.4 \%$ on US highways, and $30.6 \%$ on State highways. The end treatments widely used for shoulder guardrails are Buried-In, CAT, ET 2000 Plus, and SKT 350 terminals. Buried-In terminals constitute $57.7 \%$ of the total number of terminals, followed by CAT (21.8\%), SKT 350 (10.1\%), and ET 2000 Plus (8.8\%). 57.9\% of the terminals are placed on State highways, $23.1 \%$ on US highways, and $19 \%$ on interstates.

Most ROR crashes occurred on the right side of highway. Most ROR crashes involved a single vehicle, accounting for $96.0 \%$ of the total ROR crashes. Traffic volume and weather affected ROR crashes. However, seasonal effects were not clear. It seems that the encroachment rates obtained by this study are less than those in the AASHTO Roadside Design Guide.

Guardrail parts prices increased dramatically in the past years. For end treatment and crash cushion repairs, the majority of the repair costs were spent on parts. Hex-Foam Sandwich demonstrated the greatest repair cost and ET 2000 Plus the lowest repair cost. The repair costs are greatly overestimated for CAT, ET 2000 Plus, SKT 350 and Impact Barrel, but underestimated for other crash cushions in the INDOT Design Manual. The labor rather than the parts consumed the majority of the repair costs for regular guardrail repairs.

\section{Implementation}

The findings will be implemented by INDOT to upgrade the current practices, polices, and design manuals associated with guardrail engineering analysis and design. The findings on the characteristics and contribution factors of the ROR crashes can be utilized by INDOT planning to make more informed decisions.

The encroachment rates, guardrail crash repair costs, and maintenance costs can be used by the design committee to upgrade those default input values for guardrail benefit/cost analysis in the INDOT Design
Manual. The findings on guardrail hardware, and crash repair and maintenance costs can be used by INDOT districts to improve the efficiencies of guardrail crash and repair cost analysis.

A detailed implementation plan will be developed by PIs together with the INDOT Traffic Safety Office personnel. The focus will be on three immediate issues. First, the ArcMap interface will be fine-tuned and used by the Traffic Safety Office to determine if a low cost safety improvement program of 
providing guardrail at unprotected locations can be developed and if the ArcMap application is able to identify candidate routes and projects. Second, the outdated or substandard roadside guardrails, in particular the Buried-In end treatments on NHS highways, will be identified for upgrading. Third, specific needs for improving the roadside safety at those fatal ROR crash sites, such as installation of roadside guardrails, will be determined.

\section{Contacts}

For more information:

Karen Zhu \& Shuo Li

Principal Investigator

Indiana Department of Transportation

Office of Research and Development

West Lafayette, IN 47906

Phone: 765-463-1521

Fax: 765-497-1665

Email: karenzhu@indot.in.gov

$$
\text { sli@indot.in.gov }
$$

\section{Purdue University}

Joint Transportation Research Program

School of Civil Engineering

West Lafayette, IN 47907-1284

Phone: (765) 494-9310

Fax: (765) 496-7996

E-mail: jtrp@ecn.purdue.edu

http://www.purdue.edu/jtrp 
Final Report

FHWA/IN/JTRP-2009/7

\title{
RISK MANAGEMENT AND ASSESSMENT OF UPGRADING AND STANDARDIZING GUARDRAIL
}

\author{
By \\ Karen Zhu, Ph.D. \\ Senior Systems Analysts \\ and \\ Shuo Li, Ph.D., P.E. \\ Research and Pavement Friction Engineer \\ Office of Research and Development \\ Indiana Department of Transportation \\ West Lafayette, Indiana \\ Joint Transportation Research Program \\ Project No. C-36-64O \\ File No. 3-5-15 \\ SPR-3028 \\ Prepared in Cooperation with the \\ Indiana Department of Transportation and the \\ U.S. Department of Transportation \\ Federal Highway Administration
}

The contents of this report reflect the views of the author who is responsible for the facts and the accuracy of the data presented herein. The contents do not necessarily reflect the official views or policies of the Indiana Department of Transportation or the Federal Highway Administration at the time of publication. This report does not constitute a standard, specification, or regulation.

Purdue University

West Lafayette, Indiana 47907

December 2009 
TECHNICAL REPORT STANDARD TITLE PAGE

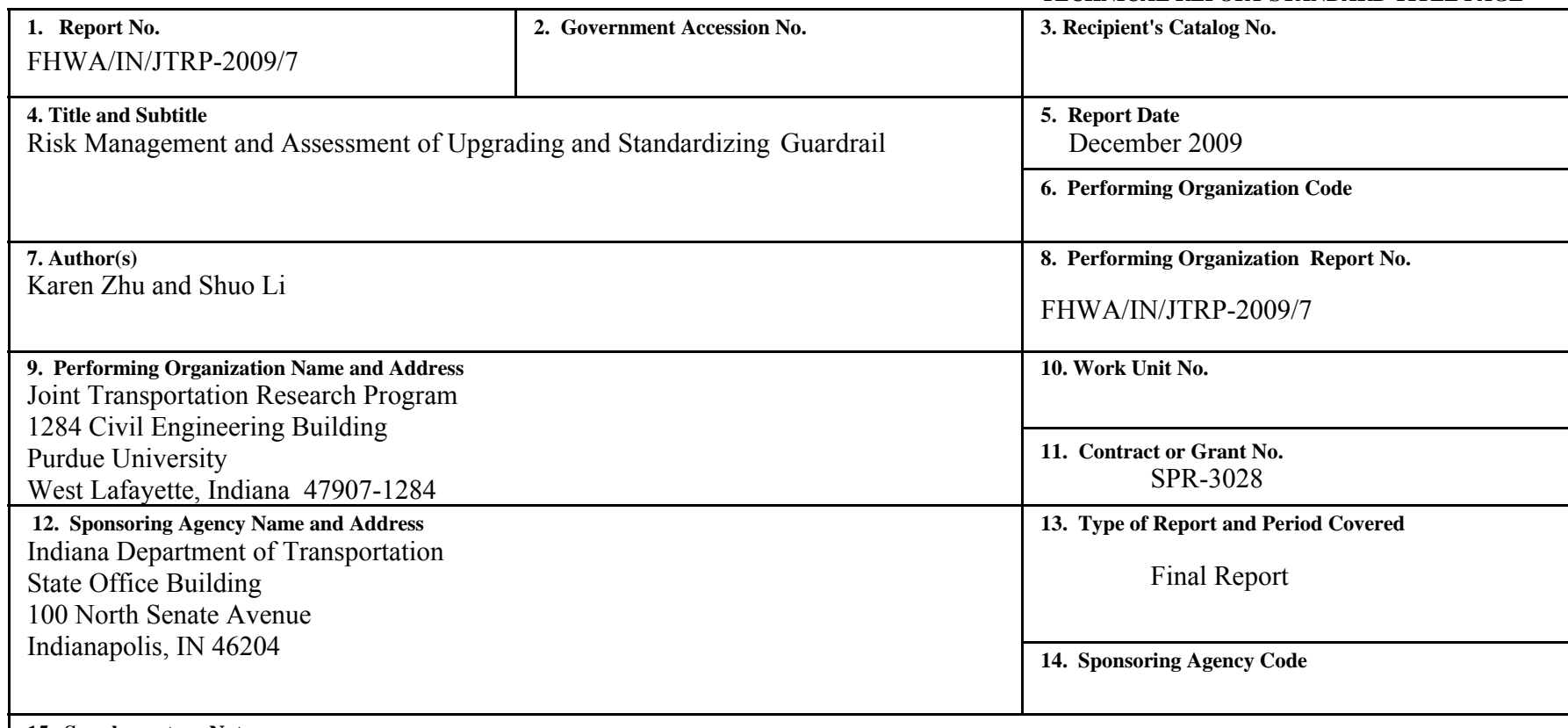

\section{Supplementary Notes}

Prepared in cooperation with the Indiana Department of Transportation and Federal Highway Administration.

\section{Abstract}

The Indiana Department of Transportation (INDOT) has installed guardrail systems on interstate highways and other highways in accordance with a variety of standards throughout the years. Traffic volume has increased and the posted speeds have been raised on most INDOT's interstate highways. Consequently, the characteristics of run-off-the-road (ROR) crashes may have changed. In the meantime, material prices have increased considerably and the guardrail maintenance and crash repair costs have increased accordingly. There is no doubt all these changes will not only greatly affect the ROR crash prediction, but also greatly affect the guardrail benefit/cost analysis. This study examined the current use of roadside guardrails on INDOT intestates, State highways, and US highways, roadways, including types and lengths of guardrails, types and numbers of guardrail end treatments, and field guardrail positions. Based on the records of total 4657 ROR crashes occurred in 2004 and 2006, this study investigated the characteristics of ROR crashes, such as frequencies and locations of ROR crashes, crash consequences (number of vehicles involved, injuries and fatalities), and the effects of main factors, in particular roadway geometrics, seasons and traffic volume, on the highways of different classes. Furthermore, this study investigated the features of vehicle-guardrail crashes, including impact positions and corresponding frequencies and consequences. ROR crash predictions were examined in all aspects in this study, including encroachment rates, crash probabilities, and severity probabilities. It was found that the encroachment rates obtained by this study are less than those in the AASHTO Roadside Design Guide.

This study evaluated the issues associated with the guardrail crash repair costs, such as parts costs, labor costs, and equipment costs. Guardrail steel parts prices increased dramatically. For guardrail terminal crash repairs, the majority of the repair costs were spent on parts. Hex-Foam Sandwich demonstrated the greatest repair cost per crash and ET 2000 Plus demonstrated the lowest repair cost per crash. The repair costs are overestimated for CAT, ET 2000 Plus, SKT 350 and Impact Barrel, but underestimated for other crash cushions in the INDOT Design Manual. Different from the guardrail terminal repairs, the labor rather than the parts consumed the majority of the repair costs for regular guardrail repairs. The average guardrail repair cost is $\$ 722$ per crash that is less than the guardrail repair cost the INDOT Design Manual. The annual average guardrail maintenance cost is $\$ 0.305$ per linear foot. ArcMap was utilized to develop an interface for effectively managing and analyzing guardrails and ROR crash data.

17. Key Words

Run-off-the-road crash, encroachment, guardrail, guardrail face, guardrail end treatment, crash cost, repair cost, maintenance cost, roadside safety data management

\section{Distribution Statement}

No restrictions. This document is available to the public through the National Technical Information Service, Springfield, VA 22161

\begin{tabular}{|c|c|c|c|}
\hline $\begin{array}{c}\text { 19. Security Classif. (of this report) } \\
\text { Unclassified }\end{array}$ & 20. Security Classif. (of this page) & 21. No. of Pages & 22. Price \\
\hline
\end{tabular}




\section{ACKNOWLEDGMENTS}

This research project was sponsored by the Indiana Department of Transportation in cooperation with the Federal Highway Administration through the Joint Transportation Research Program (JTRP). The authors would like to thank the study advisory committee members, Brad Steckler, Eric Conklin, John Nagle, Larry Vaughan, Dennis Belter, Kevin Munro, Rick Drumm, and Steve Thieroff for their valuable assistance and technical guidance in the course of performing this study. The authors are also grateful to Dan Sipes, Randy Large, Vern Van Allen, John Ritter, and Greg Pankow of INDOT for their assistance in data collection. Sincere thanks are extended to Fred Mannering of Purdue University for his assistance in crash data collection. 


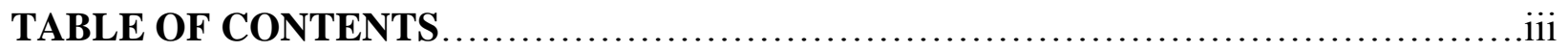

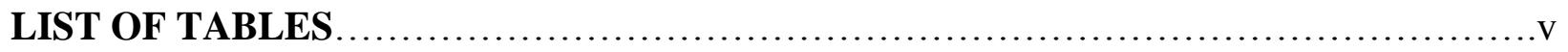

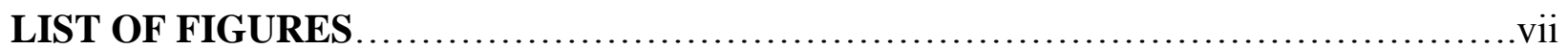

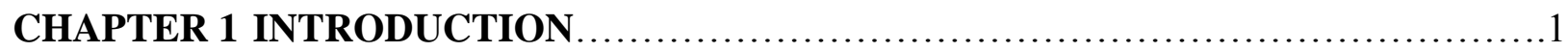

1.1 Problem Statement.......................................................................

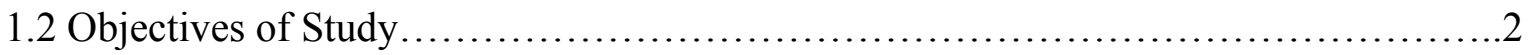

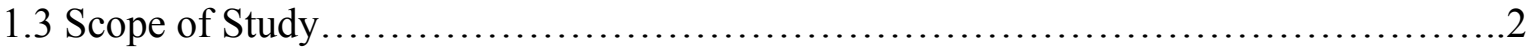

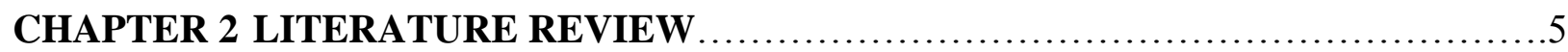

2.1 Testing and Evaluation of Roadside Guardrails.....................................

2.2 Design of Roadside Guardrails................................................

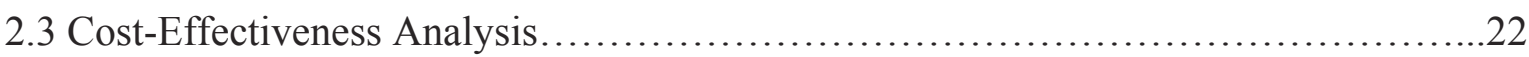

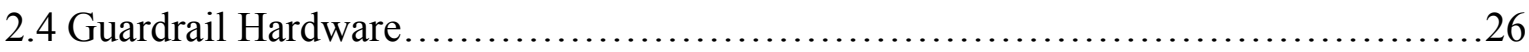

CHAPTER 3 GUARDRAIL SYSTEMS ON INDIANA ROADWAYS ....................31

3.1 The INDOT Highway Network.................................................

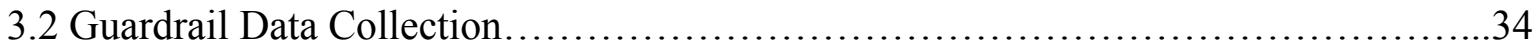

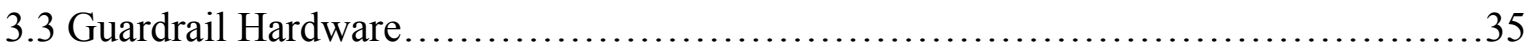

CHAPTER 4 ANALYSIS OF RUN-OFF-ROAD CRASHES .........................43

4.1 The Data Used and Analysis Methods...........................................43

4.2 Breakdown of ROR Accidents............................................... 45

4.3 Contribution Factors to ROR Accidents........................................51

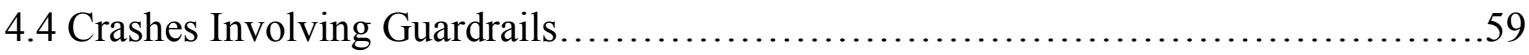

CHAPTER 5 COSTS OF RUN-OFF-ROAD CRASHES ............................ 61

5.1 Guardrail Economic Analysis.....................................................61 
5.2 ROR Crash Costs.......................................................62

5.3 Guardrail Repair and Maintenance Costs....................................69

CHAPTER 6 GIS-INTERFACED SOFTWARE FOR ROR CRASH AND GUARDRAIL

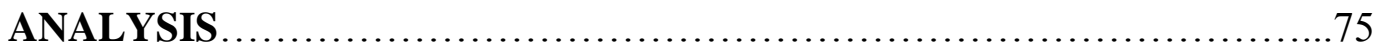

6.1 Software Introduction................................................ 75

6.2 Core Contents and Underlying Database of the Software Interface...................75

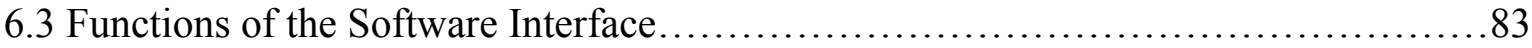

6.4 Expansion of the Software Interface........................................ 88

CHAPTER 7 FINDINGS, RECOMMENDATIONS, AND IMPLEMENTATION.......90

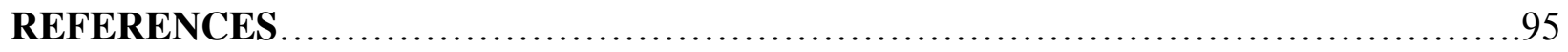




\section{LIST OF TABLES}

Table 2-1 Shy Line Offset Values

Table 2-2 Flare Rates for Guardrail Layout

Table 2-3 Guardrail Runout Lengths

Table 2.4 Clear Zone Distances for 4R Projects

Table 2-5 Shy Line Offset Values

Table 2-6 Guardrail Deflections

Table 3-1 Indiana Interstate Highways

Table 3-2 US Highways in Indiana

Table 3-3 Indiana State Roads

Table 3-4 Illustration of Retrieved Information on Guardrails

Table 4-1 Numbers of ROR Accidents by Side

Table 4-2 Percentages of ROR Accidents by Side

Table 4-3 Breakdown of ROR Accidents by Severity

Table 4-4 Breakdown of ROR Accidents by Highway Category

Table 4-5 Breakdown of ROR Cases by Severity

Table 4-6 Roadway and ROR Crash Information on Three Selected Roads

Table 4-7 Consequences of Vehicle-Guardrail Crashes

Table 5-1 Recommended Encroachment Rate

Table 5-2 ROR Crash Probabilities by Highway Category

Table 5-3 ROR Crash Damage Probabilities by Damage Level

Table 5-4 QPA Prices for CAT

Table 5-5 QPA Prices for SKT 350

Table 5-6 QPA Prices for ET 2000 Plus

Table 5-7 QPA Prices for Impact Barrel

Table 5-8 QPA Prices for QUADGUARD

Table 5-9 QPA Prices for GREAT

Table 5-10 QPA Prices for Hex-Foam Sandwich

Table 5-11 Breakdowns of End Treatment Repair Costs 
Table 5-12 Summary Statistics of Repair Costs per Crash for End Treatments and Crash Cushions (\$) 


\section{LIST OF FIGURES}

Figure 2-1 Illustration of Roadside Slopes

Figure 2-2 Graphical Illustration of Guardrail Placement

Figure 2-3 Guardrail Warrants for Speed $=90 \mathrm{~km} / \mathrm{h}$

Figure 2-4 Graphical Illustration of Guardrail Length of Need

Figure 2-5 Graphical Solution for Guardrail on the Outside of Horizontal Curves

Figure 2-6 Graphical Solution for Guardrail beyond Hazard (Two-Lane Highways)

Figure 2-7 Default ROADSIDE Input Data

Figure 2-8 Repair Cost per Accident

Figure 2-9 4-Rope, High Tensioned WRSF

Figure 2-10 Brifen WRSF Crashworthy End Terminal

Figure 3-1 Typical Roadside Guardrails

Figure 3-2 Typical W-Beam Guardrail Blocks

Figure 3-3 Typical Concrete Barrier on Roadside

Figure 3-4 Breakdown of Guardrail Length on Interstates

Figure 3-5 Percentages of Roadsides Protected with Guardrails

Figure 3-6 Distributions of Roadside Guardrails by Location

Figure 3-7 Photos of Guardrail End Treatments

Figure 3-8 Breakdown of End Treatments by Type

Figure 3-9 Percent Distribution of End Treatments by Highway Category

Figure 3-10 Percent Distribution of Guardrail Terminals

Figure 3-11 Percent Distribution of Guardrail Terminals on Different Highway Categories

Figure 4-1 Photo of a Fatal Crash Scene Taken during Site Visit

Figure 4-2 ROR Accident Numbers Normalized by Highway Length

Figure 4-3 Percent Distributions of ROR Crashes by Geometric Feature

Figure 4-4 Roadway Segments with Vertical Grades and Horizontal Curves

Figure 4-5 Monthly Distributions of ROR Crashes

Figure 4-6 Monthly Distributions of ROR Crash Injuries and Fatalities

Figure 4-7 Variations of ROR Crashes with AADT

Figure 4-8 Variations of ROR Crash Rate with AADT 
Figure 5-1Variations of ROR Rates with AADT

Figure 5-2 Numbers of ROR Crashes by Damage Level

Figure 5-3 Losses of ROR Crashes by Damage Levels

Figure 5-4 Labor Rates

Figure 5-5 Repair Costs for CAT End Treatments

Figure 6-1 A Snap-Shot of the ArcMap Software Interface

Figure 6-2 Attribute table of the "Route_layer" feature

Figure 6-3 Attribute table of the reference post feature

Figure 6-4 Attribute Table of the "Crash2004RunOut" Feature

Figure 6-5 Attribute Table of "Crash2004HitObject" Feature

Figure 6-6 Roadside Objects with Corresponding Key Numbers

Figure 6-7 Attribute Table of the "GuardRailD" Feature

Figure 6-8 ArcMap Interface with the Table of Content Showing AADT Classifications

Figure 6-9 ArcMap Interface with the Table of Content Showing Highway Types and Number of Lanes

Figure 6-10 Distribution of 2004 ROR Crashes on Indiana Highways

Figure 6-11 A Zoomed-In Area of the 2004 ROR Crash Sites

Figure 6-12 Step 1 of the Query Example

Figure 6-13 Step 2 of the Query Example

Figure 6-14 Step 3 of the Query Example

Figure 6-15 Step 4 of the Query Example

Figure 6-16 ArcMap Interface with the Map Showing 2006 ROR Fatal Crashes

Figure 6-17 Analysis of a 2006 Fatal ROR Crash 


\section{Chapter 1}

\section{INTRODUCTION}

\subsection{Problem Statement}

In order to provide uniform criteria for installing guardrail systems, the American Association of State Highway and Transportation Officials (AASHTO) Roadside Design Guide (1) suggests that all guardrails or barriers pass NCHRP Report 350 testing criteria determined in 1993 (2). The warrants for installing highway guardrail systems are established by taking into account those factors such as highway geometrics, roadside hazardous conditions, traffic characteristics, experience, costs, and historic vehicle run-off-the-road (ROR) crash data. Currently, Chapter 49 of the Indiana Department of Transportation (INDOT) Design Manual (3) guides the installation of guardrail systems on INDOT highways, including the selection of guardrail type, computation of guardrail length of need, lateral/longitudinal placement of the guardrails, transition section arrangement, and end treatment. In the past decades, however, the design guidelines and criteria for highway guardrail systems have evolved because of the accumulation of field expertise, collective knowledge and judgment, and emerging technologies. Likewise, INDOT has installed guardrail systems on interstate highways and other highways in accordance with a variety of standards throughout the years.

Recent field surveys conducted on four highways such as I-64, I-265, SR-243, and US231 and a scoping review of the statewide guardrail systems undertaken using the INDOT's Video Log System indicated that there are large discrepancies in the placement and type of guardrail systems installed even on the same stretch of highway over the years. In the meantime, traffic volume has increased continuously on INDOT highways and the truck percentages have grown dramatically. The posted speed has been raised to $70 \mathrm{mph}$ on most INDOT's interstate highways. Consequently, the characteristics of ROR crashes, such as frequency, severity, and damages, may have changed. In the meantime, material prices, in particular steel prices, have increased significantly due to the dramatic change of global economic environment, and the guardrail parts prices have changed accordingly. There is no doubt all these changes will not 
only greatly affect the ROR crash prediction, but also greatly affect the guardrail benefit/cost analysis.

\subsection{Objectives of Study}

Great efforts have been made by INDOT safety management professionals, design engineers, and planners to assess the guardrail systems. For example, the Division of Planning and Production has collected geometric and safety data from INDOT's Video Log System. Another example is the introduction of the roadside hazard ratings into INDOT's roadside safety evaluation. However, there are thousands of site candidates and guardrail systems on INDOT highways, and the roadside conditions and traffic conditions vary from place to place. In addition, the available safety fund for installation and upgrading of guardrail systems is limited, and the use of Highway Safety Improvement Program (HSIP) funds requires justified rationale. Therefore, it is a pressing need for INDOT to evaluate those factors that may affect roadside safety and guardrail benefit/cost analysis to facilitate INDOT safety management professionals to make more informed decisions on guardrail benefit/cost analysis.

The objectives of the research study are fourfold: to identify the current roadside safety features such as guardrail locations, types of guardrails and end treatments, and total guardrail lengths; to examine the current traffic conditions and ROR crash predictions; to identify the costs incurred due to ROR crashes and guardrail crash repairs; and to develop computer software based on GIS technologies for executing roadside safety and guardrail data management.

\subsection{Scope of Study}

In order to fulfill the study objectives, the scope of work for this research study is presented below:

\section{Literature Review}

A literature review was undertaken to examine and evaluate the related efforts made nationwide in the past years, including INDOT's past and existing practice in design and installation of guardrail systems, other agencies' experience, in particular the state-of-the- 
practice used in assessing guardrail systems, and published research reports and guidelines such as NCHRP Report 350, NCHRP Report 492 (4), NCHRP Report 490 (5), and AASHTO Roadside Design Guide.

\section{Database Development and Data Collection}

The success of this research study depended to a large extent on the data. This study first identified the data need by evaluating the factors considered by INDOT and other agencies in screening guardrail systems and consulting with INDOT engineers and study advisory committee (SAC) members. Accordingly, the optimum database architecture and attributes were determined and a database was developed with different data input accesses. Data on ROR crashes, field guardrails and guardrail crash repair was collected from field inspections, INDOT guardrail data source (GuardRail.xls), INDOT Video Log System, Sub District repair records, guardrail contract documents, and Indiana State Police Automated Reporting Information Exchange System (ARIES) (6).

\section{Analysis of ROR Crashes}

The analysis of ROR crashes was undertaken to examine the characteristics of ROR crashes, including frequencies, severities, damages, injuries, and fatalities by highway classes such as two-lane highways, conventional multi-lane highways, and interstate highways. Further analysis was conducted to evaluate those factors affecting ROR crashes, such as traffic volumes, number of lanes, roadway geometrics, and weather conditions. Based on the analysis results, ROR encroachment rates, ROR crash probabilities, and probabilities of crash severities were determined for ROR crash prediction.

\section{Analysis of Agency Costs}

The analysis of agency costs was performed to estimate guardrail crash repair costs, and routine maintenance costs based on the guardrail crash repair records provided by INDOT Sub Districts. The unit prices for parts, labor, and equipment were evaluated to identify their variations. The summary statistics of guardrail crash repair costs were presented for regular guardrail repairs, and end treatment and crash cushion repairs. Annual guardrail maintenance costs were also determined. 


\section{Roadside Safety and Guardrail Data Management}

A software interface has been developed using Geographic Information System (GIS) technologies to effectively manage roadside safety and guardrail data. With this software interface, users can easily utilize the available GIS application product to view, edit, and query the roadside safety data, including road features, traffic volumes, guardrails, and ROR crashes.

\section{Field Studies}

Field studies were conducted on a selected small highway network consisting of interstates, US highways, and State roads, to verify the methods and computer programs. All selected highways are part of the National Highway System. In addition, field studies were conducted to examine the roadside conditions at the fatal crash scenes, roadway geometric features, and traffic conditions. 
Chapter 2

\section{LITERATURE REVIEW}

\subsection{Testing and Evaluation of Roadside Guardrails}

\section{NCHRP Report 350}

NCHRP Report 350 was published in 1993. It represents a comprehensive update of the procedures for evaluating safety performance. Those updated procedures are intended to conduct vehicle crash testing and in-service evaluation of roadside safety features, including longitudinal barriers (bridge rails, guardrails, median barriers, transitions, and terminals), crash cushions, breakaway or yielding supports for signs and luminaries, breakaway utility poles, truck-mounted attenuators, and work zone traffic control devices. These procedures are also intended to subject roadside safety features to severe vehicle impact conditions rather than to the average highway situations. NCHRP Report 350 identifies new, existing, or modified safety features, defines the level of service for a specific safety feature, and establishes acceptable performance criteria. It aims at the safety performance of roadside safety features and lays the foundation for developing uniform design, testing and evaluation approaches for roadside safety features.

In order to minimize random errors and produce reliable test results, NCHRP Report 350 standardizes test parameters such as testing facility, test article, test vehicle, and surrogate occupants. It also normalizes test conditions such as roadside geometric features and impact conditions, and for longitudinal barriers, terminals, crash cushions, support structures, work zone traffic control devices, breakaway utility poles, which that are of importance for comparing two or more systems. NCHRP Report 350 provides the standard crash tests under six test levels (TLs) so as to evaluate occupant risk, structural integrity of the barrier, and post-impact behavior of the vehicle for a variety of vehicle masses at varying speeds and impact angles:

(1) TL-1, TL-2, and TL-3 test levels $820 \mathrm{~kg}$ car impacting a barrier at an angle of 20 degrees $2000 \mathrm{~kg}$ pick-up truck impacting a barrier at an angle of 25 degrees 
Impact speeds: 50, 70, and $100 \mathrm{~km} / \mathrm{h}$ for TL-1, TL2, and TL-3, respectively

(2) TL-4 test level (In addition to TL-3 matrix)

$8000 \mathrm{~kg}$ single-unit truck impacting a barrier at an angle of 15 degrees at $80 \mathrm{~km} / \mathrm{h}$

(3) TL-5 test level (In addition to TL-3 matrix)

Substitute a $36000 \mathrm{~kg}$ tractor-trailer (van) for the single-unit truck at TL-4.

(4) TL-6 test level (In addition to TL-3 matrix)

Substitute a $36000 \mathrm{~kg}$ tractor-trailer (tanker) for the single-unit truck at TL-4.

For barrier classifications, NCHRP Report 350 recognizes the complex nature of the vehicle crashes and the limited budget available for state highway agencies to monitor the performance of new safety features. It updates the guidelines for in-service evaluation first presented in NCHRP Report 230 (7). NCHPR Report 350 establishes evaluation criteria, taking into account the structural adequacy, occupant risk, post-impact vehicular trajectory, and roadway geometric features. It presents both experimental and operational acceptance phases for barriers. In the experimental phase, a new or modified barrier has acceptably passed crash testing and is classified as experimental and subjected to in-service evaluation. In the operational phase, a new or modified barrier has been found acceptable through an in-service evaluation and is classified as operational and its performance should be monitored continuously. NCHRP Report 350 presents guidance on conducting in-service evaluation for any problems in constructions, maintenance, and crashworthiness.

\section{NCHRP Report 490}

NCHRP Report 490 focuses on the use of in-service evaluation to determine the performance of roadside features under field conditions. It measures the performance of the roadside features in terms of vehicle collision characteristics (number, severity and injuries), roadside geometrics, agency costs and losses due to collision so that designers can optimize the safety benefits relevant to the installation of roadside safety features. In-service performance evaluation is designated to assess the relevance of full-scale crash test procedures. Roadside safety features developed solely according to crash test results may not reflect actual field conditions. In-service performance evaluation can provide independent and objective check on test and evaluation procedures. Roadside safety features may not perform as intended once 
installed. In-service performance evaluation is a process to examine how well the roadside safety features perform under field conditions and identify the underlying problems.

NCHRP Report 490 has identified the advantages of the in-service evaluation over the full-scale crash testing, such as observed conditions, known injury results, and known costs that are critical for engineering analysis of the roadside safety features. NCHRP Report 490 provides extensive information, including police reports, maintenance reports, and inventory data collected in Connecticut, Iowa, and North Carolina. Based on the techniques that have been used in in-service performance evaluation and collision data analysis, NCHRP Report 490 has developed procedures for performing a straightforward evaluation of a roadside safety feature by maintenance workers, DOT engineers, researchers or consultants. The recommended procedures can be used as a general framework for in-service evaluation of roadside safety features or implemented into the routine operations of agencies.

NCHRP Report 490 also examines the issues associated with the installation and inservice performance of two specific terminals such as BCT and MELT terminals. It was revealed that the terminals were often installed and maintained in a manner inconsistent with crash testing conditions. Terminals in place may not perform as intended due to inadequate offsets, incorrect flare, and other installation flaws that can be routinely identified by proactive actions. A scoring system can be utilized to identify poorly installed or poorly maintained roadside safety features that should be upgraded. Such a scoring system can also be employed as an acceptance criterion to ensure contractors undertake quality installation and repair work. In the in-service evaluation of guardrails, NCHRP Report 490 has found out that passenger cars dominated the in-service collision data.

\subsection{Design of Roadside Guardrails}

\section{AASHTO Roadside Design Guide}

(1) The Concept of Clear-Zone

AASHTO Roadside Design Guide 2002 provides the state-of-the-practice for addressing the roadside safety concerns. It defines clearly that the roadside covers the area between the outside shoulder edge and the right-of-way limits. In the design guide, one of the most important 
concepts that have significant impacts on the roadside safety and design is the forgiving roadside. A forgiving roadside allows for errant vehicles leaving the roadway, supports a roadside environment free of fixed objects with stable and flattened slopes, and reduces crashing severity. Base on this cornerstone, the design guide requires a clear roadside that requires an unencumbered roadside recovery that is as wide as practical on a specific highway section. As a general rule of thumb, most highway agencies have started to provide a traversable and unobstructed roadside area, i.e. clear-zone of 9 meters $(30 \mathrm{ft})$ beyond the edge of the through traveled way, in particular on high-speed highways. Obstacles within the clear zone should be removed, relocated, redesigned or shielded by traffic barriers or crash cushions.

The factors that will affect the clear-zone distance include traffic characteristics such as traffic volume and speed, and roadside slope. The roadside slope is classified into foreslope, backslope, and transverse slope (see Figure 2-1). Foreslopes may be considered as recoverable, non-recoverable, or critical. Recoverable foreslopes are $1 \mathrm{~V}: 4 \mathrm{H}$ or flatter. Non-recoverable foreslopes are between $1 \mathrm{~V}: 3 \mathrm{H}$ and $1 \mathrm{~V}: 4 \mathrm{H}$ and are considered traversable if they are smooth and free of obstacles. A critical foreslope is one steeper than $1 \mathrm{~V}: 3 \mathrm{H}$, on which a vehicle is likely to overturn. Backslopes may be identified as traversable and obstacle-free if they are $1 \mathrm{~V}: 3 \mathrm{H}$ or flatter. Transverse slopes created by median crossovers and intersecting side roads are more critical to errant drivers. If possible, transverse slopes of $1 \mathrm{~V}: 10 \mathrm{H}$ are recommended for highspeed roadways.

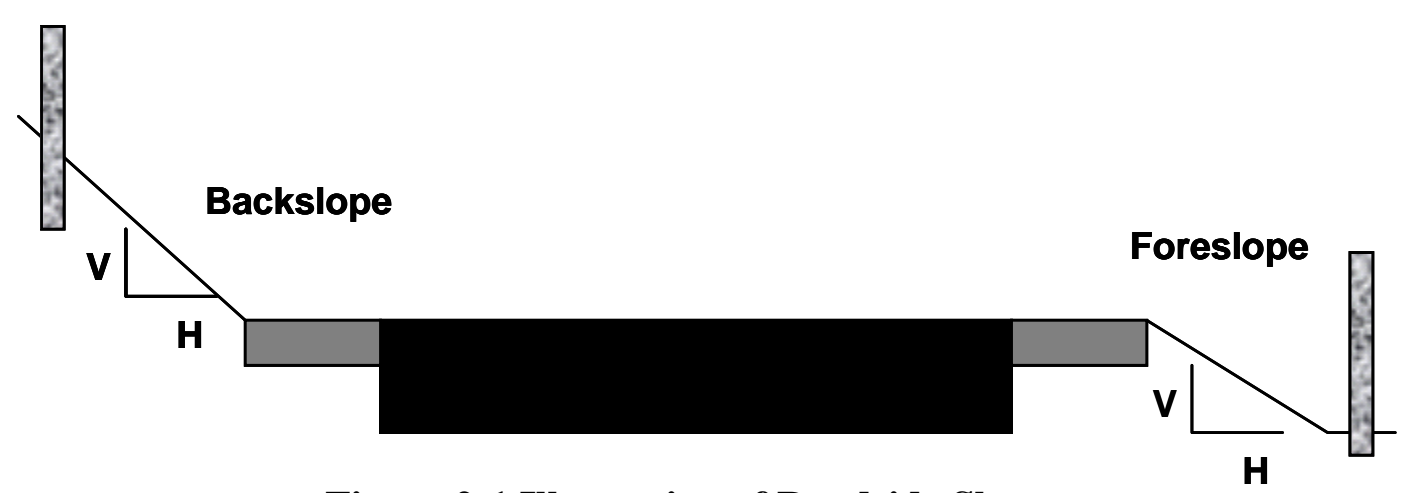

Figure 2-1 Illustration of Roadside Slopes

The AASHTO Roadside Design Guide provides figures and tables for determining the clear-zone distances. However, it should be pointed out that those figures or tables were developed from limited empirical data and represent a reasonable measure of the degree of safety 
for a particular roadside. Therefore, the application of the clear-zone concept depends on the specific situations and amounts to a compromise between maximizing safety and minimizing construction and maintenance costs. For a recoverable foreslope, the clear-zone distance can be identified directly from the figures or tables. For a non-recoverable foreslope, a clear runout area should be provided beyond the toe of the non-recoverable foreslopes. For a critical foreslope, the slope within the clear-zone should be treated or shielded. For backslopes, it is important obstacles not be located on the slopes.

\section{(2) Warrants for Roadside Guardrails}

Guardrails are obstacles in nature. As a result, the basic warrant for installing a guardrail is that reduces the severity of run-off-the-road crashes. In some cases, the guardrail warrants appears subjective. For example, a guardrail is warranted if a vehicle striking an object or running off the road may result in severer consequences than hitting a guardrail. However, engineering or benefit/cost analysis can always be employed to assist highway engineers in making decisions. In the benefit/cost analysis, there are three alternatives, including removal of existing guardrail, installation of a guardrail, and leaving the area of concern unshielded or donothing. The costs consist of costs associated with guardrail installation, maintenance and repair. The benefits include costs associated with any potential accidents. For design purpose, guardrail warrants include highway conditions such as embankments, roadside obstacles, and pedestrians or other bystanders.

The warrants associated with embankments are functions of embankment slope and height. The AASHTO Roadside Design Guide provides a figure to determine if a guardrail is needed solely based on the specific embankment slope and height. Improvements associated with the figure can be achieved by further considering the probability of encroachment and costeffectiveness. Roadside obstacles that may warrant a guardrail include fixed objects (either natural or man-made) and non-traversable terrain. The clear-zone distance can be utilized to determine if an action is needed. The AASHTO Roadside Design Guide also provides tabulated warrants for non-traversable terrain and obstacles. However, there are no objective warrants that have been established to determine the need of a guardrail for pedestrians and other by-standers. A common practice is to separate pedestrians or other by-standers from traffic, in particular on high-speed roadways. 


\section{(3) Design of Guardrails}

The design process of roadway guardrail system involves four steps: a) selection of the guardrail performance level, b) evaluation of the guardrail structural characteristics or the impacting deflection of the guardrail, c) determination of the design parameters, and 4) selection of the guardrail end treatment.

\section{Selection of the Guardrail Performance Level}

As mentioned earlier, NCHRP Report 350 has classified guardrails into six categories, i.e. TL-1, TL-2, TL-3, TL-4, TL-5, and TL-6 in terms of the criteria of performance. In general, roadside guardrails were designed in terms of passenger vehicles with masses up to 4,400 $\mathrm{lb}$ under TL-2. TL-2 guardrails were developed primarily for passenger cars and light truck in lowseverity impacts and are capable of providing limited protection when hit by heavier vehicles. When truck traffic becomes a concern or roadway geometrics are poor, guardrails capable of redirecting vehicles with masses up to 80,000 lb under TL-4 may be employed. In the real world, the selection of guardrail performance level is function of the many factors such as traffic volume, truck percentage, roadway conditions, and cost. The AASHTO Roadside Design Guide has summarized the selection criteria for roadway guardrails.

\section{Evaluation of the Guardrail Structural Characteristics}

The guardrail structural characteristics are usually measured in terms of the deflection which the guardrail may experience upon impact. Based on the distance available between the guardrail and the shielded obstacle, a system of flexible guardrail, semi-rigid guardrail, or rigid guardrail can be selected. The AASHTO Roadside Design Guide has provided the deflection measurements and simulation values for the selected guardrail systems such as single W-Beam, Double W-Beam, single Thrie-Beam and double Thrie-Beam with different post spacing at different impact angles. As the post spacing and the impact angle increase, the deflection increases. The guardrail systems currently available will be discussed later.

\section{Determination of the Parameters for Guardrail Placement}

Once a guardrail system has been selected, highway engineers have to determine the parameters for placing the selected guardrail system. The major parameters such as the lateral 
offset, flare rate, length needed and other variables are graphically illustrated in Figure 2-2. $L_{A}$ is defined as the lateral extent of the fixed object and is measured from the edge of traveled way to the far side of the object. $L_{R}$ is the lateral extent of the so-called runout length and is the distance from the upstream extent of the obstruction to the point at which a vehicle leaves the roadway. $\mathrm{L}_{1}$ is the tangent length of guardrail immediately upstream from the fixed object. $\mathrm{L}_{2}$ is the shorted distance from the edge of through traveled way to the guardrail. $\mathrm{X}$ is the length of need. $\mathrm{Y}$ is the lateral off-set that is measured from the edge of traveled way to the beginning of the length of need. The other lateral distances such as clear distance and lateral offset that have no effects on the guardrail length are not presented in Figure 2-2 but will be discussed as necessary.

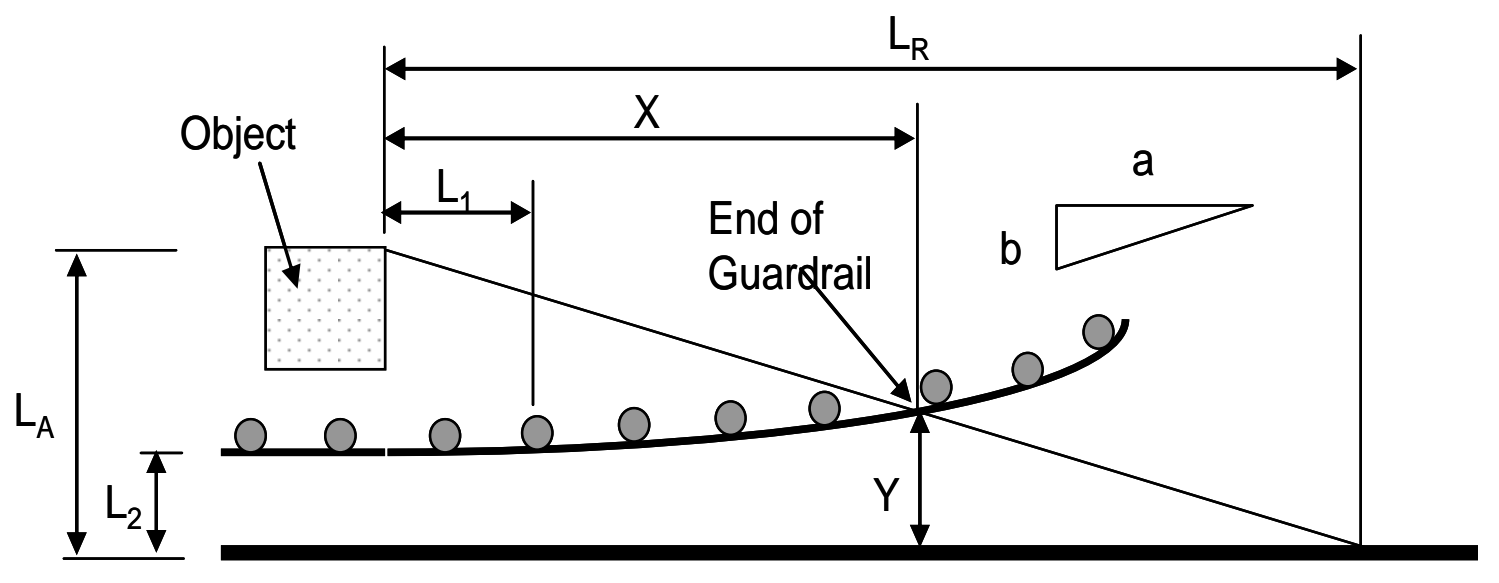

Figure 2-2 Graphical Illustration of Guardrail Placement

Lateral Offset: In general, roadside guardrails should be placed as far from the traveled way as possible if roadway conditions allow. It is also desirable to provide uniform clearance between traveled way and various roadside features, including bridge rails, retaining walls and guardrails so as to mitigate drivers' concerns for those objects. For guardrail placement, there are two lateral distances that have noticeable effects on the guardrail placement. The first lateral distance is the so-called shy line offset that is defined as the distance beyond which a roadside object will not be perceived as an obstacle by drivers. The shy line offset depends mainly on the traffic speed as shown in Table 2-1. It is recommended that the guardrail system be placed beyond the shy line offset, in particular for short and isolated placement. However, it is not necessary to maintain a uniform lateral distance between the traveled way and the guardrail. For 
long and continuous guardrail system, the guardrail system can be gradually transitioned closer to the roadway if the guardrail system is first introduced beyond the shy line offset. As a rule of thumb, a guardrail will not have significant impact on the traffic if the guardrail system is placed beyond the shoulder.

Table 2-1 Shy Line Offset Values

\begin{tabular}{|c|c|c|c|c|c|c|c|c|c|}
\hline Speed, mph & 30 & 40 & 45 & 50 & 55 & 60 & 70 & 75 & 80 \\
\hline Shy Line Offset, ft & 4 & 5 & 6 & 7 & 7 & 8 & 9 & 11 & 12 \\
\hline
\end{tabular}

Source: AASHTO Roadside Design Guide (1).

The second lateral distance highway engineers should consider carefully in guardrail placement is the deflection distance of a guardrail upon impact. To shield a fixed object, the guardrail-to-object distance should be greater than the deflection distance of the guardrail upon impact. Otherwise, the guardrail system should be stiffened by either increasing the post dimension or reducing the post spacing. To shield an embankment, the guardrail-to-embankment distance should not be less than $2 \mathrm{ft}$ so as to provide sufficient support for the guardrail posts.

Flare Rate: When a guardrail is not parallel to the edge of traveled way, it is considered flared. In the field guardrail layout, flare is used for specific purpose of minimizing the drivers' reaction to a fixed object, transitioning a guardrail to bridge or interchange sub-structures, or reducing the total length of the rail needed. The flare rate is expressed as a/b (see Figure 2-2) and depends mainly on the design speed, lateral location, and terrain effects. As highway design speed increases, a flatter rate may be employed. A flatter rate is also recommended when a steep embankment slope exists. When the guardrail is located within the shy line offset distance, a flatter flare rate is justified.

The flare rates suggested by the AASHTO Roadside Design Guide are tabulated in Table 2-2 in terms of the highway design speed and the lateral location of guardrail. It should be noted that there are some disadvantages associated with flaring a section of roadside guardrail. First, the greater the flare rate, the greater the angle at which a vehicle hits the guardrail. Second, a flared guardrail increases the likelihood that a vehicle hitting the guardrail will be redirected back into the roadway or across the roadway. As a result, a flared guardrail will increase the severity of crashes. 
Table 2-2 Flare Rates for Guardrail Layout

\begin{tabular}{|c|c|c|c|c|c|c|c|}
\hline Speed, mph (km/h) & 30 & 40 & 45 & 50 & 55 & 60 & 70 \\
\hline $\begin{array}{c}\text { Flare Rate } \\
\text { (Guardrail inside Shy Line) }\end{array}$ & $13: 1$ & $16: 1$ & $18: 1$ & $21: 1$ & $24: 1$ & $26: 1$ & $30: 1$ \\
\hline $\begin{array}{c}\text { Flare Rate } \\
\text { (Guardrail beyond Shy Line) }\end{array}$ & $\begin{array}{c}8: 1 \sim \\
7: 1\end{array}$ & $\begin{array}{c}10: 1 \sim \\
8: 1\end{array}$ & $\begin{array}{c}12: 1 \sim \\
10: 1\end{array}$ & $\begin{array}{c}14: 1 \sim \\
11: 1\end{array}$ & $\begin{array}{c}16: 1 \sim \\
12: 1\end{array}$ & $\begin{array}{c}18: 1 \sim \\
14: 1\end{array}$ & $\begin{array}{c}20: 1 \sim \\
15: 1\end{array}$ \\
\hline
\end{tabular}

Source: AASHTO Roadside Design Guide (1).

Length of Need: As illustrated in Figure 2-2, the length of need depends on the lateral location of the guardrail $\left(\mathrm{L}_{2}\right)$, the lateral location of the fixed object $\left(\mathrm{L}_{\mathrm{A}}\right)$, the flare rate $(\mathrm{a} / \mathrm{b})$, and the lateral extent of the runout length $\left(\mathrm{L}_{\mathrm{R}}\right)$. The AASHTO Roadside Design Guide provides equations to determine the length of need, $\mathrm{X}$, and the lateral offset, $\mathrm{Y}$ as follows

$$
\begin{aligned}
& X=\frac{L_{A}+(b / a) L_{1}-L_{2}}{(b / a)+\left(L_{A} / L_{R}\right)} . \\
& Y=L_{A}-\frac{L_{A}}{L_{R}} X \ldots \ldots \ldots . . .
\end{aligned}
$$

The runout lengths recommended by the AASHTO Roadside Design Guide are summarized in Table 2-3. These runout lengths were determined in part by adjusting a study of freeway median encroachment and in part by considering driver reaction time. Notice that the lateral extent of the runout length is a theoretical distance required by an errant vehicle to come to a stop. Therefore, the runout length depends on the highway design speed, driver reaction time, traffic volume, and surface friction characteristics of the traveled way. Besides, the runout length varies with traffic volume. The runout lengths shown in Table 2-3 are considered excessive by some state highway agencies. An alternative to determine the runout lengths is to evaluate the encroachment angle based on the cost-effective analysis and identify a guardrail length to intercept a vehicle's runout path.

Terrain Effects: The terrain effects are associated with the use of the drainage curbs and roadside slope. The use of any curb/guardrail combination should be avoided, in particular on high-speed roadways. This is because when a vehicle strikes a curb or traverses a slope, it is 
possible the vehicle may become airborne before hitting the guardrail. Two features associated with the effect of curbs are the height and shape of curb. In general, the height of curb should not exceed 4 in. and the guardrail system should be stiffened to reduce the potential deflection upon impact.

Table 2-3 Guardrail Runout Lengths

\begin{tabular}{|c|c|c|c|c|}
\hline \multirow{3}{*}{$\begin{array}{c}\text { Design } \\
\text { Speed, mph }\end{array}$} & \multicolumn{4}{|c|}{ Average Daily Traffic (ADT) } \\
\cline { 2 - 5 } & Runout Length, ft & Runout Length, ft & Runout Length, ft & Runout Length, ft \\
\hline 30 & 165 & 165 & 150 & 130 \\
\hline 40 & 230 & 200 & 180 & 165 \\
\hline 45 & 260 & 245 & 215 & 200 \\
\hline 50 & 330 & 300 & 260 & 245 \\
\hline 55 & 360 & 345 & 315 & 280 \\
\hline 60 & 425 & 400 & 345 & 330 \\
\hline 70 & 475 & 445 & 395 & 360 \\
\hline
\end{tabular}

Source: AAASHTO Roadside Design Guide (1).

\section{INDOT Chapter 49}

The guardrail design by INDOT is guided by the $49^{\text {th }}$ Chapter of INDOT Design Manual, Roadside Safety. Chapter 49 was developed from the AASHTO Roadside Design Guide in conjunction with the INDOT's experiences and practices. Chapter 49 emphasizes the concept of clear zone derived in the AASHTO Roadside Design Guide, and extends its applications to the 3R (Resurfacing, Restoration, and Rehabilitation) and 4R (New Construction/Reconstruction) projects by INDOT. It provides design procedures, analysis computer program, and design criteria. The other chapters in the INDOT Design Manual

\section{(1) Applicability of the Clear Zone Concept}

The fundamentals of clear zone were derived by assuming a tangent roadway section and level roadside slopes. On a down slope, Chapter 49 requires that the horizontal width of a clear zone be equivalent to a level clear zone so as for an errant vehicle to stop or recover safely. Other factors such as sharp horizontal curves and non-traversable drainage ditches also affect the area alongside the roadway, i.e. the so-called recovery area. In addition, Chapter 49 recognizes the effect of vehicle speed. A slower speed vehicle encroaching upon the roadside would not travel as far from the edge of the travel lane as one operating at a higher speed. Notice that the clear 
zone applies only to $3 \mathrm{R}$ projects and partial $4 \mathrm{R}$ projects on freeways. For $4 \mathrm{R}$ projects, the requirement for a clear zone must be satisfied though new design. For 3R projects, there is an opportunity to further enhance highway safety, in particular at hazard locations.

Chapter 49 presents the clear zone distances for 4R projects as shown in Table 2.4. These distances are derived from the 1988 AASHTO Roadside Design Guide (9) and are the estimates of the traversable area required adjacent to the edge of the travel way. Also, the clear zone distances were developed for tangent sections and various side slopes and were developed by assuming an infinite length of side slope and 3.6-m shoulders. For a given side slope and design year average daily traffic (ADT), the clear zone distance is determined in light of the design speed from Table 2.4. However, the clear zone distances in Table 2.4 are developed from limited empirical data which was then extrapolated to provide data for a wide range of conditions.

Table 2.4 Clear Zone Distances for 4R Projects

\begin{tabular}{|c|c|c|c|c|c|c|c|c|c|c|c|}
\hline \multirow{2}{*}{$\begin{array}{l}\text { Design } \\
\text { Speed }\end{array}$} & \multirow{2}{*}{$\begin{array}{c}\text { Design Year } \\
\text { AADT } \\
\text { (T) }\end{array}$} & \multicolumn{5}{|c|}{ Cut Slopes } & \multicolumn{5}{|c|}{ Fill Slopes } \\
\hline & & $3: 1$ & $4: 1$ & $5: 1$ & $6: 1$ & \multicolumn{2}{|c|}{$\begin{array}{c}\text { Flatter } \\
\text { Than } 6: 1\end{array}$} & $6: 1$ & $5: 1$ & $4: 1$ & $3: 1$ \\
\hline $\begin{array}{c}60 \mathrm{~km} / \mathrm{h} \\
\text { or less }\end{array}$ & $\begin{aligned} & <750 \\
750 & \leq \mathrm{T}<1500 \\
1500 & \leq \mathrm{T}<6000 \\
& \geq 6000\end{aligned}$ & $\begin{array}{l}3.0 \\
3.0 \\
3.5 \\
4.5\end{array}$ & $\begin{array}{l}3.0 \\
3.0 \\
3.5 \\
4.5\end{array}$ & $\begin{array}{l}3.0 \\
3.0 \\
3.5 \\
4.5\end{array}$ & $\begin{array}{l}3.0 \\
3.0 \\
3.5 \\
4.5\end{array}$ & $\begin{array}{l}3.0 \\
3.0 \\
3.5 \\
4.5\end{array}$ & $\begin{array}{l}3.0 \\
3.0 \\
3.5 \\
4.5\end{array}$ & $\begin{array}{l}3.0 \\
3.5 \\
4.0 \\
4.5\end{array}$ & $\begin{array}{l}3.0 \\
3.5 \\
4.5 \\
5.0\end{array}$ & $\begin{array}{l}3.0 \\
4.5 \\
5.0 \\
5.5\end{array}$ & \\
\hline $70 \mathrm{~km} / \mathrm{h}$ & $\begin{aligned} & <750 \\
750 & \leq \mathrm{T}<1500 \\
1500 & \leq \mathrm{T}<6000 \\
& \geq 6000\end{aligned}$ & $\begin{array}{l}3.0 \\
3.0 \\
3.5 \\
4.5\end{array}$ & $\begin{array}{l}3.0 \\
3.5 \\
4.0 \\
4.5\end{array}$ & $\begin{array}{l}3.0 \\
3.5 \\
4.0 \\
5.0\end{array}$ & $\begin{array}{l}3.0 \\
3.5 \\
4.0 \\
5.0\end{array}$ & $\begin{array}{l}3.0 \\
3.5 \\
4.0 \\
5.0\end{array}$ & $\begin{array}{l}3.0 \\
4.5 \\
5.0 \\
6.0\end{array}$ & $\begin{array}{l}3.5 \\
4.5 \\
5.0 \\
6.0\end{array}$ & $\begin{array}{l}3.5 \\
5.0 \\
6.0 \\
7.0\end{array}$ & $\begin{array}{l}4.0 \\
5.0 \\
6.0 \\
7.5\end{array}$ & $\widehat{3}$ \\
\hline $80 \mathrm{~km} / \mathrm{h}$ & $\begin{aligned} & <750 \\
750 & \leq \mathrm{T}<1500 \\
1500 & \leq \mathrm{T}<6000 \\
& \geq 6000\end{aligned}$ & $\begin{array}{l}3.0 \\
3.0 \\
3.5 \\
4.5\end{array}$ & $\begin{array}{l}3.0 \\
3.5 \\
4.0 \\
5.5\end{array}$ & $\begin{array}{l}3.0 \\
4.0 \\
5.0 \\
6.0\end{array}$ & $\begin{array}{l}3.0 \\
4.0 \\
5.0 \\
6.0\end{array}$ & $\begin{array}{l}3.0 \\
4.0 \\
5.0 \\
6.0\end{array}$ & $\begin{array}{l}3.0 \\
4.5 \\
5.0 \\
6.0\end{array}$ & $\begin{array}{l}3.5 \\
5.0 \\
5.5 \\
6.5\end{array}$ & $\begin{array}{l}3.5 \\
5.0 \\
6.0 \\
7.5\end{array}$ & $\begin{array}{l}4.0 \\
6.0 \\
8.0 \\
8.5\end{array}$ & 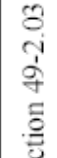 \\
\hline $90 \mathrm{~km} / \mathrm{h}$ & $\begin{aligned} & <750 \\
750 & \leq \mathrm{T}<1500 \\
1500 & \leq \mathrm{T}<6000 \\
& \geq 6000\end{aligned}$ & $\begin{array}{l}3.0 \\
3.0 \\
4.5 \\
5.0\end{array}$ & $\begin{array}{l}3.0 \\
4.5 \\
5.0 \\
6.5\end{array}$ & $\begin{array}{l}3.5 \\
5.0 \\
5.5 \\
7.0\end{array}$ & $\begin{array}{l}3.5 \\
5.0 \\
6.5 \\
7.0\end{array}$ & $\begin{array}{l}4.0 \\
5.0 \\
6.5 \\
7.0\end{array}$ & $\begin{array}{l}4.0 \\
5.0 \\
6.5 \\
7.0\end{array}$ & $\begin{array}{l}4.5 \\
6.0 \\
7.0 \\
8.0\end{array}$ & $\begin{array}{l}4.5 \\
6.5 \\
8.0 \\
8.5\end{array}$ & $\begin{array}{c}6.0 \\
8.0 \\
10.0 \\
10.5\end{array}$ & 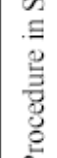 \\
\hline $100 \mathrm{~km} / \mathrm{h}$ & $\begin{aligned} & <750 \\
750 & \leq \mathrm{T}<1500 \\
1500 & \leq \mathrm{T}<6000 \\
& \geq 6000\end{aligned}$ & $\begin{array}{l}3.0 \\
3.5 \\
4.5 \\
6.0\end{array}$ & $\begin{array}{l}4.0 \\
5.0 \\
6.0 \\
7.5\end{array}$ & $\begin{array}{l}4.5 \\
5.5 \\
7.0 \\
8.0\end{array}$ & $\begin{array}{l}4.5 \\
6.0 \\
7.5 \\
8.0\end{array}$ & $\begin{array}{l}5.0 \\
6.5 \\
8.0 \\
9.0\end{array}$ & $\begin{array}{l}5.0 \\
6.5 \\
8.0 \\
9.0\end{array}$ & $\begin{array}{c}5.5 \\
7.5 \\
9.5 \\
10.0\end{array}$ & $\begin{array}{c}6.0 \\
8.0 \\
10.0 \\
11.0\end{array}$ & $\begin{array}{c}7.5 \\
10.0 \\
12.5 \\
13.5\end{array}$ & \& \\
\hline $110 \mathrm{~km} / \mathrm{h}$ & $\begin{aligned} & <750 \\
750 & \leq \mathrm{T}<1500 \\
1500 & \leq \mathrm{T}<6000 \\
& \geq 6000\end{aligned}$ & $\begin{array}{l}3.0 \\
3.5 \\
5.0 \\
6.5\end{array}$ & $\begin{array}{l}4.0 \\
5.5 \\
6.5 \\
8.0\end{array}$ & $\begin{array}{l}4.5 \\
6.0 \\
7.0 \\
8.5\end{array}$ & $\begin{array}{l}4.5 \\
6.0 \\
8.0 \\
8.5\end{array}$ & $\begin{array}{l}5.5 \\
7.0 \\
8.5 \\
9.0\end{array}$ & $\begin{array}{l}5.5 \\
7.0 \\
8.5 \\
9.0\end{array}$ & $\begin{array}{c}6.0 \\
8.0 \\
9.5 \\
10.5\end{array}$ & $\begin{array}{c}6.0 \\
8.5 \\
10.5 \\
11.5\end{array}$ & $\begin{array}{c}8.0 \\
11.0 \\
13.0 \\
14.0\end{array}$ & \\
\hline
\end{tabular}

Source: INDOT Design Manual (3). 


\section{(2) Guardrail Warrants for Embankments}

Chapter 49 presents the warrants for installing guardrail at design speeds of 60, 70, 80, 90, 100 , and $110 \mathrm{~km} / \mathrm{h}$ on embankments. As illustrated in Figures 2-3 are the warrants for the design speed of $90 \mathrm{~km} / \mathrm{h}$. Generally, guardrail for embankments is not warranted on facilities with design speeds of $50 \mathrm{~km} / \mathrm{h}$ or less. However, this should not apply to interchange ramps. While these warrants were developed using 3.6-m lanes and 3.0 to 3.6-m shoulders, they can be used for any lane and shoulder widths. For a given design year ADT, the slope-height combinations which fall on or below the curve do not warrant shielding. To make an adjustment for horizontal curvature and grade, Chapter 49 provides the Grade Traffic Adjustment Factor (Kg) and the Curvature Traffic Adjustment Factor (Kc). The following example illustrates how to use these embankment warrant figures.

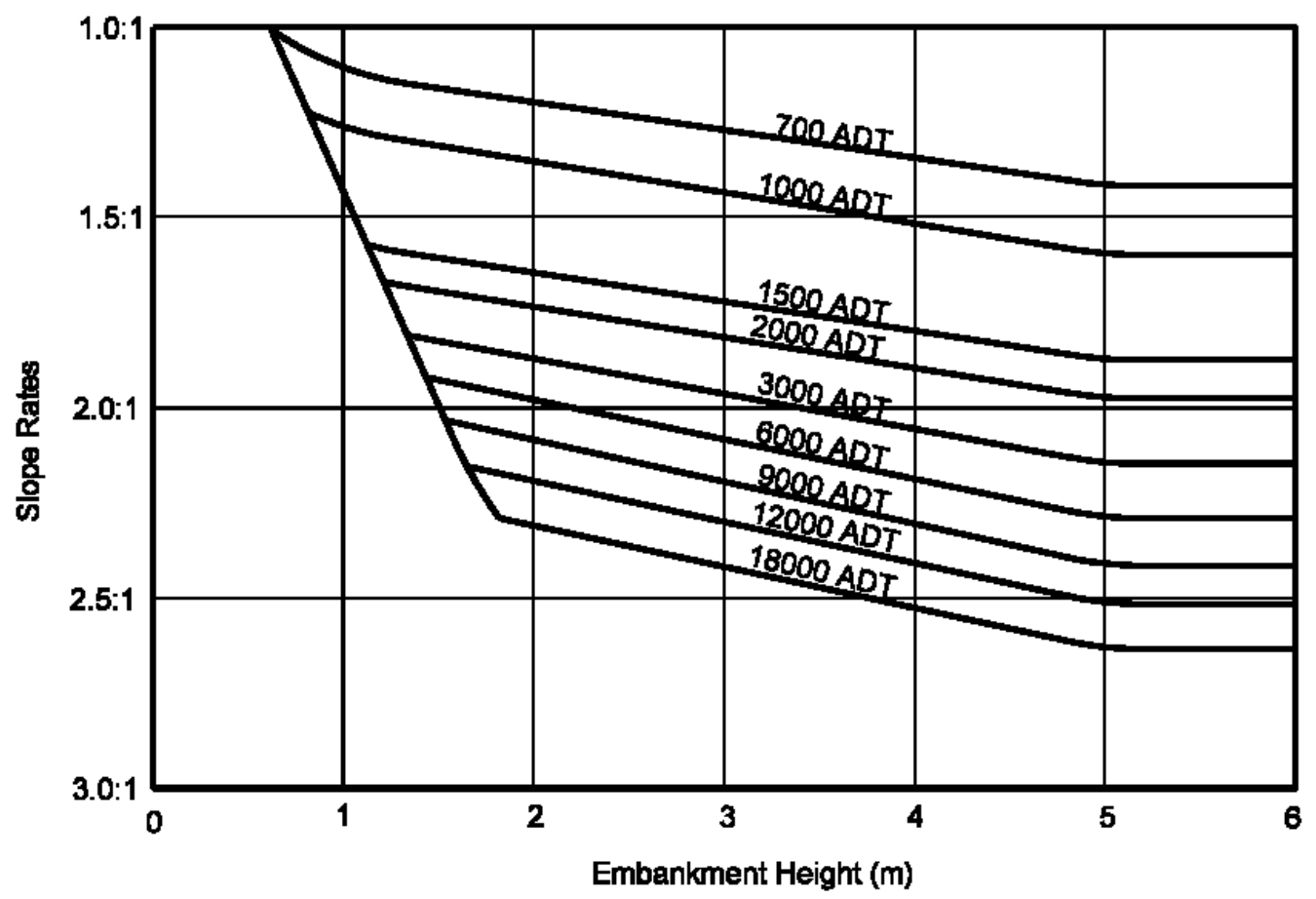

Figure 2-3 Guardrail Warrants for Speed $=90 \mathrm{~km} / \mathrm{h}$

Source: INDOT Design Manual (3).

(3) Guardrail Lateral Placement

In Chapter 49, the lateral placement of a guardrail depends on the following factors: the clearance between barrier and hazard being shielded; the effects of terrain between the edge of 
the traveled way and the guardrail on the errant vehicle's trajectory; the probability of impact with barrier as a function of its offset; the flare rate and length of need of transitions and approach guardrails; and the need to offset guardrail and concrete barrier so that the full shoulder width can be used. During the process of determining the guardrail lateral placement, the designer should consider the following.

\section{Barrier Offset}

To minimize the probability of impact with the barrier, Chapter 49 also requires that the roadside barrier be placed as far from the traveled way as conditions allow. In general, a roadside barrier should be placed beyond the shy line offset as given in Table 2-5. On new construction, the desirable guardrail offset is $0.6 \mathrm{~m}$ and the minimum guardrail offset is $0.3 \mathrm{~m}$ from the effective usable shoulder width. For $3 \mathrm{R}$ projects, the desirable guardrail offset is $0.6 \mathrm{~m}$ from the edge of the effective usable shoulder, or the shy line offset in Table 2-5, whichever is larger. In restrictive situations, however, a guardrail offset may be zero from the effective usable shoulder, depending on the functional classification of highway.

Table 2-5 Shy Line Offset Values

\begin{tabular}{|c|c|c|c|c|c|c|c|}
\hline Speed, $\mathrm{km} / \mathrm{h}$ & 50 & 60 & 70 & 80 & 90 & 100 & 110 \\
\hline Shy Line Offset, $\mathrm{m}$ & 1.1 & 1.4 & 1.7 & 2.0 & 2.2 & 2.4 & 2.8 \\
\hline
\end{tabular}

Source: INDOT Design Manual (3).

Chapter 49 stresses that the designer should evaluate the practicality of offsetting the guardrail more than $0.6 \mathrm{~m}$ beyond the edge of the required shoulder width. The assessment must be made based in light of costs and accidents. For example, the designer should compare the additional costs of all items such as benching, borrow and grading needed to construct the flat slopes required to install barrier on the embankment, against the reduced cost of installation and maintenance of the lesser amount of barrier which would be required by locating it farther from the roadway. Also, the designer should consider the location's accident history and the area's maintenance records regarding the repair of nuisance impacts. On new construction, the desirable guardrail offset is $0.6 \mathrm{~m}$ and the minimum guardrail offset is $0.3 \mathrm{~m}$ from the effective usable shoulder width. 
On reconstruction projects, the desirable guardrail offset is $0.6 \mathrm{~m}$ and the minimum guardrail offset is $0 \mathrm{~m}$ from the effective usable shoulder width. If the design year AADT exceeds 100,000 , the guardrail offset should be $0.6 \mathrm{~m}$ from the effective usable shoulder width. When installing a guardrail for a large culvert on a new alignment on 4R projects, the shoulder should not be paved to the guardrail face. A width of $1.0 \mathrm{~m}(0.43 \mathrm{~m}$ of guardrail plus $0.57 \mathrm{~m}$ behind the guardrail) should be used from the front face of the guardrail to the shoulder break point.

\section{Barrier Deflection}

If the distance between the guardrail face and the face of an object is less than the dynamic deflection distance, i.e. the Barrier Deflections given in Chapter 49 (see Table 2-6 below), it is necessary to reduce the post spacing to obtain a dynamic deflection distance less than the clearance between the face of guardrail post and the face of object. If not practical, either the object or the guardrail should be relocated to provide adequate deflection distance. The deflection distances for thrie-beam guardrails should only be used at problem or special locations.

Table 2-6 Guardrail Deflections

\begin{tabular}{|c|c|c|c|}
\hline $\begin{array}{l}\text { TEST } \\
\text { LENEL }\end{array}$ & THPE OF BAIL. & $\begin{array}{l}\text { Chat } \\
\text { THST }\end{array}$ & 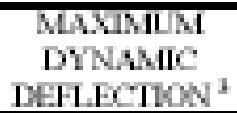 \\
\hline$T \perp-3$ & Guardrail, 1905-m Post spacturg & 2 & $10 \mathrm{~m}$ \\
\hline $\mathrm{T} \perp=3$ & 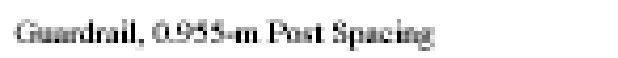 & 2 & tom $\mathrm{m}$ \\
\hline Tl-3 & Guardrail, 0475-m Bot spucter & 2 & $04 \mathrm{~m}$ \\
\hline $\mathrm{T} \perp-4$ & 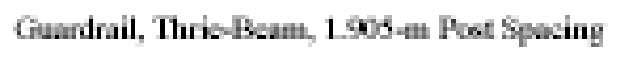 & 2 & $09 \mathrm{~m}$ \\
\hline $\mathrm{TL}=3$ & Guardrail, Neted, One Los-Fill Culvet & 1 & $1.1 \mathrm{~m}$ \\
\hline $\mathrm{TL}-\mathrm{B}$ & Guadrail, Type B, 3810 -at Bost spoing & $₫$ & $23 m$ \\
\hline$T \perp-3$ & Guadrail, Type B, 100d-at Bost spoing & 1 & $1 . \mathrm{m}$ \\
\hline $\mathrm{TL}=\mathrm{B}$ & Guardrail, Type B, 1954-41 Bst spoing & 1 & $10 \mathrm{~m}$ \\
\hline $\mathrm{T} 1-3$ & 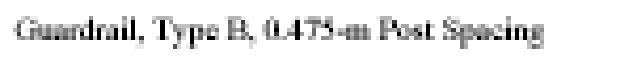 & $\mathbb{1}$ & $\cos m$ \\
\hline+ & Compreis Banter & 1 & ail $\mathrm{m}$ \\
\hline
\end{tabular}

Source: INDOT Design Manual (3). 


\section{Shoulder Section}

In general, the outside shoulder is paved to the face of guardrail if the face of the rail is located $4.2 \mathrm{~m}$ or less from the edge of the travel lane on INDOT routes. On local projects, the shoulder section at guardrail locations may be paved to the face of the guardrail when the face of the guardrail is less than $0.6 \mathrm{~m}$ from the outside edge of the paved shoulder. Where the face of the guardrail is greater than $0.6 \mathrm{~m}$ from the outside edge of the paved shoulder, the width of the paved shoulder may remain the same as in the sections without guardrail.

\section{Guardrail and Embankment Slopes}

Chapter 49 does not recommend a semirigid roadside barrier on a slope steeper than 10:1. Also, no barrier should be placed on any slope steeper than 6:1.

\section{Guardrail and Curbs}

It is believed that curbs in front of guardrail may cause an errant vehicle to break through the rail and become airborne. Because there has been very little research on the curb placement in the vicinity of a traffic barrier, Chapter 49 recommends that the best practice be to avoid using curbs in the vicinity of guardrail. If a curb is essential for drainage, the maximum curb height should not exceed $100 \mathrm{~mm}$ and the curb should be placed so that the face of the curb is at or behind the face of the guardrail.

In urban areas, the guardrail-curb combination should be offset at least the shy line distance from the edge of the travel lane. This offset may be either continuous (curb with or without guardrail) or variable. A continuous offset should be used if there are numerous separate runs of guardrail along a route to provide a uniform curb line offset. Thrie-beam guardrail should be used instead of the standard W-beam guardrail where curbs and sidewalks approach a bridge rail. When a guardrail needs to be installed in the vicinity of an existing curb, the curb should be removed or relocated.

\section{(4) Guardrail Length of Need}

In Chapter 49, the guardrail length of Need consists of three basic components, such as the length needed in advance of the hazardous object, the length of the hazard itself, and the 
length of the trailing end or length needed to protect traffic in the opposing direction, as shown in Figure 2-4. The equation for determining the guardrail length of need is as follows:

$$
\mathrm{L}_{\mathrm{TOTAL}}=\mathrm{L}_{\mathrm{ADVANCE}}+\mathrm{L}_{\mathrm{HAZARD}}+\mathrm{L}_{\mathrm{OPPOSING}}
$$

in which, $\mathrm{L}_{\text {ADVANCE }}$ is the length of need in advance of the hazard, $\mathrm{L}_{\text {HAZARD }}$ is the length of the hazard itself, $\mathrm{L}_{\mathrm{OPPOSING}}$ is the length of the trailing end or length needed to protect traffic in opposing lanes.

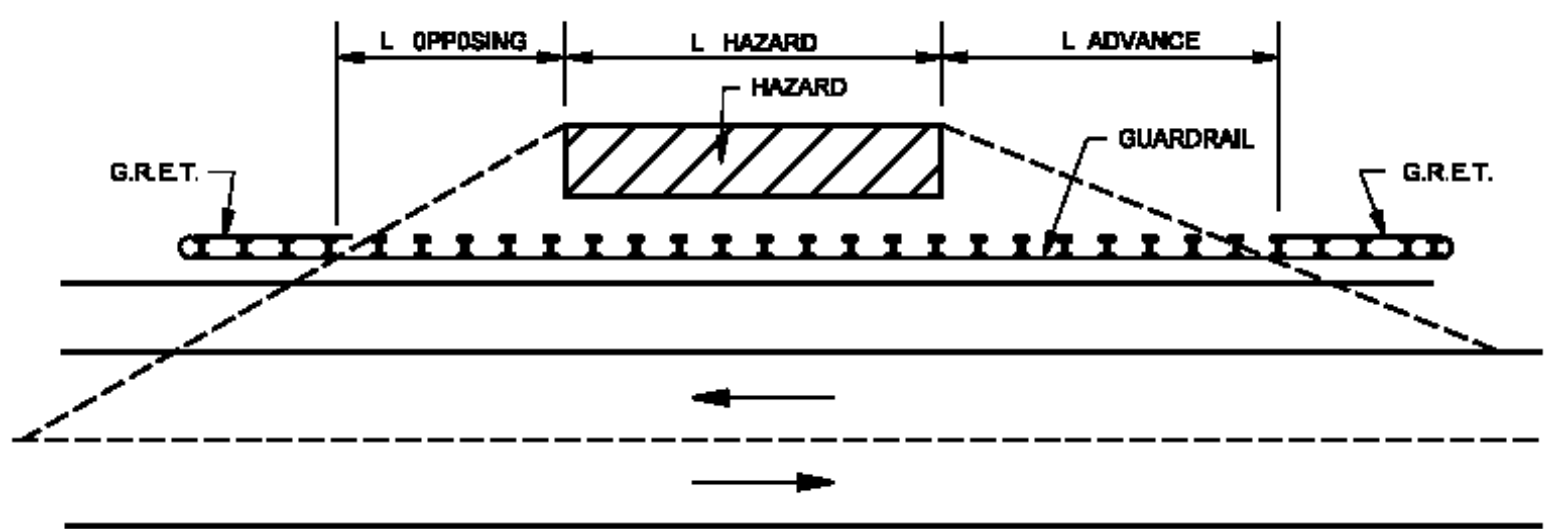

Figure 2-4 Graphical Illustration of Guardrail Length of Need

Source: INDOT Design Manual (3)

\section{Guardrail Length Needed in Advance of Hazard}

The guardrail length of need in advance of the hazard is determined the same as that in the AASHTO Roadside Design Guide and is the function of the runout length, shy line offset, and flare rate relative to the shy line. The method to determine the guardrail length of need can be graphical solution or mathematical solution below:

Method I-Graphical Solution: For tangents \& inside horizontal curves, the procedures are first to select the runout length $\left(\mathrm{L}_{\mathrm{R}}\right)$, and then to determine the lateral distance to be protected by calculating the clear zone distance $\left(\mathrm{L}_{\mathrm{C}}\right)$ and comparing it to the lateral distance from the edge of travel lane to the outside edge of the hazard $(\mathrm{LH})$, use the lesser of $\mathrm{LC}$ and $\mathrm{LH}$. Once the runout length $(\mathrm{Lr})$ and the lateral distance are determined, they can be scaled directly on the drawing 
along the edge of the travel lane. Simulating the vehicular runout path, a line can be drawn between the lateral point farthest from the edge of the travel lane and the end of the runout length farthest from the hazard. To shield the hazard, the guardrail installation must intersect this line. The guardrail can be either flared or parallel to the roadway based on the site conditions. For outside horizontal curves, Figure 2-5 demonstrates the graphical solution for guardrail installation on the outside of horizontal curves. Notice that the guardrail length of need is determined by scaling its intercept with the tangential runout path of an encroaching vehicle instead of using the approach runout length, LR. If the runout length measured along the edge of the driving lane is shorter than the distance to the tangential runout path intercept, the shorter distance should be used. For the guardrail installation outside the horizontal curves, the graphical solution should be employed.

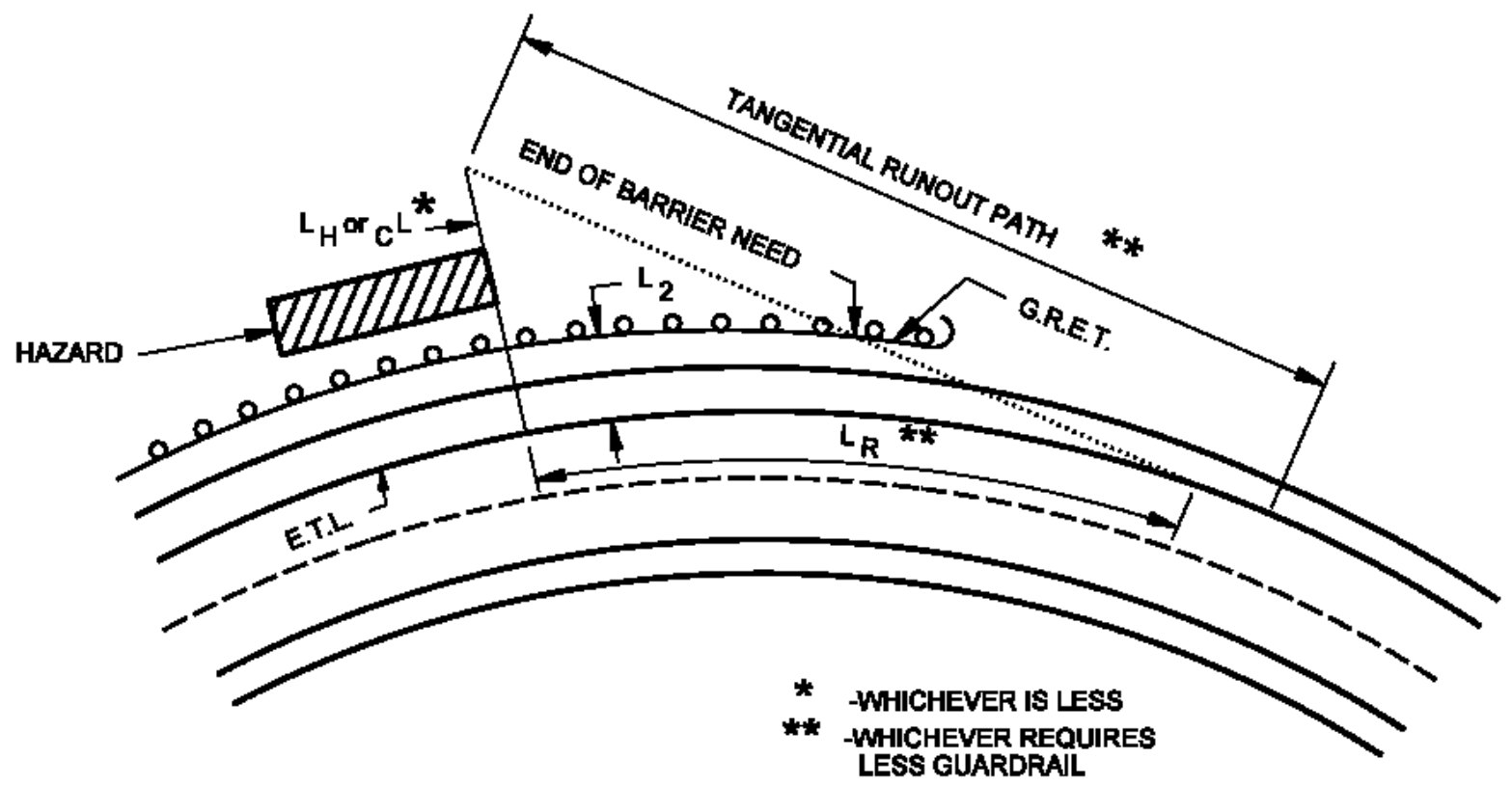

Figure 2-5 Graphical Solution for Guardrail on the Outside of Horizontal Curves Source: INDOT Design Manual (3)

Method II- Mathematical Solution: The mathematical solution should be used for the guardrail design on tangent sections only. The equations for calculating the guardrail length of need are the same as those developed by the AASHTO Roadside Design Guide, i.e. Equations 21 and $2-2$. 
If guardrail is needed to protect the opposing traffic, the needed guardrail length is determined in the same manner as above (Figure 2-6). However, the lateral dimensions are measured from either the centerline for a 2-lane highway or the edge of the travel lane for a divided highway. The minimum length of guardrail in advance of the hazard depends on the highway facility design speed and the type of end treatment to be used. For a design speed of 80 $\mathrm{km} / \mathrm{h}$ or greater, it should be the greater of the calculated length or $30 \mathrm{~m}$ when the end treatment of GRET type I is used. Otherwise, it should be the greater of the calculated length or $15 \mathrm{~m}$. For a facility with a design speed of $70 \mathrm{~km} / \mathrm{h}$ or less, the minimum rail length should be the greater of the calculated length or $15 \mathrm{~m}$.

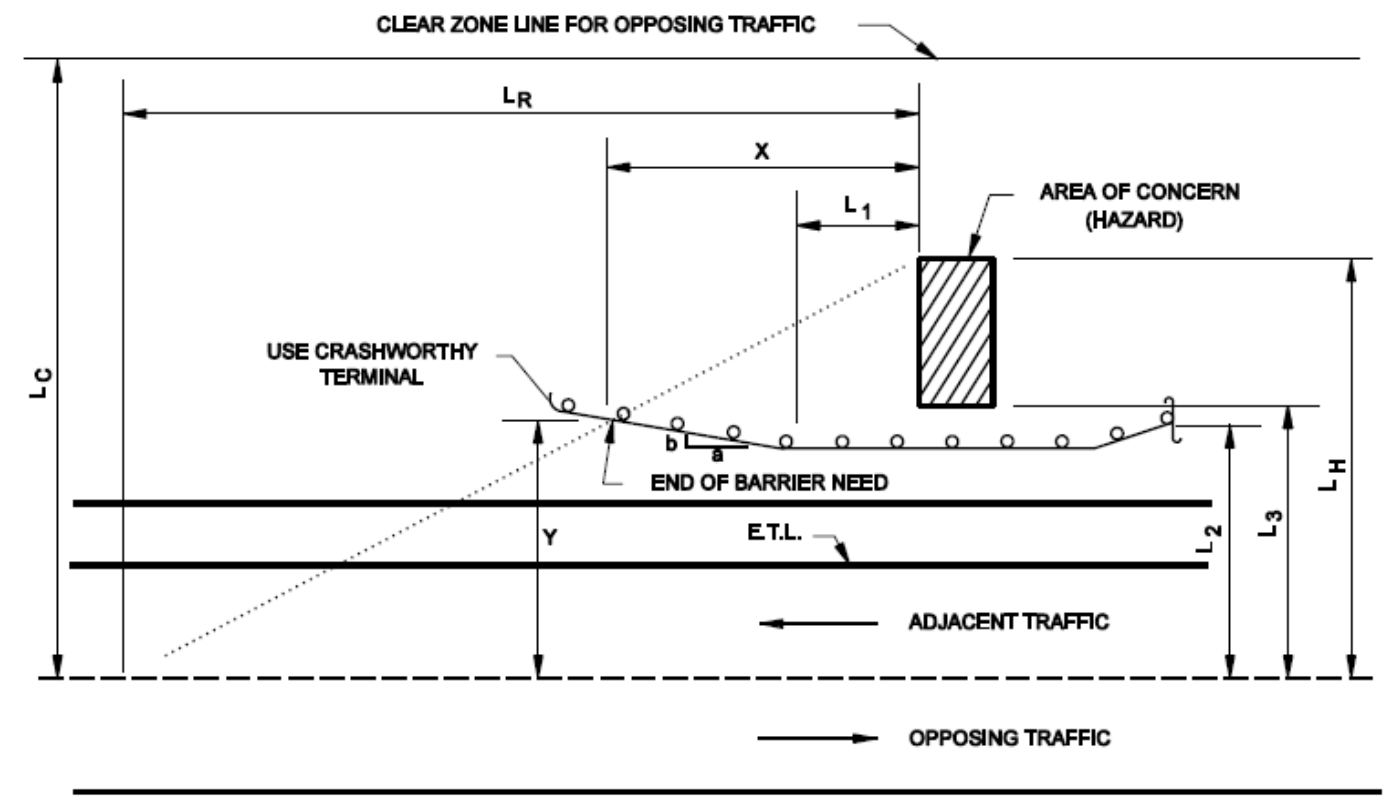

Figure 2-6 Graphical Solution for Guardrail beyond Hazard (Two-Lane Highways) Source: INDOT Design Manual (3)

\subsection{Cost-Effectiveness Analysis}

There are many situations, in which highway engineers have to make decisions on the use of roadside safety features and select the appropriate performance level for each situation. There also exist situations where engineers need to decide if the existing roadside safety features may be outdated or substandard and need to be removed upgraded to meet the current performance 
standards or traffic conditions. In order to make informed decisions in these situations, it is desirable for highway engineers to undertake cost-effectiveness analysis, i.e. to assess the risk of vehicle run-off-the-road accidents against the cost for installing and maintaining roadside safety features such as guardrails. Currently, there are two computer programs that are intended for highway engineers to accomplish this, the ROADSIDE program and the Roadside Safety Analysis Program (RSAP) program.

\section{The ROADSIDE Computer Program}

\section{(1) The Basic Features of ROADSIDE Program}

The ROADSIDE computer program is the computerized Cost-Effectiveness Selection Procedure provided by the 1988 AASHTO Roadside Design Guide and has been used to determine if roadside safety improvements are cost effective. This program allows users to compute the costs that are anticipated in accidents, installation, maintenance and repair during the service period for a certain safety improvement at a specific location. It also allows a cost comparison of alternative roadside safety improvements and assists users in selecting an alternative improvement that may yield the greatest anticipated benefits. However, ROADSIDE is not intended for users to determine if a roadside safety improvement is warranted at a specific location. In addition, ROADSIDE does not readily allow users to undertake the analysis of the safety improvement at different performance levels.

ROADSIDE provides a screen that exhibits the default basic input data necessary for calculating collision costs, predicting the number of encroachment as illustrated in Figure 2-7. The Users can either accept the default input data or change the default input data according to the individual's experience or the agencies' data. ROADSIDE also provides a screen for the variable input data, including the roadway geometrics, lane width, and highway agency's costs associated with installation, repair, and maintenance of a safety improvement facility. ROADSIDE compare the alternative improvements using three different methods such as the present worth method (PW), the equivalent uniform annual cost (EUAC) method, and the benefit/cost ratio method. The PW method is used to select the alternative improvement with the minimum PW. The EUAC method is to identify the alternative improvement with the minimum 
total EUAC. In addition, sensitivity analysis can be undertaken using the ROADSIDE program to evaluate the effect of each input variable on the societal and agency costs.

\section{(2) Accident and Agency Costs}

Accident costs are measured in terms of three categories of accidents, including fatal, injury and property damage only (PDO). Injury and PDO accidents are further divided into various levels of severity. It has been realized that the accident costs vary from agency to agency and over time significantly. The default accident costs in ROADSIDE are selected as median values. Other sources for accidents include the 1988 FHWA Technical Advisory T 7570.1 (8) that provides the comprehensive costs of motor vehicle traffic accidents. FHWA Technical Advisory T 7570.1 was cancelled in 1994 and superseded by FHWA Technical Advisor T 7570.2. (9). Accident history records can also be employed to estimate the cost for a specific accident.

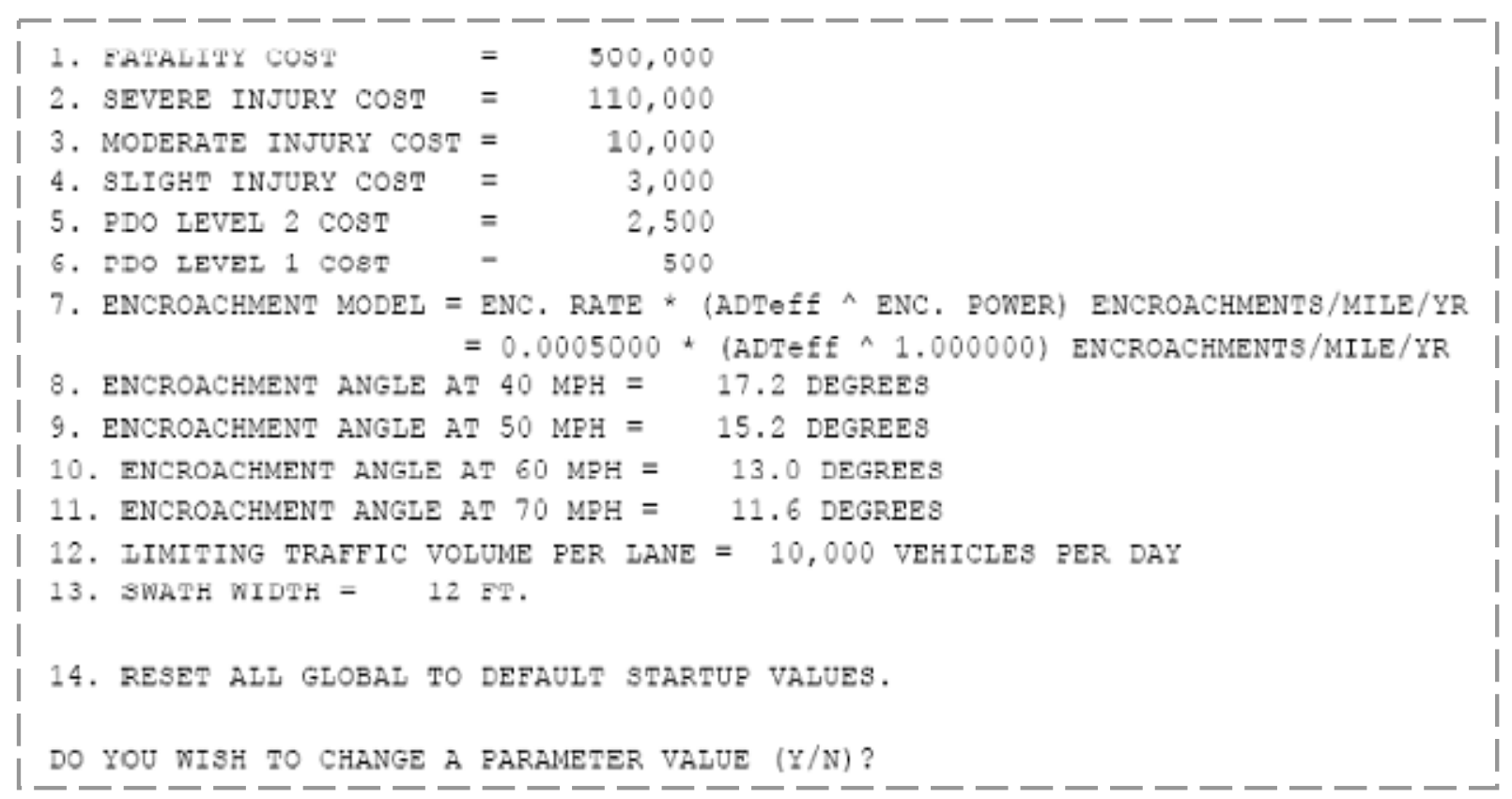

Figure 2-7 Default ROADSIDE Input Data

Source: INDOT Design Manual (3)

Typical agency costs consist of initial installation cost, repair cost (per accident), routine maintenance cost (per year), and salvage cost, of which, the installation cost is the most 
significant factor. In INDOT, the installation cost is provided the latest INDOT Catalog of Unit Price Averages for Roads-Bridges-Traffic. Figure 2-8 shows the repair costs for different types of guardrails, end treatments, and crash cushions. Due to the complexity of determining routine maintenance costs and salvage values, they are assumed to be zero. Also, a typical project life is assumed to be 20 years with a discount rate of $4 \%$.

\begin{tabular}{|l|c|}
\hline \multicolumn{1}{|c|}{ TYPE OF BARRIER/TERMINAL } & REPAIR COST PER ACCIDENT \\
\hline W-Beam Guardrail & $\$ 1200.00$ \\
Concrete Safety Shape & $\$ 0.00$ \\
Buried End & $\$ 500.00$ \\
C-A-T Unit & $\$ 4000.00$ \\
SENTRE System & $\$ 4000.00$ \\
ET 2000 & $\$ 4000.00$ \\
BRAKEMASTER System & $\$ 4000.00$ \\
G.R.E.A.T. System & $\$ 4000.00$ \\
Gravel Barrel Array & $\$ 3000.00$ \\
Hex-Foam Sandwich System & $\$ 4000.00$ \\
\hline
\end{tabular}

\section{Figure 2-8 Repair Cost per Accident}

Source: INDOT Design Manual (3)

\section{The Roadside Safety Analysis Program (RSAP)}

The Roadside Safety Analysis Program (RSAP) (4) utilizes the probability-based approach to estimate vehicle encroachment and consists of two integrated programs: the Main Analysis Program and the User Interface Program. The Main Analysis Program contains procedures and algorithms, including encroachment module, crash prediction module, severity prediction module, and benefit/cost analysis module intended for cost-effectiveness analysis. The User Interface Program provides a user-friendly environment for data input and review of analysis results. Focusing on the effectiveness, the new procedures incorporated new data and improved algorithms, capable of evaluating roadside safety treatment at a specific spot or over a certain section.

The encroachment module is to estimate the encroachment frequency for a specific highway segment. It first estimates the probability of an encroachment and multiplies the encroachment rate with traffic volume traffic to generate encroachment frequency. The average encroachment frequency is then adjusted to take into account the effects of the highway 
characteristics. The crash prediction module is to determine if the encroachment will result in a crash. A crash will occur if one or more roadside features are identified in the vehicle path. The severity prediction module is developed to estimate the crash severity, i.e. the probability of injury for a predicted crash. The crash severity affects the cost-effectiveness significantly because the ultimate goal of a safety improvement is to reduce the crash severity and the crash cost is basically a function of the crash severity. Finally, the benefit/cost module utilizes the Monte Carlo simulation method to perform the cost-effectiveness analysis.

\subsection{Guardrail Hardware}

In the AASHTO Roadside Design Guide, roadside guardrails are divided into three categories in terms of their deflection characteristics upon impact by the designated vehicles, including flexible system, semi-rigid system, and rigid system. Different roadside guardrail system provides different safety features. Therefore, the selection of guardrail system relies mainly on the safety requirement. Because different guardrail system presents different aesthetic features, however, the aesthetic feature may become a factor in the decision process, in particular in residential areas or on scenic routes.

\section{Flexible Guardrail Systems}

In general, flexible guardrail systems are designed to be more forgiving than the other guardrail systems and are capable of dissipating the much of the impact energy by deflecting the barrier. Therefore, the impact force imposed on the errant vehicle hitting flexible systems will be much lower than hitting semi-rigid or rigid systems. Upon impact by an errant vehicle, flexible systems tend to slow down the errant vehicle and even allow the errant vehicle to leave the roadway. Compared to the other guardrail systems, the use of flexible systems requires larger clear zone beyond the traveled roadway to deflect the impacting vehicle. Of the many flexible systems, the most common guardrail types are the three-strand cable system and the W-Beam (weak post) system.

(1) Cable Guardrails

Cable guardrails are designed to wrap around the errant vehicle and redirect the impacting vehicle after sufficient tension is developed in the cables. Upon impact, the cables will 
be stretched and the posts will be bent or even break. Therefore, the vehicle's kinetic energy will be dissipated. The main advantages associated with cable guardrails are as follows:

- Low initial cost and simple to install;

- Inexpensive repair cost and easy to repair;

- Wide range of applications;

- Open design preventing accumulation of drifting snow or sand; and

- Visually attractive.

While a 3-strand cable system has been widely used in the past years, INDOT started the so-called Brifen wire rope safety fence (WRSF) on interstate highways (10). The Brifen WRSF system installed by INDOT is a high-tension, 4-cable barrier system as shown in Figures 2-9 and 2-10. The Brifen WRSF system consists of a regular section between the transitional sections, transitional sections to terminals, and end terminals. It utilizes $3 / 4$ " galvanized wire ropes that are pre-stretched during manufacturing to reduce stretching during impact. The highly pre-stretched interwoven ropes create high post/rope friction, which causes each post to act as a mini-anchor, producing numerous benefits. It helps limit the extent of damage to errant vehicles. It also provides satisfactory performance even around tight curves and eliminates the need for intermediate anchors. In addition, it produces deflections more predictable during impact. The end terminal of the Brifen WRSF system is a crash worthy end terminal (Figure 2-10).

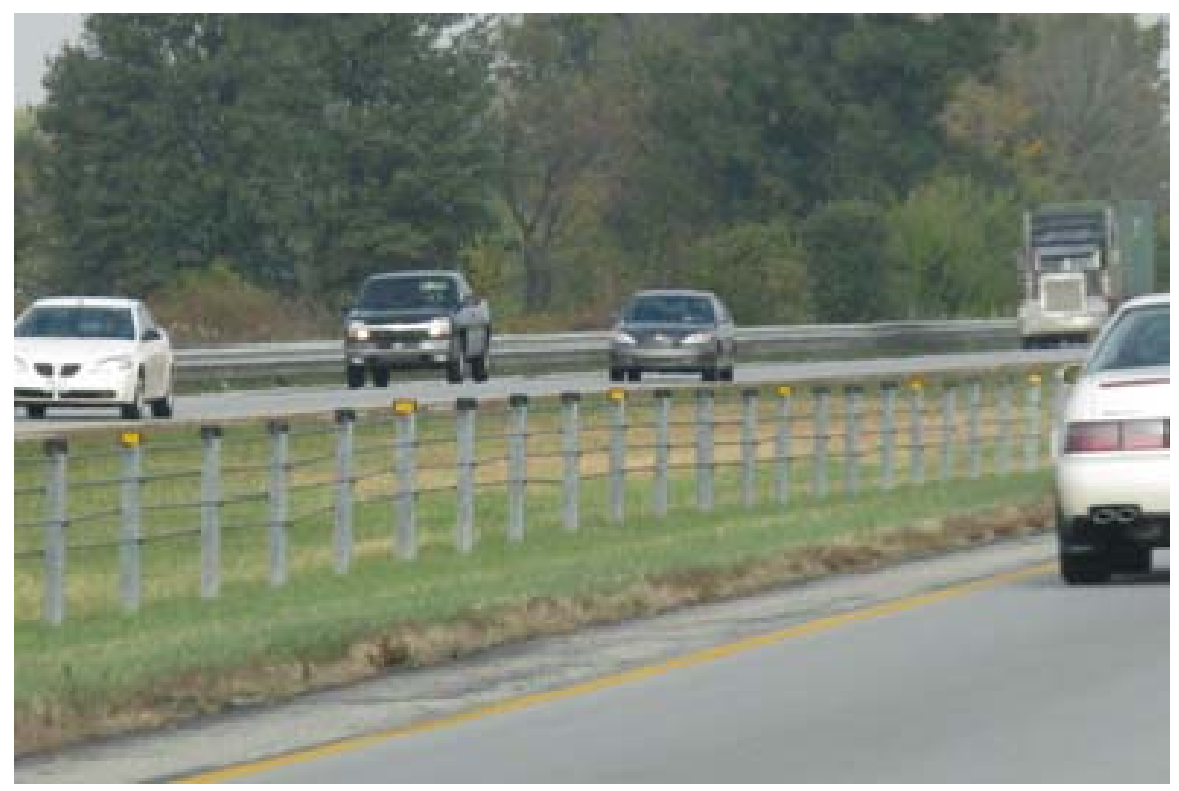

Figure 2-9 4-Rope, High Tensioned WRSF 


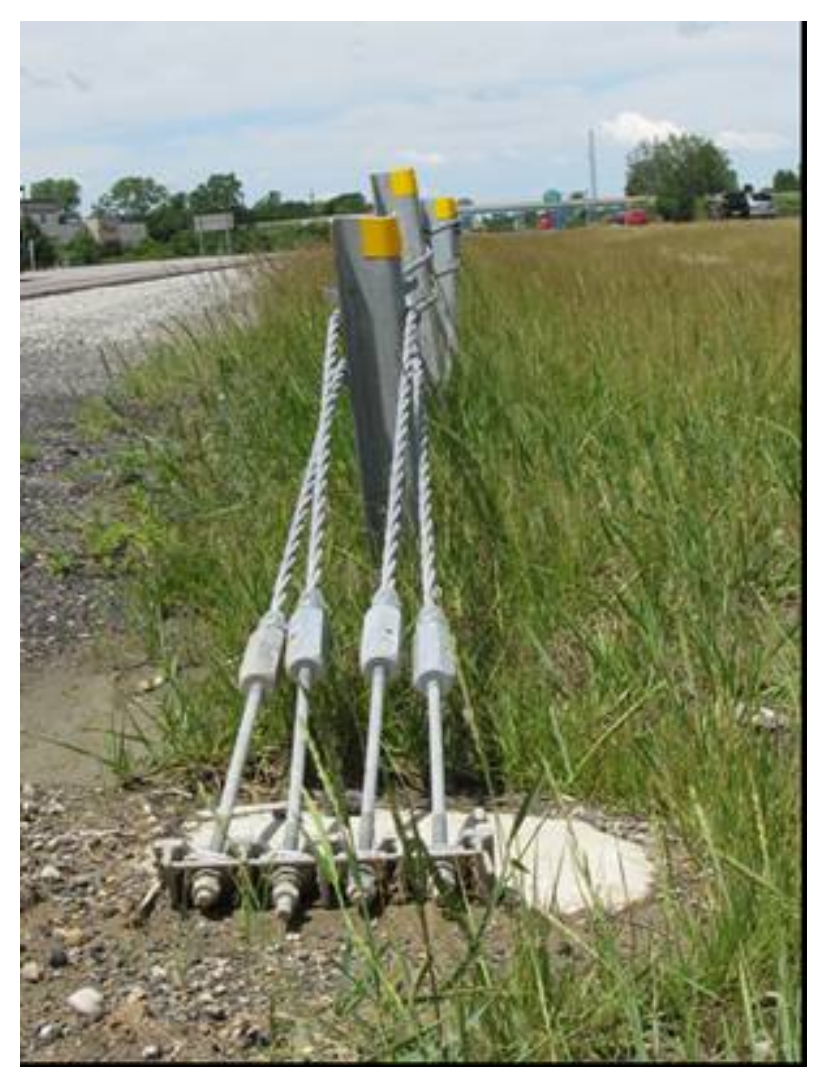

Figure 2-10 Brifen WRSF Crashworthy End Terminal

The 4-cable Brifen WRSF meets the requirements of the NCHRP 350 Test Level 4 (TL4). The maximum dynamic deflection is 7.25 feet and 4.4 feet when impacted by a $17,600 \mathrm{lb}$ single-unit truck and an $1800 \mathrm{lb}$ car. However, drawbacks have been identified to the use of cable guardrail systems $(1,11)$. First, cable guardrails require larger clear areas on both sides of the cables to allow the design deflections during impacting from both sides. Second, cable guardrails, in particular the posts, can be easily damaged and repairs are needed following an impact because any damage will leave the entire length of cable ineffective. Third, considerable maintenance is required to keep the cables properly tensioned because cable tension relaxes over time. Fourth, long lengths of the cable guardrails are non-functional. Also, the effectiveness of cable guardrail systems will be reduced on the inside of curve. Finally, the so-called tripping force may occur while an errant vehicle slides with lateral motion. If the errant vehicle with a high center of gravity hits a curb or a slack cable, it may roll over due to the tripping force. If a vehicle with a low center of gravity hits a slack cable, it may trampoline back into the traffic, resulting collision accidents. 


\section{(2) W-Beam Guardrail System (Weak Post)}

The W-Beam guardrail system with weak posts is also categorized as a flexible system. This system is probably the most common guardrail system that can be observed on interstates, US highways, State routes, and local roads. Similar to the cables in a cable guardrail system, the W-Beam rail redirects the errant vehicle after tension is developed in the rail upon impacting. The posts are designed solely to hold the W-Beam rail and to separate from the rail when struck. The post size is identical to the cable guardrail system. However, the post spacing is 12 feet to match the W-Beam hole pattern. The impact performance is TL-2 for the standard W-Beam guardrail system with a rail mounting height of $550 \mathrm{~mm}$. The dynamic lateral deflection may reach $1.4 \mathrm{~m}$ for a $2000 \mathrm{~kg}$ pickup truck at $71 \mathrm{~km} / \mathrm{h}$ and an impact angle of $26.1^{0}$.

W-Beam guardrail systems are constructed of galvanized steel. Compared to cable guardrail systems, W-Beam guardrail systems require smaller clear areas due to the reduced lateral deflection upon impact. After minor impacting, W-Beam guardrail systems may still present effectiveness and require fewer repairs. However, W-Beam guardrail systems are more obtrusive. They have narrow restraining widths and are vulnerable to vaulting. Modifications have been made to the standard W-Beam guardrail system, such as raining the mounting height to $820 \mathrm{~mm}$ and adding back-up plates at each post. The modified W-Beam guardrail systems have an impact performance of TL-3 with a dynamic deflection of $2.12 \mathrm{~m}$ for a $2000 \mathrm{~kg}$ pickup truck at $102 \mathrm{~km} / \mathrm{h}$ and an impact angle of $26.5^{\circ}$.

\section{Semi-Rigid Guardrail Systems}

Typical semi-rigid guardrail systems include box beam guardrails, blocked-out W-Beam guardrails (strong post) with a designator of SGR04a-b, and blocked-out Thrie-Beam guardrails (strong post) with a designator of SGR09. However, the strong-post W-Beam guardrail is the most common semi-rigid guardrail system. Instead of the weak posts of PSE03 with a section of S75 $\times 8.5$, the strong posts are steel PWE01 or PWE02 posts with a section of $\mathrm{W} 150 \times 13.5$. Also, the spacing for strong posts has been reduced by almost $50 \%$ compared to the weak-post WBeam guardrail. The maximum dynamic deflection is $0.9 \mathrm{~m}$ and $0.6 \mathrm{~m}$ for the blocked-out $\mathrm{W}$ Beam guardrail and the blocked-out Thrie-Beam guardrail, respectively. With proper block-outs, both the strong-post W-Beam and Thrie-Beam guardrails may have an impact performance TL- 
3. The warrants for installing semi-rigid guardrail systems include a traffic volume of 50000 vehicles or more per day and insufficient clear area for flexible guardrail systems.

The block-outs are utilized to hold the steel rail away from the posts to reduce the chance that part of an impacting vehicle will extend under the rail and snag on the posts. Because the strong posts are much stouter than the weak posts, an impacting vehicle snagging on the strong posts could cause a vehicle to turn and roll over. Compared to the flexible guardrail systems, semi-rigid guardrails will result in severe lateral deceleration to the impacting vehicle. In some situations, it may be difficult for the semi-rigid guardrails to fit between the paved shoulder and a steep shoulder break. However, the semi-rigid guardrails require shorter deflection distance. A mild hit may not cause too many repairs for a semi-rigid guardrail system.

\section{Rigid Guardrail Systems}

Rigid guardrails usually have a solid section and have no deflections when struck by an impacting vehicle. In general, rigid guardrails have been used in the highway median where the area available for installation is limited and requires a safe separator. Rigid guardrails are also been used on the roadsides at dangerous locations such as steep subgrades and bridges. In addition, rigid guardrails are utilized to protect the substructures of interchange or overpass bridges. The most common rigid guardrail is the so-called New Jersey concrete safety shape barrier or Jersey barrier with a designator of SGM11a-b. In the design of Jersey concrete barriers, the critical parameter is the distance from the ground to the slope break point, which decides the lifting of the impacting vehicle.

The roadside Jersey barriers have a sloped front face and vertical back face. Except for the back face, the performance and design of the roadside Jersey barrier is identical to the median Jersey barrier. The impact performance for the 810-mm high SGM11a-b Jersey barriers is rated TL-4. If the height is raised to $1070 \mathrm{~mm}$, the impact performance is TL-5. Because of the rigidity, rigid concrete guardrails require no lateral deflection distance and can effectively separate opposing traffics and prevent errant vehicles from leaving the roadway. In most cases, minor or mild hits will not cause damages to rigid concrete barriers. Therefore, rigid concrete barriers require minimal maintenance and repair. However, rigid concrete barriers are highly obtrusive. Because of their heavy size and poor visual prominence, rigid concrete barriers are rarely used on scenic routs. 
Chapter 3

\section{GUARDRAIL SYSTEMS ON INDIANA ROADWAYS}

\subsection{The INDOT Highway Network}

\section{Interstate Highways}

INDOT is responsible for a state highway network consisiting of Interstate highways, U.S. highways, and state roads. The interstate highway system in Indiana is approximately 1200 miles ling and consists of fourteen interstate highways, including six local interstate corridors with three-digit route numbers and eight core interstate highways with two-digit route numbers, as shown in Table 3-1. The six local interstate corridors are located in the urban areas to provide connections between the core freeways and serve local, short-distance trip demands. As an illustration, I-865 is a connector northwest of the capital city of Indiana, Indianapolis. I-275 is a loop in Ohio, Indiana, and Kentucky and the longest continuous circular beltway in the country. I-164 is a spur highway of the parent highway, I-64 in Evansville, Indiana.

Table 3-1 Indiana Interstate Highways

\begin{tabular}{|c|c|c|c|}
\hline Road & $\begin{array}{c}\text { Max. Posted Speed } \\
\text { (mph) }\end{array}$ & Lane Numbers & $\begin{array}{c}\text { Lengths } \\
\text { (Miles) }\end{array}$ \\
\hline I-164 & 60 & 4 & 21 \\
\hline I-265 & 55 & 4 & 7 \\
\hline I-275 & 65 & 4 & 3 \\
\hline I-465 & 55 & $6 \sim 12$ & 52 \\
\hline I-469 & 70 & 4 & 31 \\
\hline I-865 & 65 & 4 & 5 \\
\hline I-64 & 70 & 4 & 124 \\
\hline I-65 & 70 & $4 \sim 8$ & 261 \\
\hline I-69 & 70 & $4 \sim 6$ & 158 \\
\hline I-70 & 70 & $4 \sim 6$ & 156 \\
\hline I-74 & 70 & $4 \sim 8$ & 171 \\
\hline I-80 & 55 & $6 \sim 8$ & 16 \\
\hline I-90 & 70 & $4 \sim 6$ & 157 \\
\hline I-94 & 70 & 6 & 46 \\
\hline
\end{tabular}


The eight core interstate highways serve inter-city or inter-state, long-distance trips. For example, I-65 enters Indiana at Jeffersonville in the southern Indiana and ends at Gary, Indiana, and is the longest interstate route within the boundary of Indiana. It intersects with I-70, I-74, I80, I-90, and I-94. In addition, four auxiliary routes, including I-265, I-465, and I-865, spur from I-65. Most Interstate highways in rural areas provide four lanes in two directions and 6 or more lanes in urban areas. In general, the design speed for a specific interstate may vary from location to location, depending on the road and traffic conditions. The maximum posted speed is $55 \mathrm{mph}$ on I-265, I-465, and I-80. The maximum posted speed was raised from $65 \mathrm{mph}$ to $70 \mathrm{mph}$ for passenger cars on most rural interstate highways in 2006.

\section{Other Major Routes}

Beside the fourteen Interstate highways, the INDOT highway network also consists of approxaimetely 20 US highways. These 22 US highways add up to about 3320 miles and provide important regional connections. Provided in Table 3-2 is a summary of the information on all of these 20 US highways. It is shown that the US highways have either two-digit route number or three-digit route number. In general, the US highways with two-digit route numbers are components of the National Highway System (NHS) in Indiana. Most US highways are undivided, 2-lane routes. Some US highways are undivided 2-lane routes in rural areas and divideed, four-lane routes in urban areas. The maximum posted speed is either $55 \mathrm{mph}$ or 60 mph, depending on the location and geometric condition.

State roads comprise the major part of the INDOT highway network. There are about 177 state roads that add up to approximately 7670 miles. There is no state rule preventing the same numbering between state roads and US highways. However, it is discouraged that the state road and US highway have the same number. Most major state roads have a two-digit route number. The state roads with three-digit route numbers are usually short spur routes of their parent roads. Tabluated in Table 3-3 is the information on those state roads that are componenets of the NHI in Indiana. Most state roads have a maximum posted speed of $55 \mathrm{mph}$. SR-152 is a short connector between I-80/90 combination and US-20 and is also known as Indianaplois Boulevard that runs through Hammond in northwest Indiana. 
Table 3-2 US Highways in Indiana

\begin{tabular}{|c|c|c|}
\hline Road & Max. Posted Speed (mph) & Lengths (Miles) \\
\hline US-6 & 55 & 149 \\
\hline US-12 & 55 & 45 \\
\hline US-20 & 55 & 157 \\
\hline US-24 & 60 & 170 \\
\hline US-27 & 55 & 118 \\
\hline US-30 & 60 & 152 \\
\hline US-31 & 60 & 266 \\
\hline US-33 & 55 & 107 \\
\hline US-35 & 55 & 210 \\
\hline US-36 & 55 & 139 \\
\hline US-40 & 55 & 156 \\
\hline US-41 & 55 & 280 \\
\hline US-50 & 55 & 172 \\
\hline US-52 & 60 & 169 \\
\hline US-131 & 50 & 0.7 \\
\hline US-136 & 55 & 75.3 \\
\hline US-150 & 55 & 173 \\
\hline US-224 & 55 & 40 \\
\hline US-231 & 55 & 298 \\
\hline US-421 & 55 & 232 \\
\hline No: 1 . & \\
\hline
\end{tabular}

Note: 1 mile $=1.609 \mathrm{~km}$

Table 3-3 Indiana State Roads

\begin{tabular}{|c|c|c|}
\hline Road & Max. Posted Speed (mph) & Lengths (Miles) \\
\hline SR-3 & 55 & 224 \\
\hline SR-25 & 55 & 123 \\
\hline SR-26 & 60 & 150 \\
\hline SR-32 & 55 & 157 \\
\hline SR-37 & 55 & 230 \\
\hline SR-45 & 45 & 55 \\
\hline SR-46 & 55 & 154 \\
\hline SR-57 & 55 & 80 \\
\hline SR-62 & 55 & 228 \\
\hline SR-63 & 55 & 96 \\
\hline SR-66 & 55 & 153 \\
\hline SR-152 & 35 & 2.5 (urban) \\
\hline
\end{tabular}

Note: 1 mile $=1.609 \mathrm{~km}$ 


\subsection{Guardrail Data Collection}

\section{Guardrail Database}

The data on the existing guardrails on Indiana roadways statewide was gathered from three data sources, including GuardRail.xls, INDOT video log system, and site visit. The GuardRail.xls is the INDOT guardrail database in the format of Microsoft Excel. The GuardRail.xls is still under development, and only consists of guardrail data for one half of the roadway network under INDOT jurisdiction. Since the GuardRail.xls contains huge information, including 53914 records and 1,347,850 data points, a computer program was developed using Visual Basic 6.0 for data retrieval. The guardrail data retrieved from the database, GuardrRail.xls, included road way information such as district, road and direction, and guardrail information such as guardrail location, length, and type of end treatment. Presented in Table 3-4 is an illustration of the retrieved information on guardrails.

Table 3-4 Illustration of Retrieved Information on Guardrails

\begin{tabular}{|c|c|c|c|c|c|c|c|c|c|}
\hline District & Road & Direction & Date & RPfrom & RPto & FrontEndType & EndType & Length & Environment \\
\hline 6 & I164 & I & $5 / 3 / 2005$ & 0.425 & 0.544 & CAT & None & 0.119 & FreeStanding \\
\hline 6 & I164 & I & $5 / 3 / 2005$ & 10.924 & 11 & SKT350 & None & 0.076 & PreBridge \\
\hline 3 & I465 & I & $5 / 21 / 2005$ & 0.098 & 0.155 & Unknown & None & 0.057 & FreeStanding \\
\hline 4 & I65 & D & $5 / 20 / 2005$ & 253.068 & 253.003 & CAT & None & 0.065 & FreeStanding \\
\hline 4 & I65 & D & $5 / 20 / 2005$ & 252.684 & 252.65 & ETPlus & None & 0.034 & FreeStanding \\
\hline 1 & I65 & D & $5 / 20 / 2005$ & 182.622 & 182.571 & CAT & None & 0.051 & FreeStanding \\
\hline 1 & I65 & D & $5 / 20 / 2005$ & 179.045 & 178.967 & SKT350 & None & 0.078 & FreeStanding \\
\hline 5 & I65 & D & $5 / 22 / 2005$ & 61.947 & 61.92 & BreakMaster & None & 0.027 & FreeStanding \\
\hline 5 & I65 & D & $5 / 22 / 2005$ & 61.758 & 61.598 & SKT350 & None & 0.16 & PreBridge \\
\hline 2 & I69 & D & $5 / 13 / 2005$ & 116.49 & 116.339 & SENTRE & None & 0.151 & FreeStanding \\
\hline 7 & I90 & D & $5 / 17 / 2005$ & 130.772 & 130.719 & ETPlus & None & 0.053 & FreeStanding \\
\hline
\end{tabular}

The first column, "District", provides district code. INDOT has seven districts, including Crawfordsville, Fort Wayne, Greenfield, LaPorte, Seymour, Vincennes, and Toll Road districts. The second column, "Road" shows the name of roadway. The third column, "Direction" shows the direction in terms of "I" and "D". The letter, "I" represents the direction of "Increase", i.e. northbound or eastbound, and the letter, " $\mathrm{D}$ " represents the direction of "Decrease", i.e. southbound or westbound. The column of "Date" indicates the date when the guardrail data was 
collected. Columns RPfrom and RPto represent the reference posts for both the starting point and ending point of the guardrail, respectively. Columns FromEndType and EndType are the types of the end treatments at the starting point and ending point of the guardrail, respectively. The column of Length shows the length of the guardrail in miles. The last column, "Environment", indicates whether the guardrail is either located at the ends of bridges.

\section{Other Data Sources}

The INDOT video log system provides video log images gathered by a consultant under contract. This system displays four windows, including image, image/location, road condition, and digitized image control windows. The image window shows the front and side images along roadways when the images were captured. The image/location window presents the information related to the images, such as date tested, distance from the beginning of road section, location of the image in true miles, and geographical coordinates. The road condition window provides detailed information on International Roughness Index (IRI) and average rut depths in both the right and left wheel-paths.

In the situations where a highway consists of both 2-lane and multi-lane sections, the video log images are very useful to identify the approximate lengths of different sections. As the INDOT video log images are re-captured every two years, the images and location data may not precisely show or locate the present roadway features and roadside conditions. Therefore, site reviews were conducted when concerns arose and where roadside objects, such as guardrails, utility pole, traffic sign post, drainage facilities, trees, and other obstacles, were presented. In particular at those locations where fatal roadside accidents occurred, site review is very useful to identify possible roadway contributing circumstances and determine necessary countermeasures to enhance roadside safety.

\subsection{Guardrail Hardware}

\section{Guardrail Beams}

The total length of the guardrails examined in this study is 6,491,480 linear feet, accounting for approximately half of the all roadside guardrails under INDOT jurisdiction. Most guardrails on the roadways are the W-beam guardrails with strong posts as shown in Figure 3- 
1(a). In order to minimize post-snagging problems, a steel rubrail can be added below the Wbeam as shown in Figure 3-1(b). Also, the W-beam should be blocked out from the posts using steel, wood, or plastic blocks as shown in Figure 3-2. The post spacing depends on the deflection distance, i.e., the clearance between the W-beam face and the object being shielded. In general, the post spacing is $1.905 \mathrm{~m}$ when the deflection distance is greater than $1.30 \mathrm{~m}, 0.955 \mathrm{~m}$ when the deflection distance is less than $1.30 \mathrm{~m}$ but not less than $1.0 \mathrm{~m}$, and $0.475 \mathrm{~m}$ when the deflection distance is less than $1.0 \mathrm{~m}$ but not less than $0.84 \mathrm{~m}$. When no deflection distance is available, concrete median barrier (CMB) as shown in Figure 3-3 will be used, in particular when the substructures of overpass bridges being shielded. The minimum rail height is $685 \mathrm{~mm}$, and the maximum rail height is $760 \mathrm{~mm}$.

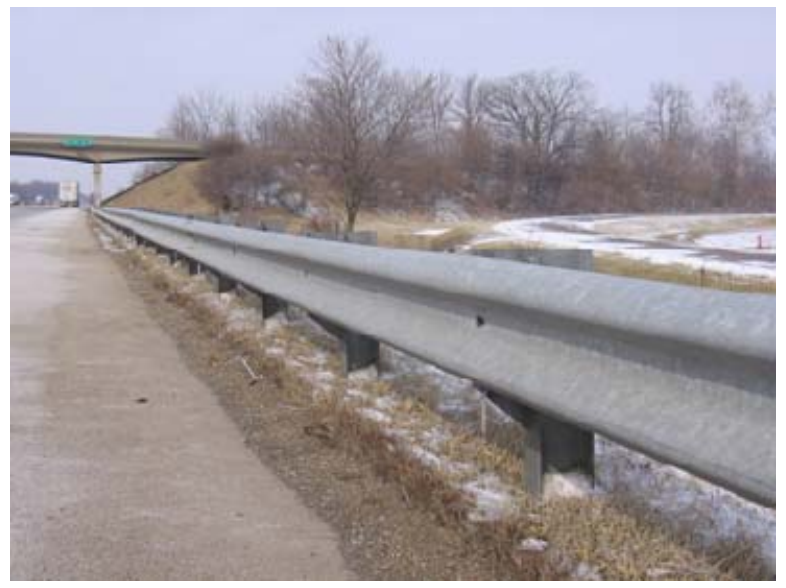

(a) W-Beam Guardrail

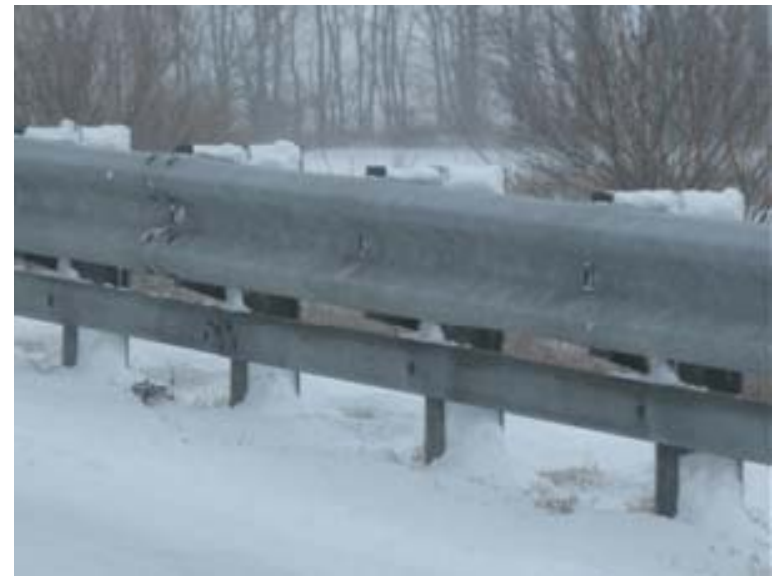

(b) W-Beam Guardrail with a Rubrail

Figure 3-1 Typical Roadside Guardrails

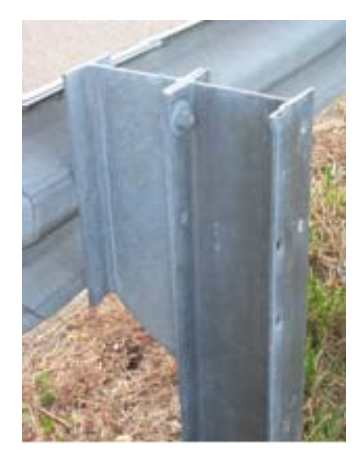

(a) Steel Block

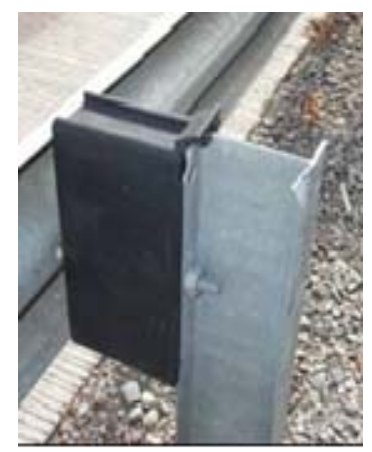

(b) Plastic Block

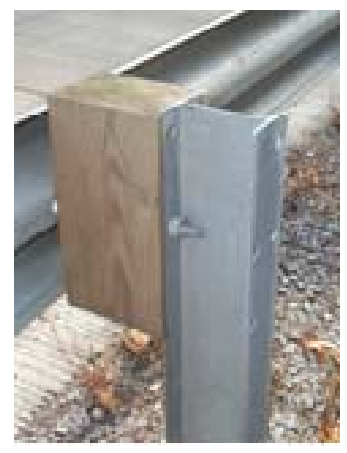

(c) Wood Block

Figure 3-2 Typical W-Beam Guardrail Blocks 


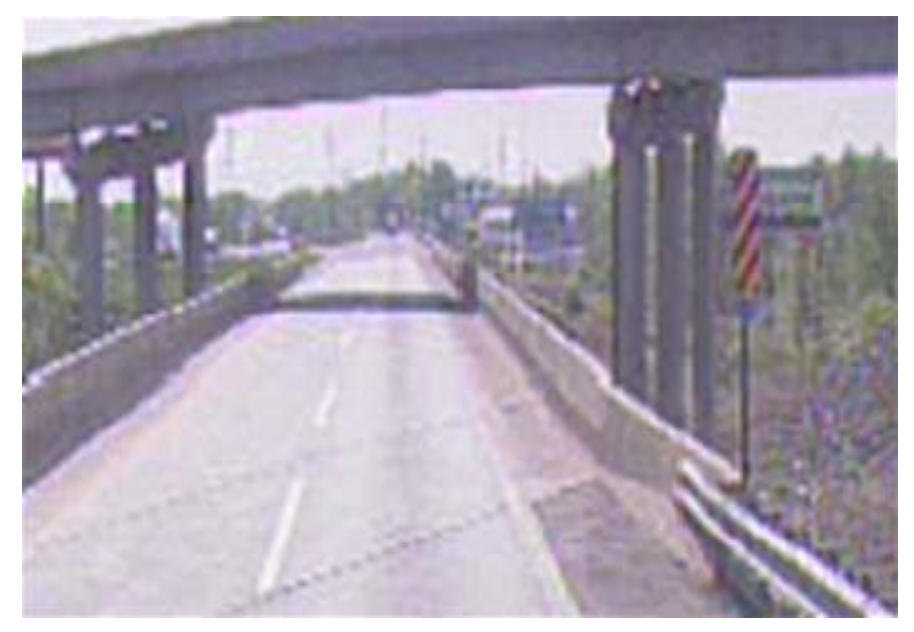

Figure 3-3 Typical Concrete Barrier on Roadside

Most roadside guardrails are placed on embankments or placed to shield roadside obstacles such as bridge piers and abutments, trees, utility poles, traffic sign supports and posts, drainage structures, and trees. In Indiana, approximately $42.2 \%$ (or $2,736,307$ feet) of the 6,491,480 linear feet guardrails examined are placed on interstate highways, $21.2 \%(1,378,941$ feet) on US highways, and $36.6 \%(2,376,232)$ on state highways. Figure $3-4$ shows the breakdown of guardrail lengths on interstate highways. The solid line shows the percentages of the total interstate mileage shared by different interstate highways. The broken line indicates the percentages of the total guardrail length placed on different interstates. It is demonstrates that in general, both the solid and broken lines follow a similar trend. As an illustration, I-65 is the longest interstate and constitutes about $21.6 \%$ of the total interstate mileage. Consequently, I-65 shares the greatest percentage, i.e., $21.3 \%$ of the total length of guardrails placed on all interstate highways.

However, there exist noticeable discrepancies on some interstates. On I-465, I-74, or I90 , the percentage of guardrail length is greater than the percentage of mileage. However, I-64 and I-69 show greater percentages of guardrail lengths than the percentages of mileage. The only possible reason is that the roadside features, such as topography and presence of obstacles, are different along these interstates. Presented in Figure 3-5 are the percentages of the interstate roadsides protected with guardrails. I-465 has the greatest percentage of roadsides protection. I465 is a beltway circling the capital city of Indiana, Indianapolis. I-465 is enclosed by developed areas and cannot provide sufficient roadside clearances at many locations. I-469 is a bypass 
parent I-69 and runs through mainly flat rural farming land. The embankments are relatively low and side slopes are generally traversable along I-469. Therefore, I-469 has the least percentage of roadsides protected with guardrails. In addition, many guardrails are placed on both sides of bridges. As shown in Figure 3-6, the total length of the guardrails connected to bridge rails constitutes up to $37.7 \%$ of the total guardrail length on interstates. On US highways, $31.4 \%$ of the total guardrail length is connected to bridge rails. On state highways, $30.6 \%$ of the total guardrail length is connected to bridge rails.

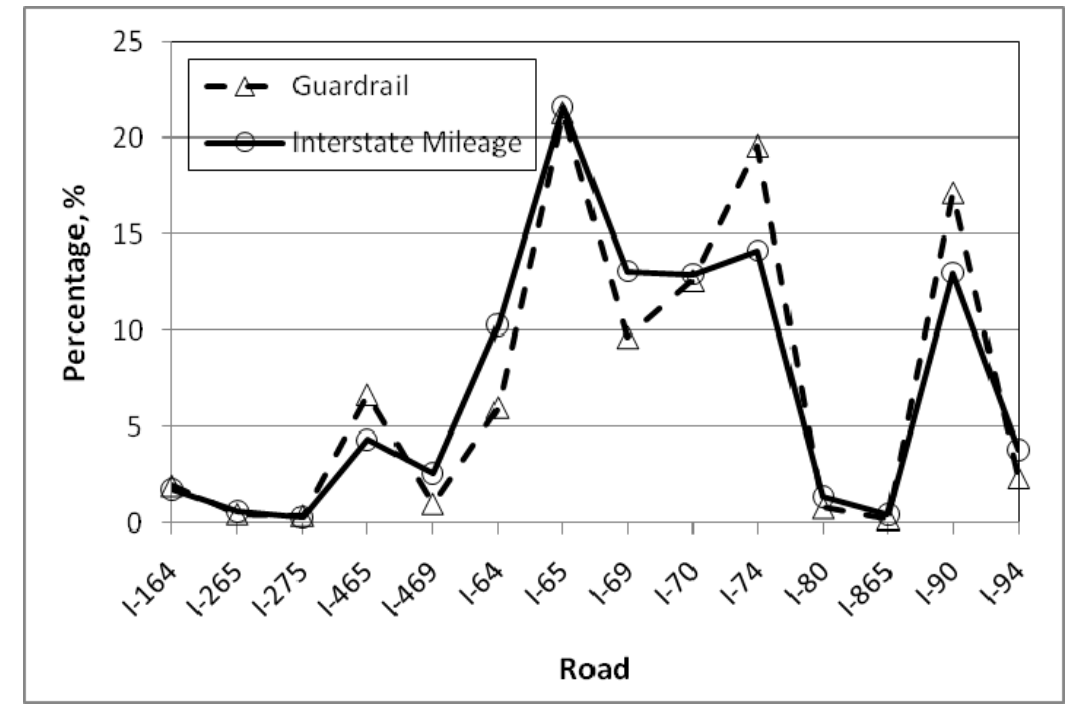

Figure 3-4 Breakdown of Guardrail Length on Interstates

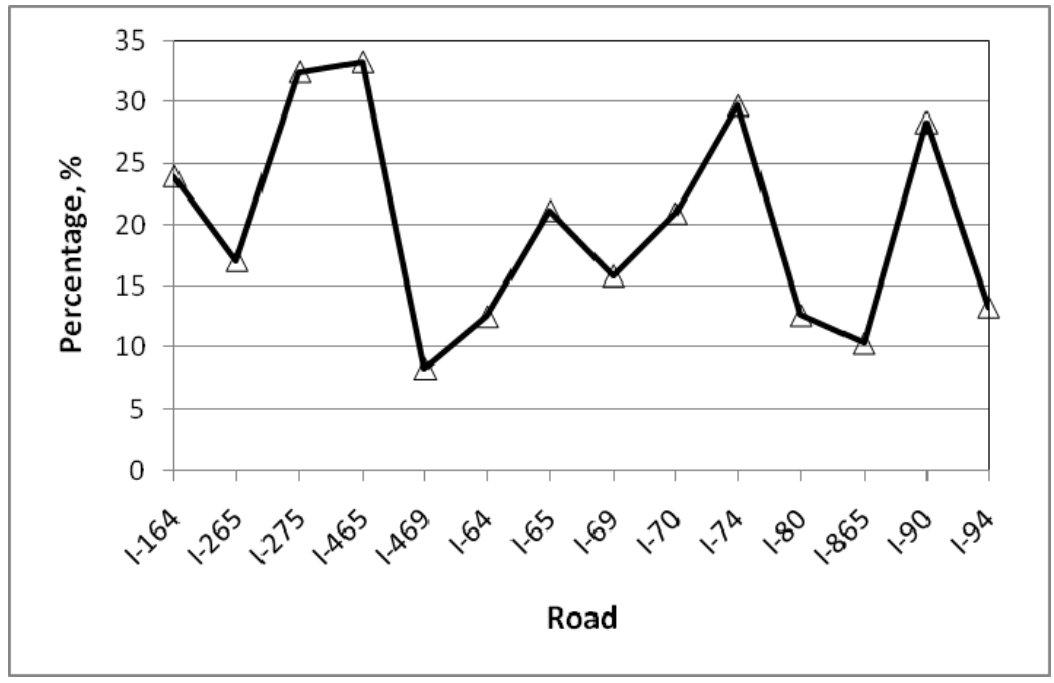

Figure 3-5 Percentages of Roadsides Protected with Guardrails 


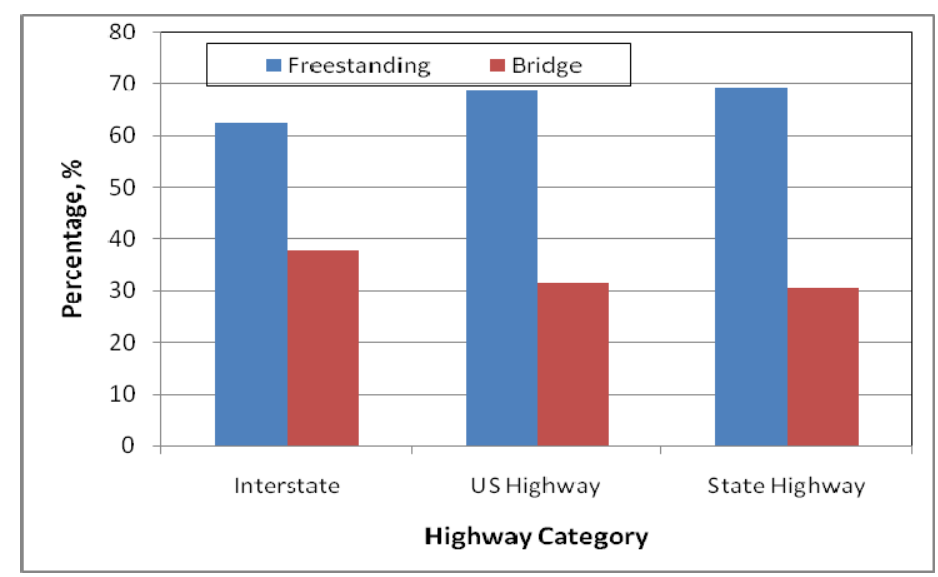

Figure 3-6 Distributions of Roadside Guardrails by Location

\section{End Treatments}

End treatment is an essential part for a guardrail system. As a crash involving an errant vehicle impacting the end of roadside barrier tends to be a head-on crash, a crashworthy end treatment must be utilized to decelerate the impacting vehicle. The end treatments on INDOT roadways include 6 different types of terminals, such as CAT, ET 2000 Plus, SKT 350, BuriedIn, BREAKMASTER, and SENTRE as shown in Figure 3-7. It should be noted that the use of Buried-In terminals requires special cares to avoid errant vehicles overriding on the guardrail, in particular the steepness of the slope.

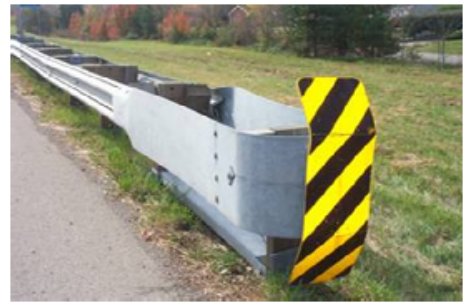

(1) CAT

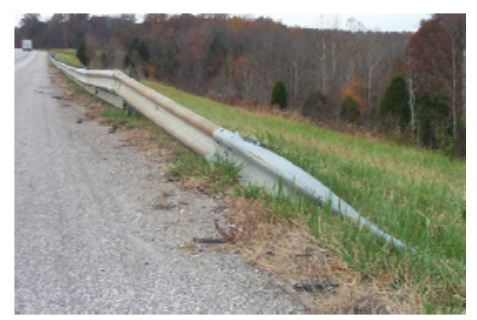

(4) Buried-In

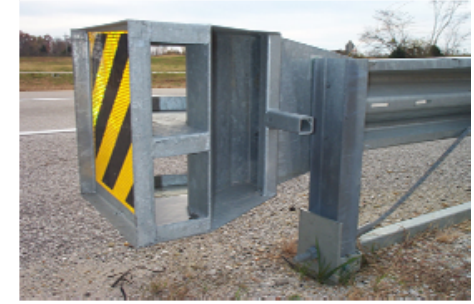

(2) ET 2000 Plus

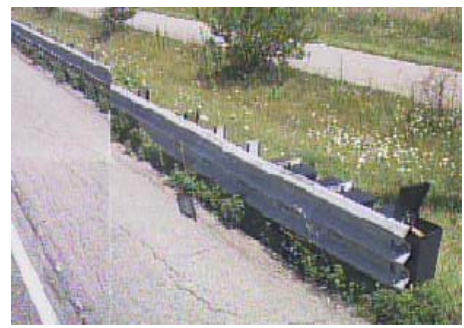

(5) SENTRE

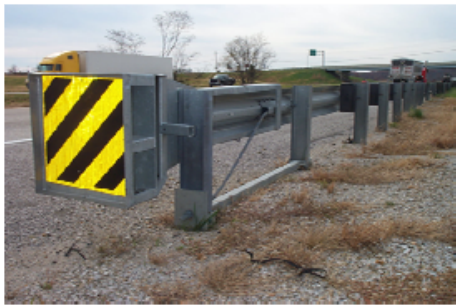

(3) SKT 350

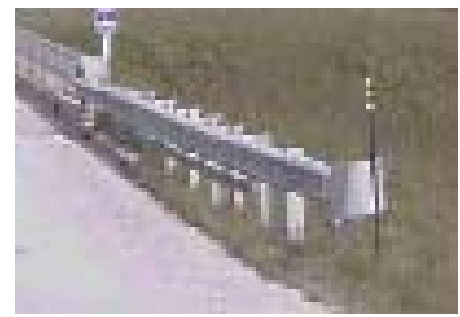

(6) BREAKMASTER

Figure 3-7 Photos of Guardrail End Treatments 
Of the 15,030 end treatments connected to the guardrails on the right shoulders, there were 148 BREAKMASTER terminals, 3,278 CAT terminals, 1,322 ET 2000 Plus terminals, 96 SENTRE terminals and 1,515 SKT 350 terminals, and 8,671 unknown end treatments which consists greatly of Buried-In terminals. Figure 3-8 shows the breakdown of those 15,030 end treatments by terminal type. The most commonly used terminal is those under the Unknown Category which constitutes about $58.0 \%$ of the total end treatments examined, followed by the CAT terminal that approximately accounts for $21.7 \%$ of the total end treatments.

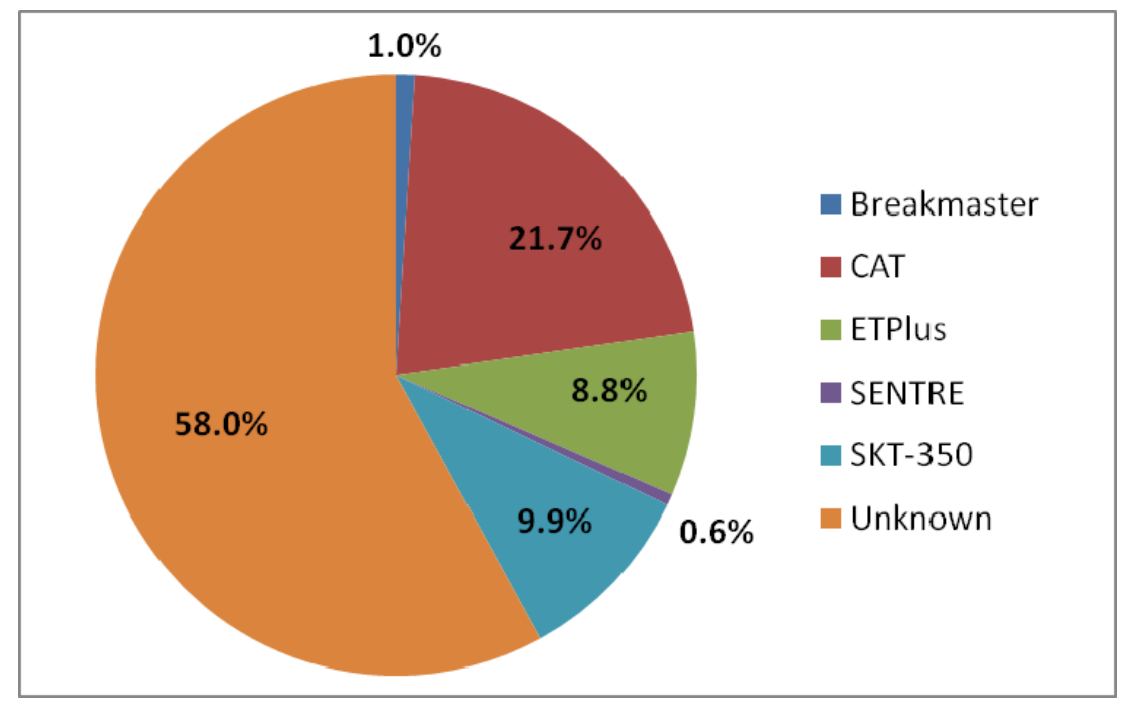

Figure 3-8 Breakdown of End Treatments by Type

Figures 3-9 shows the percent distribution of the total end treatments by highway category. State highways have the greatest number of guardrail terminals which comprise percentage of the almost $60 \%$ of the total terminals examined. While interstate highways have the greatest percent of the total guardrail lengths, their terminals constitute the lowest percentage, i.e. $19 \%$ of the total terminals. This is probably because interstate highways usually have higher standards in alignment design than US and State highways. Therefore, the interstate highway embankments are higher than those on other highways, and most guardrail systems on interstate highways are much longer than those on other highways.

Presented in Figure 3-10 is the percent distribution of guardrail terminals by type on interstate, US and State highways, respectively. On interstate highways, CAT terminals are the most commonly used end treatment and account for about $69 \%$ of the total terminals on 
interstate highways. ETPlus and SKT-350 terminals represent, respectively, $12 \%$ and $10 \%$ of the total terminals. Very few Breakmaster terminals are currently placed on interstate highways. On State highways, the dominant terminal type is those under the Unknown Category, accounting for up to $77 \%$ of all terminals. SKT-350, ETPlus and CAT account for $8.7 \%, 7.2 \%$, and $6.6 \%$ of the total terminals. Only one SENTRE terminal was observed on State highways. Similar observations were made on US highways. Unknown terminals comprise $54.7 \%$ of all terminals, followed by CAT (20.4\%), SKT-350 (12.6\%), and ETPlus (10.3\%) terminals.

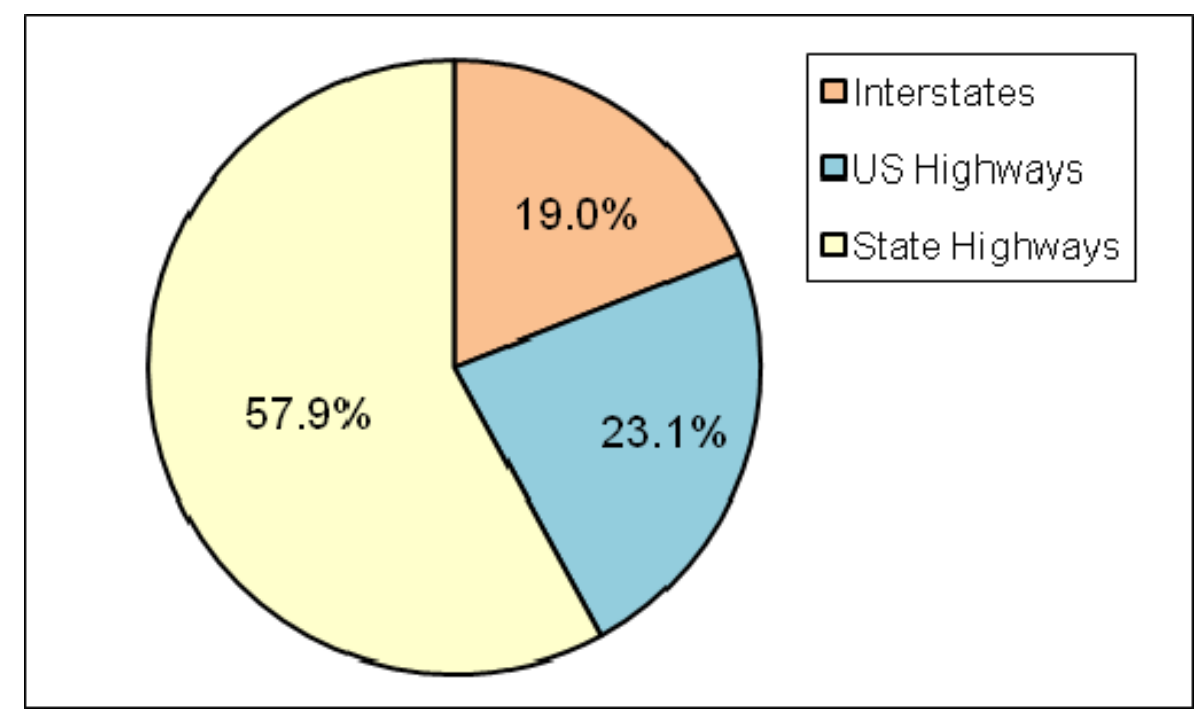

Figure 3-9 Percent Distribution of End Treatments by Highway Category

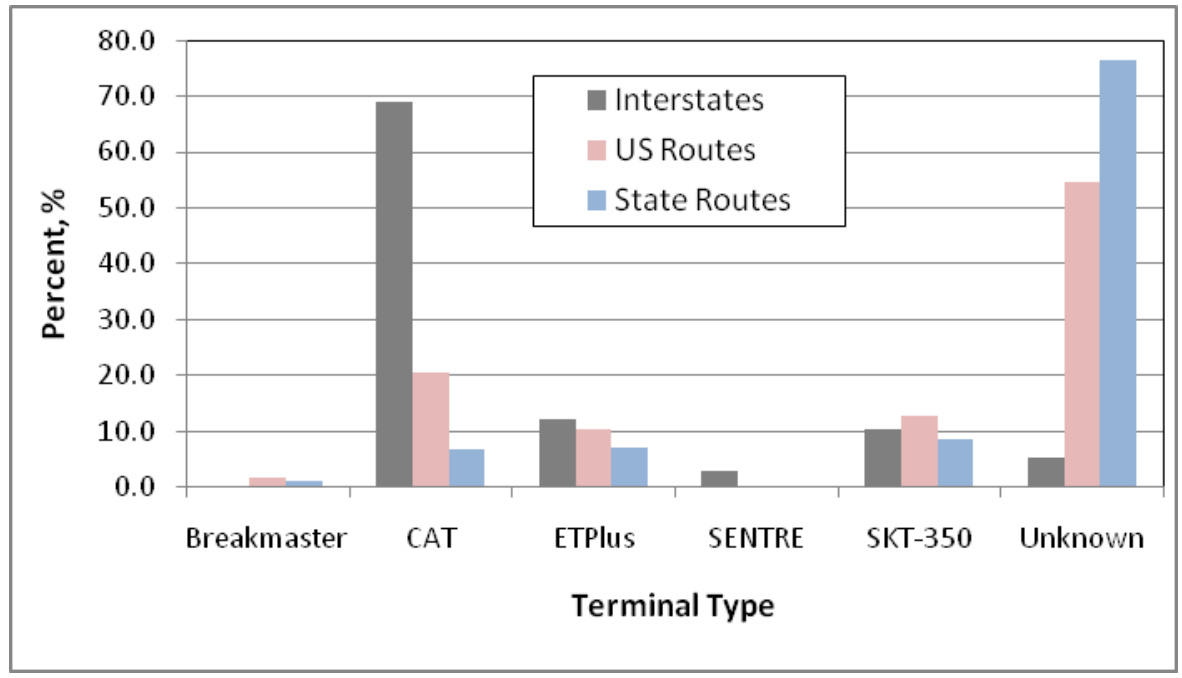

Figure 3-10 Percent Distribution of Guardrail Terminals by Guardrail Type 
Figure 3-11 shows the percent distribution of a certain type of terminal by highway category. Obviously, most CAT terminals are placed on interstates. Unknown terminals are mainly placed on interstate and US highways. Both SENTRE and Breakmaster terminals are not commonly used. Again, the category of unknown terminals consists greatly of Buried-In guardrail terminals. It is the FHWA police that the Buried-In end terminals be replaced on the NHS highways.

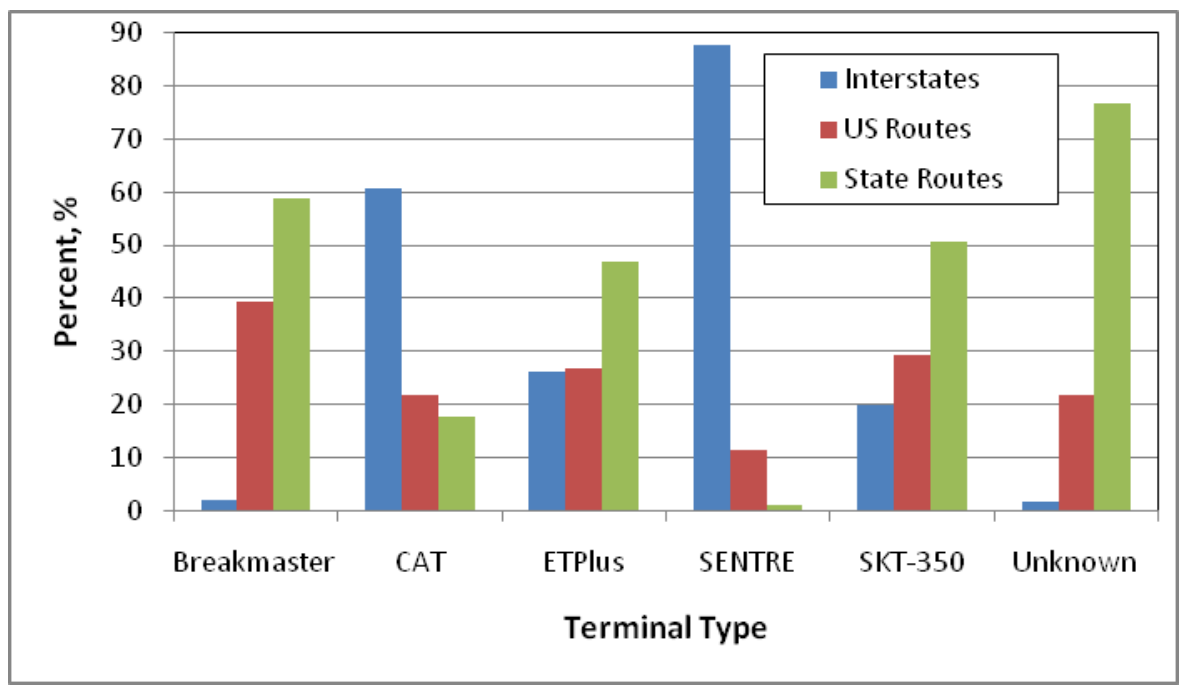

Figure 3-11 Percent Distribution of Guardrail Terminals on Different Highway Categories 


\section{Chapter 4}

\section{ANALYSIS OF RUN-OFF-ROAD CRASHES}

\subsection{The Data Used and Analysis Methods}

\section{The Run-Off-Road Crash Data}

This study examined two-year ROR crashes occurred on the highways under the jurisdiction of INDOT, including 2232 ROR accidents in 2004, and 2425 crashes in 2006, respectively. Each ROR accident record provided detailed information on the conditions of roadway geometrics, vehicles involved, persons injured, fatalities, damages, and roadside objects impacted by the errant vehicles. Other information such as time, weather, and global positioning system (GPS) coordinates was also provided. In the analysis, all ROR accidents were first categorized as ROR Right or ROR Left. In the category of ROR Right, the errant vehicles ran off the right shoulder. In the category of ROR Left, the errant vehicles ran off the left shoulder onto the medians for multi-lane and interstate highways or crossed over the roadway centerlines and ran off the shoulder in the opposite direction on 2-lane highways. In each category, the ROR accidents were further categorized into ROR Only or ROR Crash. ROR Only represents that errant vehicles left the roads without hitting any roadside object. ROR Crash indicates that errant vehicles left the roads and impacted one or more objects on roadside.

In the case of ROR Crash, the roadside objects impacted by errant vehicles were identified, and the crash outcomes were specified in terms of the number of vehicles involved, the number of people injured and the number of fatalities. The damage of properties due to each ROR Crash was estimated in a dollar amount. The roadway features such as alignment geometrics and highway class at the crash scenes were defined. While the AASHTO Roadside Design Guide estimates the encroachments in terms of either an undivided road or a divided road based on the average daily traffic (ADT) volume, this study examined the ROR accidents on the basis of three highway classes, including 2-lane highways, conventional multi-lane highways and interstates. It is a fact that traffic volume changes from location to location and fluctuates over time. However, this information at a crash scene is often not available. Dividing multi-lane 
highways into two separate classes could not only generate more accurate and meaningful results, but also make the results potentially more applicable.

\section{The Data Analysis Tools}

ArcMap (12) was utilized to create the map components of ROR accidents and display the geographical distribution of ROR accidents. The detailed information on the development of ArcMap is provided in Chapter 6. With ArcMap, the authors could zoom into the map to identify the location of crash being reviewed. Once the location of the crash site was determined, the INDOT Video Log System was utilized to review the field condition and roadside features. In the situations where a highway consists of both 2-lane and multi-lane sections, the video log images were also used to identify the approximate lengths of different sections. As the INDOT video log images are re-captured every two years, the images and location data may not precisely show and locate the roadway features and roadside conditions. Therefore, site reviews were conducted to verify roadside objects, such as guardrails, utility pole, traffic sign post, drainage facilities, trees, and other obstacles. During the process of this study, the authors conducted site reviews at 12 fatal crash sites on 11 highways, including interstate, US, and State highways. As shown in Figure 4-1 is a picture of a fatal crash site at a railroad crossing on SR-55. An errant vehicle ran off the road into the ditch and caused a fatal crash.

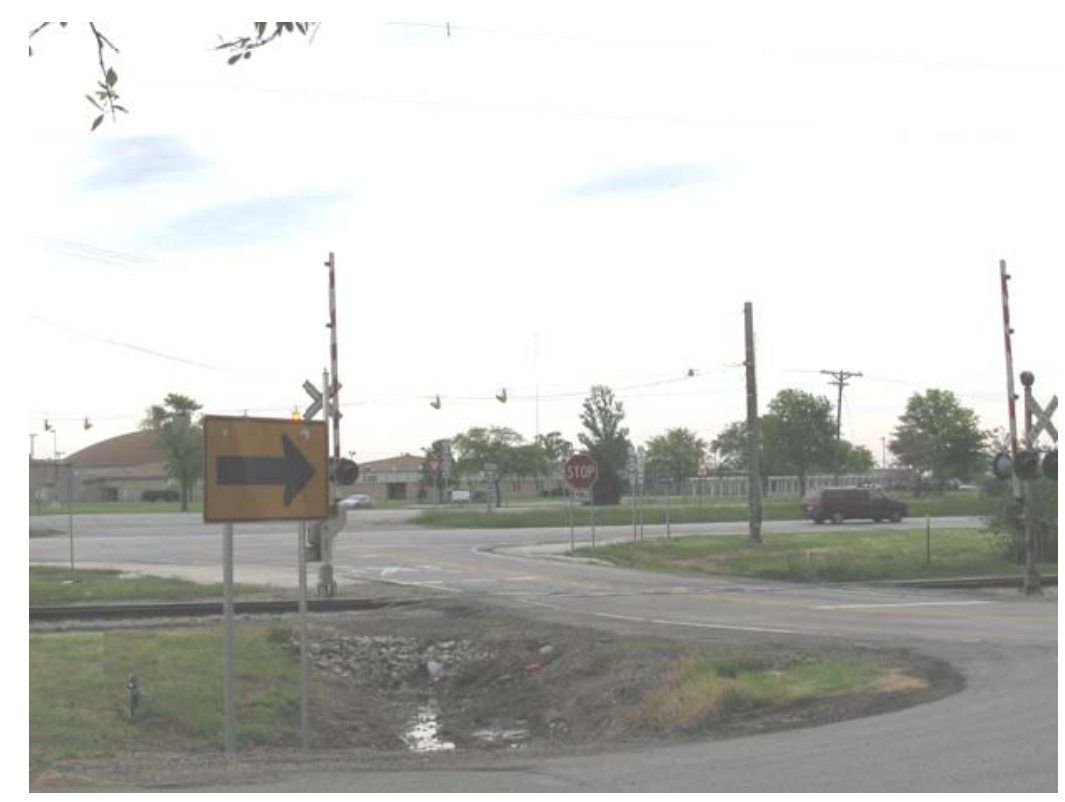

Figure 4-1 Photo of a Fatal Crash Scene Taken during Site Visit 


\subsection{Breakdown of ROR Accidents}

\section{Breakdown of ROR Accidents by Highway Side}

ROR accidents can occur not only on the right side of highway, but also in the median on divided highways or on the left side of a 2-lane highway when the errant vehicle does not strike a vehicle in the opposing lanes. Presented in Table 4-1 is a breakdown of the ROR accidents by side on 2-lane highways, conventional multi-lane highways, and interstate highways in 2004 and 2006, respectively. The columns of Cases, Vehicles, Injured, and Fatalities indicate the numbers of ROR accidents, vehicles involved, persons injured, and fatalities, respectively. It is shown that the number of total ROR accidents increased from 2218 in 2004 to 2411 in 2006 or by $8.0 \%$. On 2-lane highways, while the numbers of ROR accidents are very close, the number of ROR accidents on the left side decreased from 91 to 22 or by $77.8 \%$. However, the number of fatalities increased from 37 in 2004 to 53 in 2006.

Table 4-1 Numbers of ROR Accidents by Side

\begin{tabular}{|c|c|c|c|c|c|c|}
\hline Year & Highway Side & Highway Category & Cases & Vehicles & Injured & Fatalities \\
\hline \multirow[t]{10}{*}{2004} & \multirow[t]{3}{*}{ ROR_Right } & 2-lane & 1311 & 1327 & 560 & 37 \\
\hline & & Multi-Lane & 341 & 352 & 108 & 7 \\
\hline & & Interstate & 387 & 402 & 134 & 8 \\
\hline & \multirow[t]{3}{*}{ ROR_Left } & 2-lane & 91 & 93 & 41 & 0 \\
\hline & & Multi-Lane & 20 & 1 & 1 & 0 \\
\hline & & Interstate & 68 & 72 & 20 & 2 \\
\hline & \multirow[t]{3}{*}{ Combined } & 2-lane & 1402 & 1420 & 601 & 37 \\
\hline & & Multi-Lane & 361 & 353 & 109 & 7 \\
\hline & & Interstate & 455 & 474 & 154 & 10 \\
\hline & \multicolumn{2}{|l|}{ Sum } & 2218 & 2247 & 864 & 54 \\
\hline \multirow[t]{10}{*}{2006} & \multirow{3}{*}{ ROR_Right } & 2-lane & 1391 & 1415 & 629 & 48 \\
\hline & & Multi-Lane & 467 & 472 & 177 & 7 \\
\hline & & Interstate & 488 & 507 & 168 & 9 \\
\hline & \multirow{3}{*}{ ROR_Left } & 2-lane & 22 & 22 & 9 & 5 \\
\hline & & Multi-Lane & 19 & 19 & 8 & 1 \\
\hline & & Interstate & 24 & 24 & 7 & 0 \\
\hline & \multirow[t]{3}{*}{ Combined } & 2-lane & 1413 & 1437 & 638 & 53 \\
\hline & & Multi-Lane & 486 & 491 & 185 & 8 \\
\hline & & Interstate & 512 & 531 & 175 & 9 \\
\hline & \multicolumn{2}{|l|}{ Sum } & 2411 & 2459 & 998 & 70 \\
\hline
\end{tabular}


Table 4-2 shows the percentages of both ROR Right and ROR Left accidents by highway category. Most accidents occurred on the right side of highway. The percentages of ROR Right varied from $93.5 \%, 95.0 \%$, and $85.1 \%$ in 2004 to $98.4 \%, 96.1 \%$, and $95.3 \%$ in 2006 for 2-lane, multi-lane, and interstate highways, respectively. Fluctuations can be observed in relation to the percentages of ROR accidents, in particular the fatal ROR accidents associated with 2-lane and interstate highways. The percentage of fatal ROR Left increased from $0 \%$ to $9.4 \%$ on 2-lane highways, and decreased from $20.0 \%$ to $0 \%$ on interstate highways. However, the percentages of ROR Right and ROR Left accidents are very consistent for multi-lane highways, regardless of the measurements.

Table 4-2 Percentages of ROR Accidents by Side

\begin{tabular}{|c|c|c|c|c|c|c|}
\hline Year & Hwy Class & Highway Side & Cases & Vehicles & Injured & Dead \\
\hline \multirow{4}{*}{2004} & \multirow{2}{*}{ 2-lane } & ROR_Right & 93.5 & 93.5 & 93.2 & 100.0 \\
\cline { 3 - 7 } & \multirow{2}{*}{ Multi-Lane } & ROR_Left & 6.5 & 6.5 & 6.8 & 0.0 \\
\cline { 3 - 7 } & \multirow{2}{*}{ Interstate } & ROR_Right & 95.0 & 94.6 & 99.1 & 87.5 \\
\cline { 3 - 7 } & & ROR_Left & 5.0 & 5.4 & 0.9 & 12.5 \\
\cline { 3 - 7 } & \multirow{2}{*}{$2-l a n e$} & ROR_Right & 85.1 & 84.8 & 87.0 & 80.0 \\
\cline { 3 - 7 } & & ROR_Left & 14.9 & 15.2 & 13.0 & 20.0 \\
\hline \multirow{3}{*}{2006} & \multirow{2}{*}{ Multi-Lane } & ROR_Right & 98.4 & 98.5 & 98.6 & 90.6 \\
\cline { 3 - 7 } & & ROR_Left & 1.6 & 1.5 & 1.4 & 9.4 \\
\cline { 3 - 7 } & \multirow{2}{*}{ Interstate } & ROR_Light & 96.1 & 96.1 & 95.7 & 87.5 \\
\cline { 3 - 7 } & & ROR_Right & 9.9 & 3.9 & 4.3 & 12.5 \\
\cline { 3 - 7 } & & ROR_Left & 4.7 & 4.5 & 4.0 & 0.0 \\
\hline
\end{tabular}

Table 4-3 shows the percent distribution of the ROR accidents by severity on both sides in the three highway categories. The severity is defined in terms of the number of the vehicles involved, persons injured, or fatalities in each ROR accident, and was classified into four levels, i.e., 1, 2, 3, and 4 or more in this study. As an illustration on 2-lane highways, the percentages for "Vehicles" in relation to the ROR accidents occurred on the right side are $99.0 \%, 0.7 \%$, $0.3 \%$, and $0.0 \%$ for severity $1,2,3$, and 4 or more, respectively in 2004 . This indicates that in the total number of ROR accidents occurred on the right side of 2-lane highway in 2004, 99.0\% involved 1 vehicle, $0.7 \%$ involved 2 vehicles, $0.3 \%$ involved 3 vehicles, and $0 \%$ involved 4 or more vehicles. Therefore, most ROR accidents involved only a single vehicle, regardless of the highway category and the side of highway. The ROR accidents involving a single vehicle 
accounted for $96.0 \%$ of the total ROR accidents or more on the three classes of highways, in particular for ROR Right accidents. Similarly, most ROR accidents involved only one person. This implies that the majority of persons injured or killed in the ROS accidents were drivers.

Table 4-3 Breakdown of ROR Accidents by Severity

\begin{tabular}{|c|c|c|c|c|c|c|c|c|c|c|}
\hline \multirow{2}{*}{$\begin{array}{c}\text { Highway } \\
\text { Class }\end{array}$} & \multirow{2}{*}{$\begin{array}{l}\text { Highway } \\
\text { Side }\end{array}$} & \multirow{2}{*}{ Severity } & \multicolumn{4}{|c|}{2004} & \multicolumn{4}{|c|}{2006} \\
\hline & & & 1 & 2 & 3 & $\geq 4$ & 1 & 2 & 3 & $\geq 4$ \\
\hline \multirow{9}{*}{ 2-lane } & \multirow{3}{*}{ Right } & Vehicles & 99.0 & 0.7 & 0.3 & 0.0 & 98.3 & 1.7 & 0.0 & 0.0 \\
\hline & & Injured & 85.7 & 10.6 & 3.2 & 0.4 & 84.0 & 11.0 & 3.7 & 1.4 \\
\hline & & Fatality & 87.1 & 9.7 & 0.0 & 3.2 & 93.0 & 2.3 & 4.7 & 0.0 \\
\hline & \multirow{3}{*}{ Left } & Vehicles & 97.8 & 2.2 & 0.0 & 0.0 & 100.0 & 0.0 & 0.0 & 0.0 \\
\hline & & Injured & 75.0 & 21.9 & 3.1 & 0.0 & 87.5 & 12.5 & 0.0 & 0.0 \\
\hline & & Fatality & No & No & No & No & 50.0 & 0.0 & 0.0 & 50.0 \\
\hline & \multirow{3}{*}{ Both } & Vehicles & 98.9 & 0.8 & 0.3 & 0.0 & 98.3 & 1.7 & 0.0 & 0.0 \\
\hline & & Injured & 85.1 & 11.4 & 3.2 & 0.4 & 84.0 & 11.0 & 3.7 & 1.3 \\
\hline & & Fatality & 87.1 & 9.7 & 0.0 & 3.2 & 91.1 & 2.2 & 4.4 & 2.2 \\
\hline \multirow{9}{*}{ Multi-Lane } & \multirow{3}{*}{ Right } & Vehicles & 97.7 & 2.1 & 0.0 & 0.3 & 98.9 & 1.1 & 0.0 & 0.0 \\
\hline & & Injured & 83.3 & 14.4 & 1.1 & 1.1 & 91.1 & 6.4 & 1.9 & 0.6 \\
\hline & & Fatality & 83.3 & 16.7 & 0.0 & 0.0 & 100.0 & 0.0 & 0.0 & 0.0 \\
\hline & \multirow{3}{*}{ Left } & Vehicles & 88.9 & 11.1 & 0.0 & 0.0 & 100.0 & 0.0 & 0.0 & 0.0 \\
\hline & & Injured & 100.0 & 0.0 & 0.0 & 0.0 & 100.0 & 0.0 & 0.0 & 0.0 \\
\hline & & Fatality & 100.0 & 0.0 & 0.0 & 0.0 & 100.0 & 0.0 & 0.0 & 0.0 \\
\hline & \multirow{3}{*}{ Both } & Vehicles & 97.2 & 2.5 & 0.0 & 0.3 & 99.0 & 1.0 & 0.0 & 0.0 \\
\hline & & Injured & 83.5 & 14.3 & 1.1 & 1.1 & 91.5 & 6.1 & 1.8 & 0.6 \\
\hline & & Fatality & 85.7 & 14.3 & 0.0 & 0.0 & 100.0 & 0.0 & 0.0 & 0.0 \\
\hline \multirow{9}{*}{ Interstate } & \multirow{3}{*}{ Right } & Vehicles & 96.6 & 2.8 & 0.5 & 0.0 & 96.9 & 2.3 & 0.8 & 0.0 \\
\hline & & Injured & 85.6 & 11.7 & 0.0 & 2.7 & 85.0 & 9.0 & 3.0 & 3.0 \\
\hline & & Fatality & 100.0 & 0.0 & 0.0 & 0.0 & 100.0 & 0.0 & 0.0 & 0.0 \\
\hline & \multirow{3}{*}{ Left } & Vehicles & 95.6 & 2.9 & 1.5 & 0.0 & 100.0 & 0.0 & 0.0 & 0.0 \\
\hline & & Injured & 64.3 & 28.6 & 7.1 & 0.0 & 83.3 & 16.7 & 0.0 & 0.0 \\
\hline & & Fatality & 100.0 & 0.0 & 0.0 & 0.0 & $\sim$ & $\sim$ & $\sim$ & $\sim$ \\
\hline & \multirow{3}{*}{ Both } & Vehicles & 96.5 & 2.9 & 0.7 & 0.0 & 97.1 & 2.1 & 0.8 & 0.0 \\
\hline & & Injured & 83.2 & 13.6 & 0.8 & 2.4 & 84.9 & 9.4 & 2.9 & 2.9 \\
\hline & & Fatality & 100.0 & 0.0 & 0.0 & 0.0 & 100.0 & 0.0 & 0.0 & 0.0 \\
\hline
\end{tabular}

\section{Breakdown of ROR Accidents by Highway Category}

Table 4-4 presents a breakdown of the ROR accidents by number and by percentage in the three highway categories, respectively. More ROR accidents occurred in 2006 than in 2004 in terms of the number, persons injure or fatalities. The majority of ROR accidents occurred on 2-lane highways, accounting for $60.9 \%$ of the total ROR accidents. The number of ROR 
accidents on interstate highways is slightly greater than that on multi-lane highways. Similar observations were made in relation to vehicles involved, persons injured, and fatalities. On 2lane highways, the numbers of ROR accidents are very close. However, the number of fatalities climbed by $43.2 \%$ from 37 fatalities to 53 fatalities. As tabulated in Table 4-5 is a breakdown of the ROR accidents as percent of the total number of accidents, vehicles involved, persons injured, or fatalities by severity for each class of highway. Again, most ROR accidents involved one vehicle, regardless of the highway class. Fatal ROR accidents involving three or more fatalities occurred only on 2-lane highways. This simply concluded that ROR accidents were more severe on 2-lane highways.

Table 4-4 Breakdown of ROR Accidents by Highway Category

(a) Numbers of ROR Accidents

\begin{tabular}{|c|c|c|c|c|}
\hline \multicolumn{6}{|c|}{$\mathbf{2 0 0 4}$} \\
\hline Highway Class & Cases & Vehicles & Injured & Fatalities \\
\hline 2-lane & 1402 & 1420 & 601 & 37 \\
\hline Multi-Lane & 359 & 372 & 109 & 8 \\
\hline Interstates & 455 & 474 & 154 & 10 \\
\hline \multicolumn{5}{|c|}{$\mathbf{2 0 0 6}$} \\
\hline Highway Class & Cases & Vehicles & Injured & Fatalities \\
\hline 2-lane & 1413 & 1437 & 638 & 53 \\
\hline Multi-Lane & 486 & 491 & 185 & 8 \\
\hline Interstates & 512 & 531 & 175 & 9 \\
\hline
\end{tabular}

(b) Percentages of ROR Accidents

\begin{tabular}{|c|c|c|c|c|}
\hline \multicolumn{5}{|c|}{2004} \\
\hline Highway Class & Cases & Vehicles & Injured & Fatalities \\
\hline 2-lane & 63.3 & 62.7 & 69.6 & 67.3 \\
\hline Multi-Lane & 16.2 & 16.4 & 12.6 & 14.5 \\
\hline Interstates & 20.5 & 20.9 & 17.8 & 18.2 \\
\hline \multicolumn{5}{|c|}{2006} \\
\hline Highway Class & 58.6 & 58.4 & 63.9 & 75.7 \\
\hline 2-lane & 20.2 & 20.0 & 18.5 & 11.4 \\
\hline Multi-Lane & 21.2 & 21.6 & 17.5 & 12.9 \\
\hline Interstates &
\end{tabular}


Table 4-5 Breakdown of ROR Cases by Severity

\begin{tabular}{|c|c|c|c|c|c|c|c|c|}
\hline \multicolumn{9}{|c|}{ 2-lane Highway } \\
\hline Year & \multicolumn{4}{|c|}{2004} & \multicolumn{4}{|c|}{2006} \\
\hline Severity & 1 & 2 & 3 & $\geq 4$ & 1 & 2 & 3 & $\geq 4$ \\
\hline Vehicles & 1386 & 11 & 4 & 0 & 1389 & 24 & 0 & 0 \\
\hline Injured & 427 & 57 & 16 & 2 & 436 & 57 & 19 & 7 \\
\hline Fatalities & 27 & 3 & 0 & 1 & 41 & 1 & 2 & 1 \\
\hline \multicolumn{9}{|c|}{ Multi-Lane Highway } \\
\hline Year & \multicolumn{4}{|c|}{2004} & \multicolumn{4}{|c|}{2006} \\
\hline Severity & 1 & 2 & 3 & $\geq 4$ & 1 & 2 & 3 & $\geq 4$ \\
\hline Vehicles & 349 & 9 & 0 & 1 & 481 & 5 & 0 & 0 \\
\hline Injured & 76 & 13 & 1 & 1 & 151 & 10 & 3 & 1 \\
\hline Fatalities & 6 & 1 & 0 & 0 & 8 & 0 & 0 & 0 \\
\hline \multicolumn{9}{|c|}{ Interstate } \\
\hline Year & \multicolumn{4}{|c|}{2004} & \multicolumn{4}{|c|}{2006} \\
\hline Severity & 1 & 2 & 3 & $\geq 4$ & 1 & 2 & 3 & $\geq 4$ \\
\hline Vehicles & 439 & 13 & 3 & 0 & 497 & 11 & 4 & 0 \\
\hline Injured & 104 & 17 & 1 & 3 & 118 & 13 & 4 & 4 \\
\hline Fatalities & 10 & 0 & 0 & 0 & 9 & 0 & 0 & 0 \\
\hline
\end{tabular}

A highway with greater length should experience more ROR accidents. However, this does not necessarily imply that a longer highway is more risky than a shorter one. In order to provide uniform numbers, the ROR accidents on each highway were normalized by dividing the total number of ROR accidents, vehicles involved, persons injured, or fatalities on the highway by the length. For a highway consisting of 2-lane and multi-lane segments, the ROR accidents were divided into two groups accordingly, and the actual length for each group was used. Figure 4-2 shows the normalized numbers for the three highway categories, respectively. In general, the three normalized numbers show a similar pattern regardless of the highway category. As the length of highway increases, these three normalized numbers decreases. When the length of highway is approximately 25 miles, the three normalized numbers decrease dramatically. Afterwards, the three normalized numbers decrease slowly and tend to approach certain numbers. This implies that the ROR accidents are subject to a limit on highways with reasonable lengths. No trends can be observed in relation to the normalized numbers of fatalities for all the three classes of highways. This is probably because the fatality of ROR accident is the result of complex and multiple factors, and is more unpredictable. 


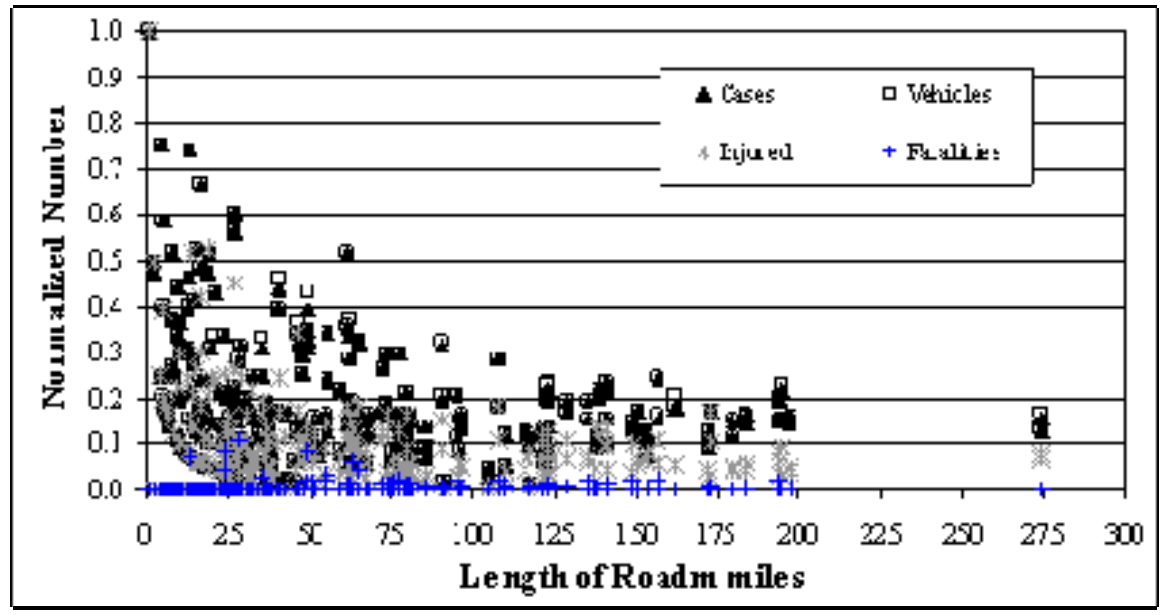

(a) 2-lane Highway

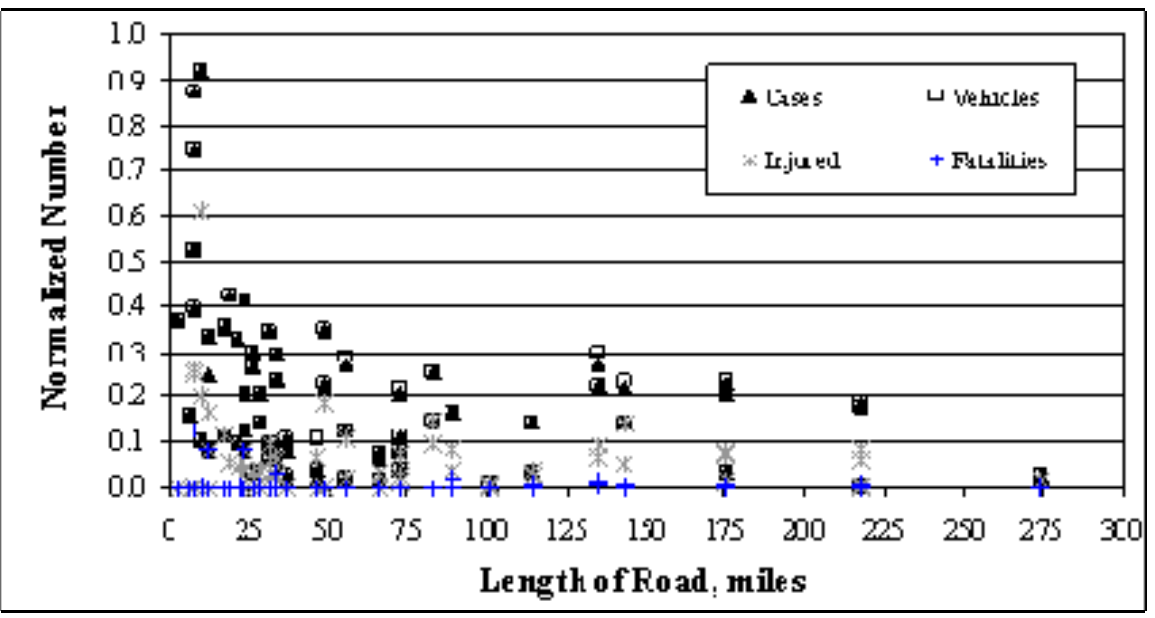

(b) Multi-Lane Highway

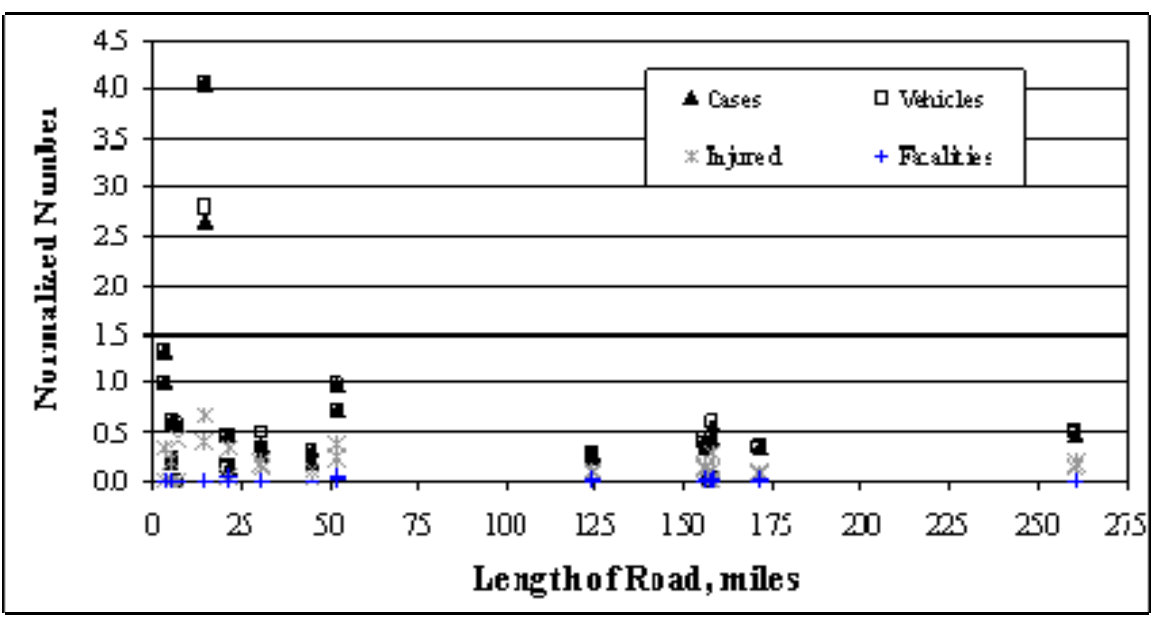

(c) Interstate

Figure 4-2 ROR Accident Numbers Normalized by Highway Length 


\subsection{Contribution Factors to ROR Accidents}

\section{Highway Geometrics}

Highway geometric feature or the Road Character in the standard crash report is classified as Straight-Level (SL), Straight-Grade (SG), Straight-Hillcrest (SH), Curve-Level (CL), Curve-Grade (CG), and Curve-Hillcrest (CH). Figure 4-3 shows the percent distributions of ROR crashes, injuries, and fatalities occurred in both 2004 and 2006 by highway category. In general, the percent distributions of the crashes are similar to those of the injuries, regardless of the highway category. The percent distributions of the fatalities present noticeable differences. The above observations imply that any crash tended to cause injuries, but did not necessarily cause fatalities that depended on more complicated circumstances. However, it is indicated that when horizontal curves were involved (CL and CG in the figures), the percentages increased for all crashes, injuries, and fatalities. Vertical curves had some effects on crashes, injuries and fatalities ( $\mathrm{SG}$ and $\mathrm{CG}$ in the figures). As a highway consists of mainly SL segments, the geometric feature of SL comprised the greatest percentages in all situations except for the fatalities on multi-lane highways.

For 2-lane highways, the effects of curves were noticeable on crashes, injuries, and fatalities, in particular when the geometric feature was CL. All the three distribution curves for crashes, injuries, and fatalities follow a similar trend. Similar observations can be made for multi-lane highways. However, the distribution curve of fatalities exhibits irregular trends with the features of SL and SG. In addition, the feature of CL represents the greatest percentage of fatalities. For interstate highways, one noticeable difference is that the effect of CG was greater than that of $\mathrm{CL}$ for both crashes and injuries. Nevertheless, the geometric feature of CL witnessed more fatalities than the geometric feature of CG. Most fatalities occurred on SL sections, accounting for $84 \%$ of total fatalities. In addition to the use of INDOT Video-log, this study conducted multiple field visits to the ROR crash sites to further examine the effect of highway geometrics on the ROR crashes. Figure 4-4 shows the pictures of SR-64 near RP 20 and I-65 near RP 164. Both locations consist of composite curves. The former experienced 6 ROR crashes (about $16.2 \%$ of total ROR crashes) and the latter experienced 17 ROR crashes (about $8.3 \%$ of the total ROR crashes) in 2004 and 2006. 


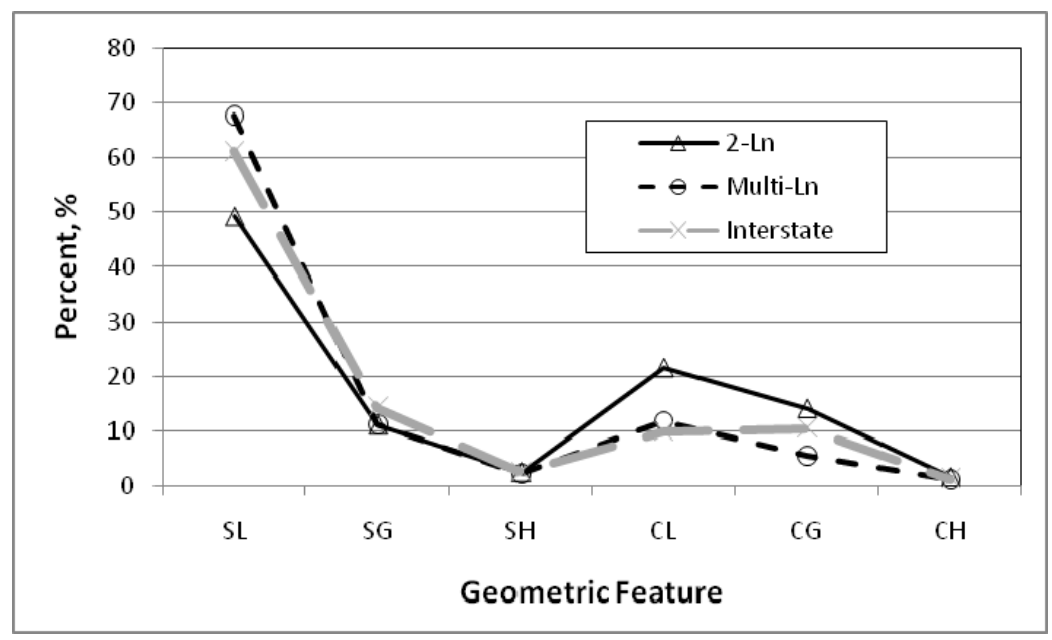

(a) Crashes

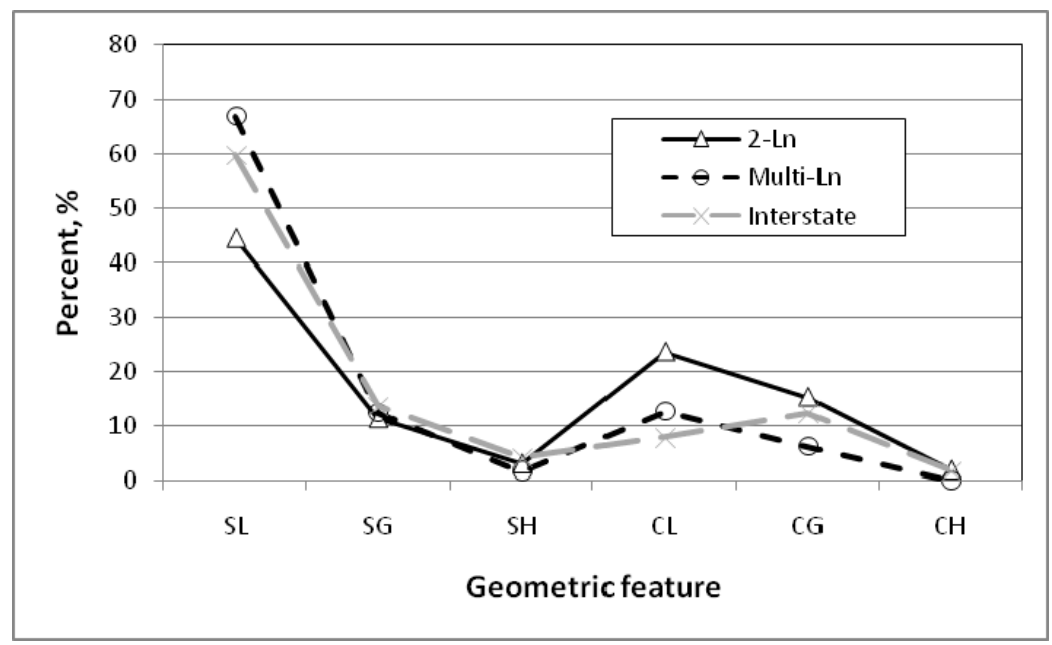

(b) Injuries

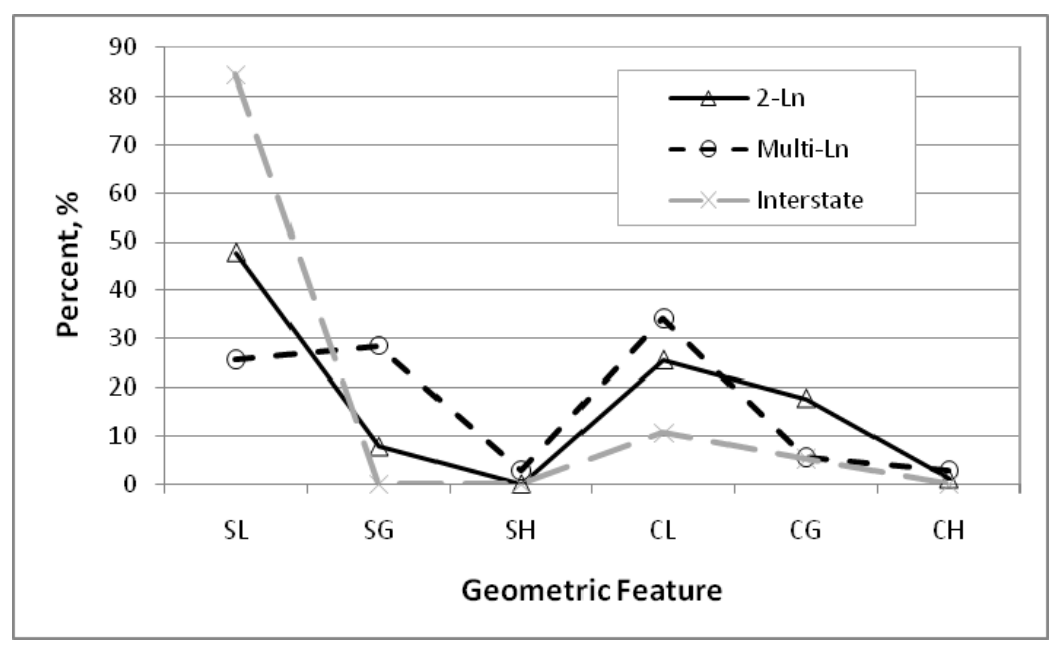

(c) Fatalities

Figure 4-3 Percent Distributions of ROR Crashes by Geometric Feature 


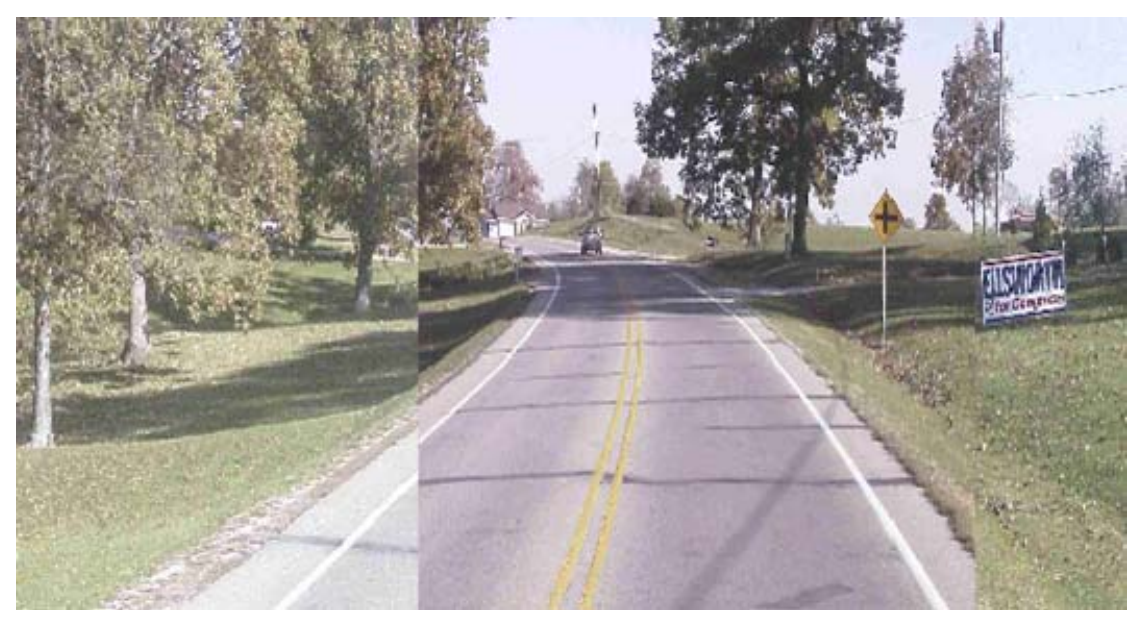

(a) SR-64 near RP 20

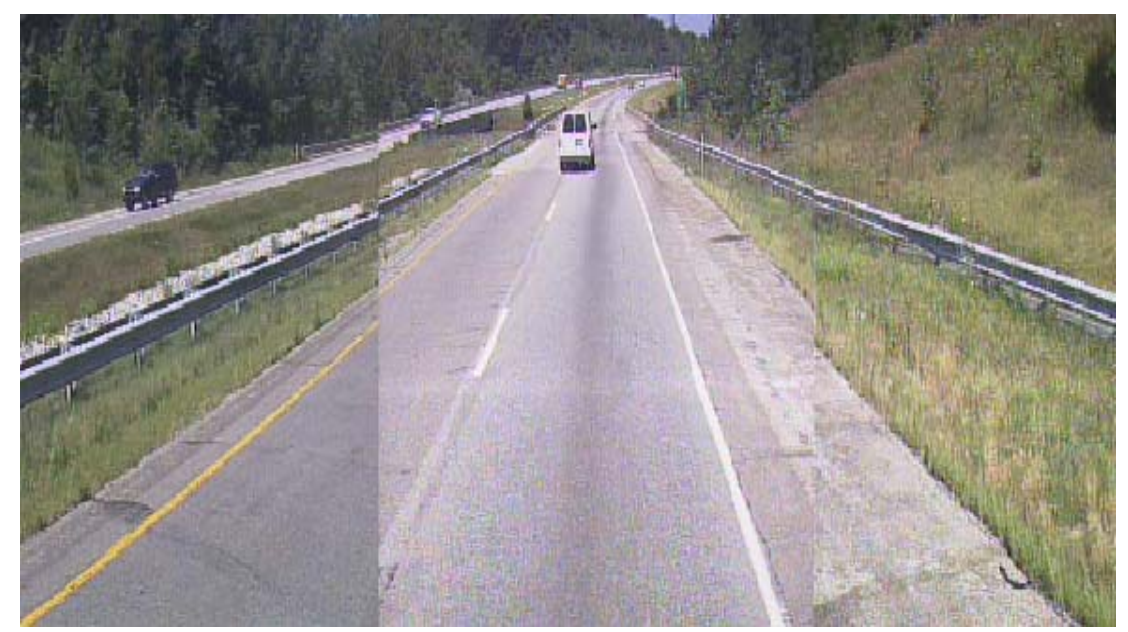

(b) I-65 near RP 164

Figure 4-4 Roadway Segments with Vertical Grades and Horizontal Curves

\section{Seasonal Characteristics}

In many cases, ROR crashes are secondary crashes resulting from various primary accidents, including skidding, sideswipe and collision between vehicles. It is well known that weather is one of the primary contribution factors to those primary crashes. For example, pavements may be covered with snow or ice during winters or become wet on rainy days. Therefore, the pavement surface skid resistance may decrease dramatically and more crashes may occur. Figure 4-5 shows the monthly distributions of ROR crashes by highway category in 2006. On 2-lane highways, June recorded the greatest number of ROR crashes that constitutes about $9.5 \%$ of the total ROR crashes. The second greatest number of ROR crashes was recorded 
in January, which comprises about $9.3 \%$ of the total ROR crashes. On multi-lane highways, the greatest number of ROR crashes was recorded in October, which represents $10 \%$ of the total ROR crashes. On interstate highways, the greatest number of ROR crashes was recorded in January, which accounts for $10.7 \%$ of the total ROR crashes. No similar trends were identified for these threes highway categories. Monthly distributions of the ROR crashes varied more significantly on 2-lane highways than on multi-lane and interstate highways.

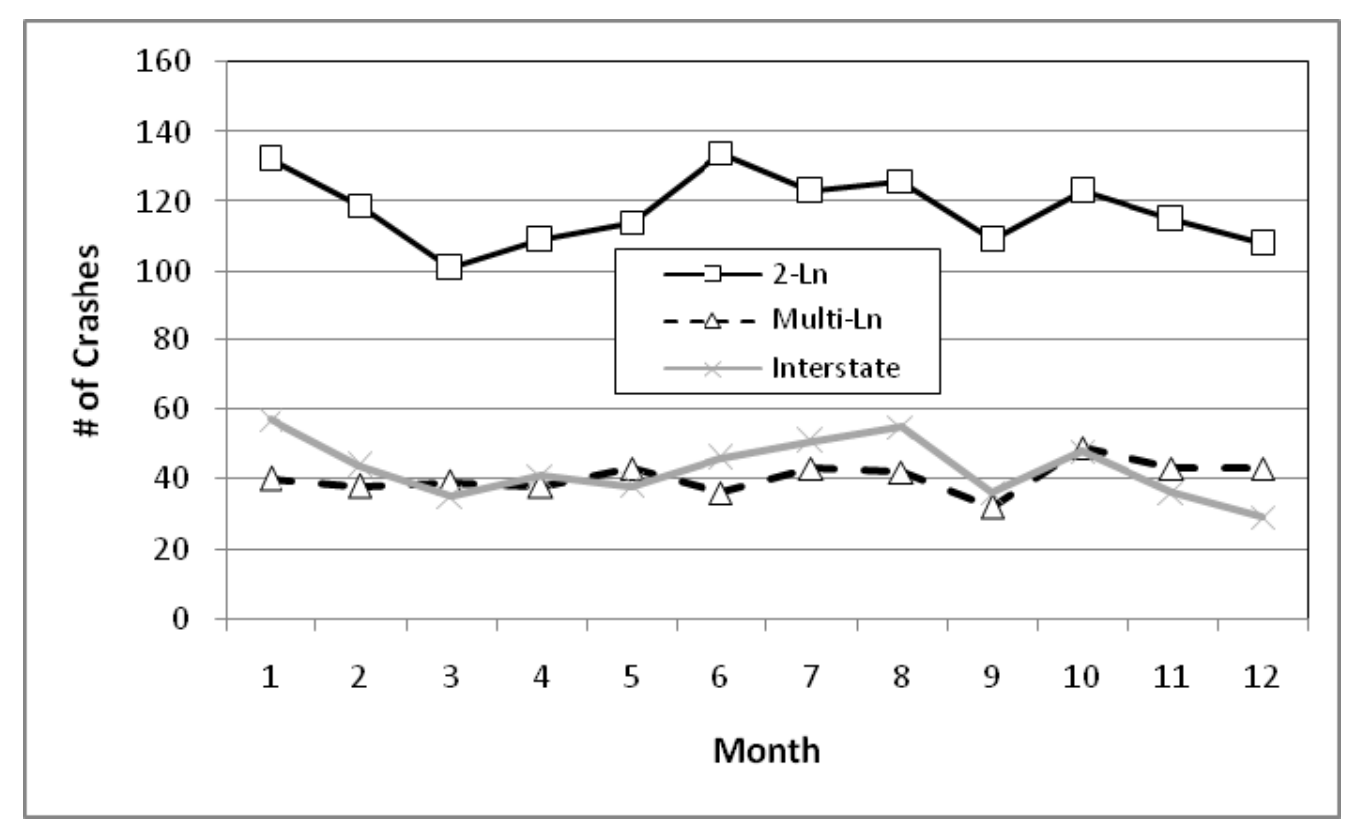

Figure 4-5 Monthly Distributions of ROR Crashes

This study further examined the monthly distributions of the injuries and fatalities resulted from all ROR crashes as shown in Figure 4-6. It is indicated that in Figure 4-6(a), more injuries occurred in warm seasons for all the three highway categories. The greatest percentage was recorded in June for 2-lane highways and July for both multi-lane and interstate highways, respectively. For fatalities, the greatest number was recorded in September on 2-lane highways, in October on multi-lane highways, and in January on interstate highways. Again, no similar trends were identified in either the injury or fatal distributions and more significant variations were observed on 2-lane highways. While the data did not provide a strong link between weather and ROR crashes, it is indicated that the patterns associated with ROR crashes are different on 2 lane, multi-lane, and interstate highways. 


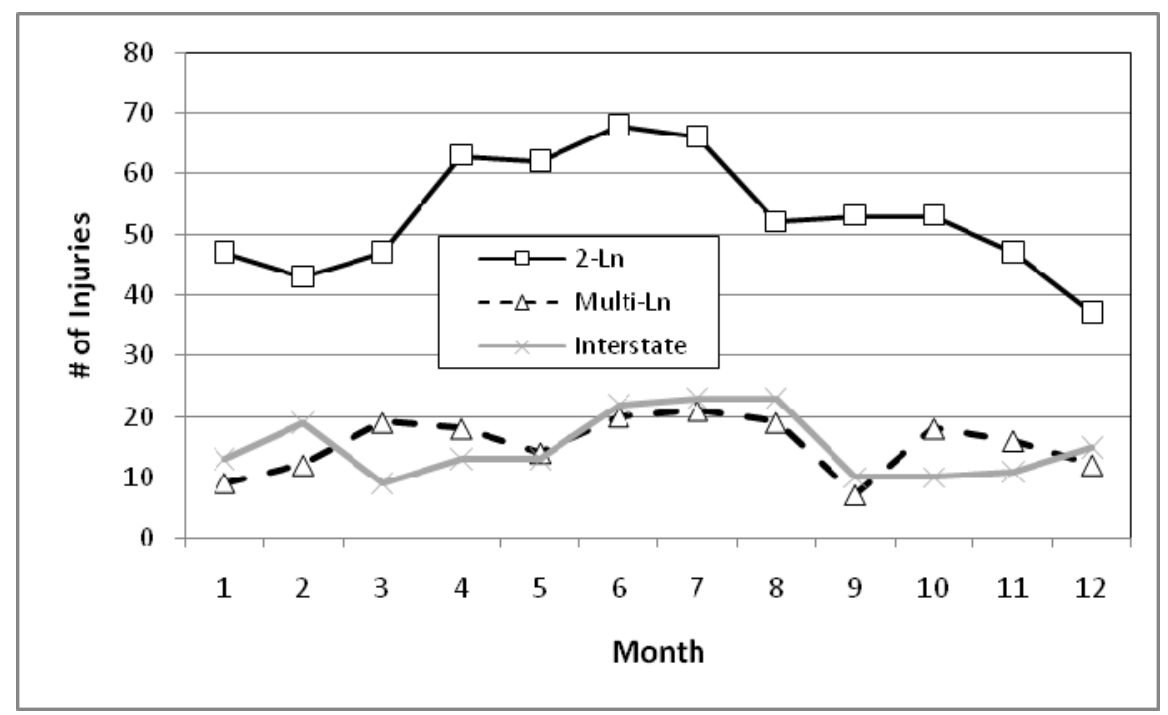

(a) Injuries

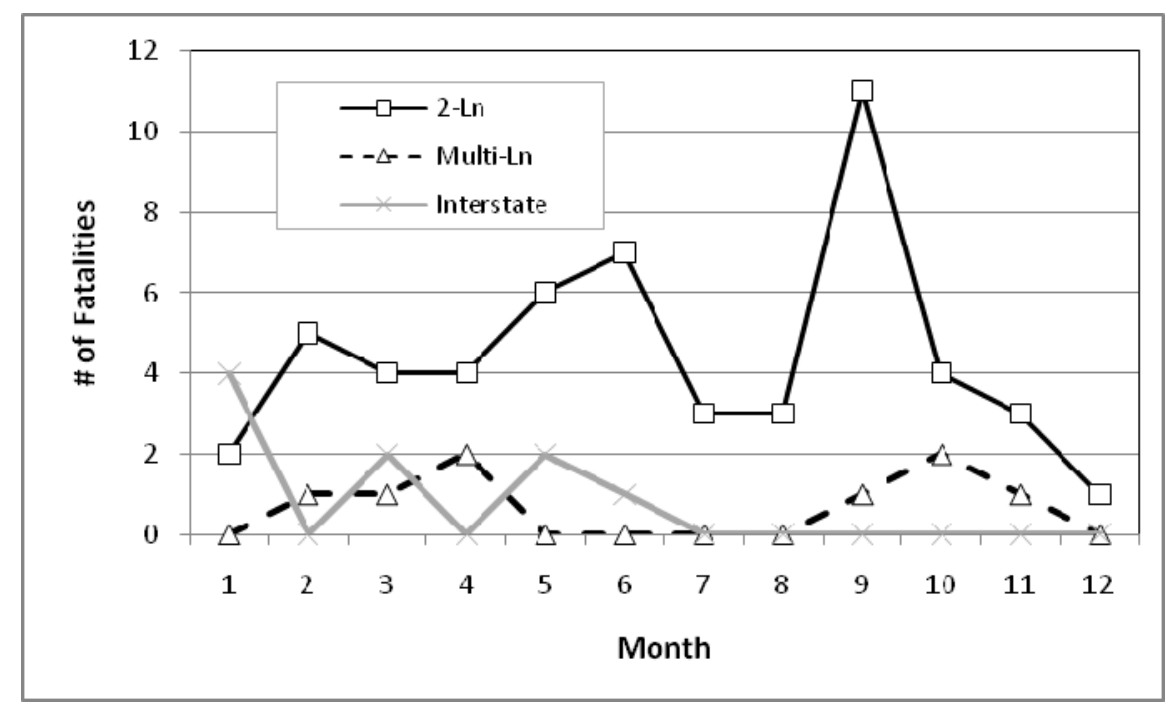

(b) Fatalities

Figure 4-6 Monthly Distributions of ROR Crash Injuries and Fatalities

\section{Effect of Traffic Volume}

Presented in Figure 4-7 are the variations of the ROR crashes with traffic volume. Each data point represents a specific road. The vertical axis represents the ROR rate, i.e. the number of ROR crashes per mile for a specific road, which was computed by dividing the total number of ROR crashes by the length of road. The horizontal axis represents the overall AADT for the whole road and is the weighted-average by highway length. In reality, traffic volume varies from 
location to location even along a certain road. During traffic surveys by INDOT, a certain road was first divided into many segments and the AADT was identified for each segment with a specific length. If a certain road is divided into $\mathrm{n}$ segments, the weighted-average of AADT was computed as follows:

$$
\overline{A A D T}-\frac{\sum_{i=1}^{m}\left(L_{i} \times A A D T_{i}\right)}{\sum_{i=1}^{n} L_{i}}
$$

in which, $\overline{\mathrm{AADT}}=$ the weighted-average of $\mathrm{AADT}, \mathrm{L}_{\mathrm{i}}=$ the length of section $\mathrm{i}$, and $\mathrm{AADT}_{\mathrm{i}}=$ the AADT observed on section i.
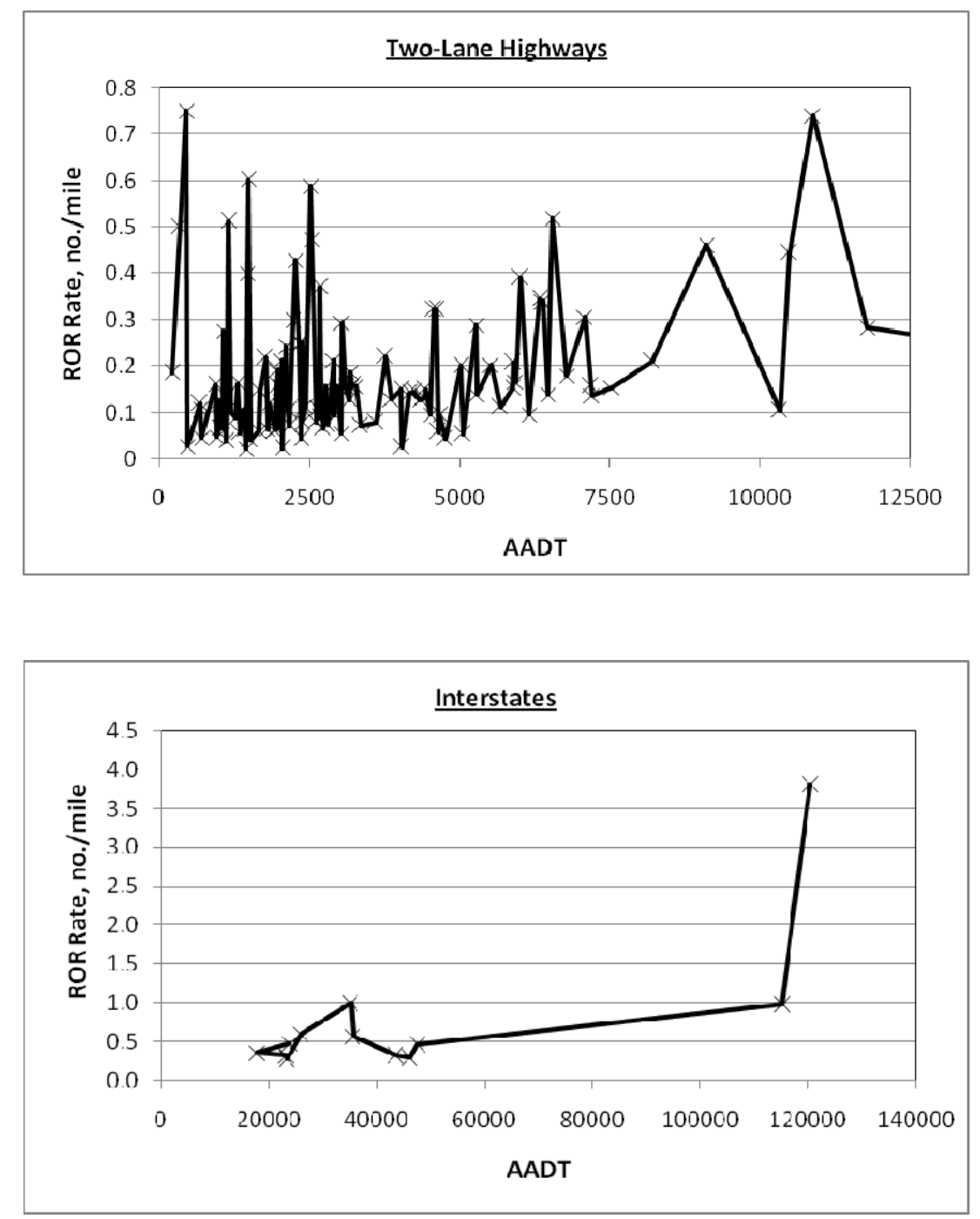

Figure 4-7 Variations of ROR Crashes with AADT 
Figure 4-7 does not show multi-lane highways because of insufficient data points. For 2lane highways, while the ROR rate fluctuates significantly, it increases as AADT increases. Similar observations can be made for interstate highways. While noticeable fluctuation arises, the ROR rate generally increases with AADT. It was also noted that in the process of data analysis, those roads with short lengths tended to produce large ROR rates. Different roads may have different posted speeds which may have significant effect on the ROR crashes. In particular, the presence of horizontal and vertical curves affected the ROR significantly. Therefore, it is natural that the ROR rates experienced dramatic fluctuations.

In order to examine the effect of traffic volume on the ROR crashes in depth, this study collected detailed information on ROR crashes, length, and AADT in different roadway segments on SR-64, US-30, and I-65, respectively. The general information on the three roadways is provided in Table 4-6. The ROR crashes are the total crashes occurred in 2004 and 2006. Based mainly on the locations of junctions, SR-64, US-30, and I-65 were divided into 52, 60, and 83 segments, respectively. The shortest segment was observed on SR-64, and longest segment on I-65. The overall AADT is the weighted-average by segment length. Obviously, traffic volumes varied significantly from road to road, and from segment to segment along a same road. The coefficient of variation for the actual AADT counts in all segments was approximately $66 \%$ on US-30, $63 \%$ on SR- 64 , and $52 \%$ on I- 65 .

Table 4-6 Roadway and ROR Crash Information on Three Selected Roads

\begin{tabular}{|c|c|c|c|c|c|c|}
\hline Road & Class & $\begin{array}{c}\text { No. of ROR } \\
\text { Crashes }\end{array}$ & $\begin{array}{c}\text { Overall } \\
\text { AADT }\end{array}$ & $\begin{array}{c}\text { AADT } \\
\text { Range }\end{array}$ & $\begin{array}{c}\text { No. of } \\
\text { Segments }\end{array}$ & $\begin{array}{c}\text { Segment } \\
\text { Length, mi. }\end{array}$ \\
\hline SR-64 & 2-Lane & 37 & 5280 & $2200-21150$ & 52 & $0.14-7.69$ \\
\hline US-30 & Multi-Lane & 55 & 19890 & $9530-81900$ & 60 & $0.20-8.11$ \\
\hline I-65 & Interstate & 204 & 47560 & $18270-157430$ & 83 & $0.29-14.76$ \\
\hline
\end{tabular}

To make the ROR crash data comparable, the ROR crash rate was computed by dividing the number of ROR crashes by the segment length for each segment. The variations of the ROR crash rates with AADT are presented in Figure 4-8. In general, the ROR crash rate increased as AADT increased. This trend in variation can be easily identified on SR-64 and I-64. Regardless of highway class, the greatest ROR crash rates occurred at locations with high AADT and composite curves or winding segments. For example, the segment between RP 110 and RP 114 on I-65 is a winding segment in the urban area of Indianapolis and experienced 14 ROR crashes. 

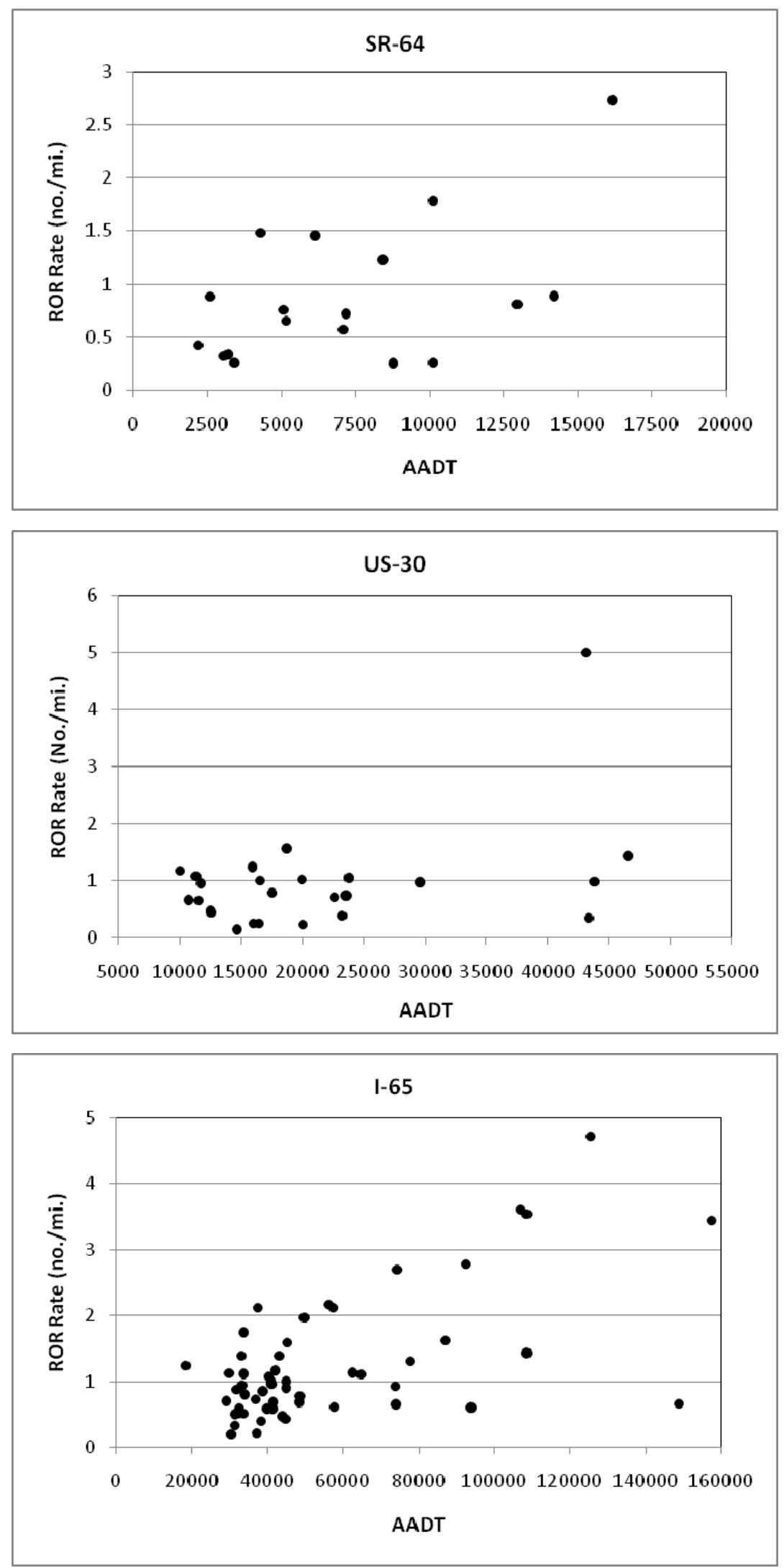

Figure 4-8 Variations of ROR Crash Rate with AADT 


\subsection{Crashes Involving Guardrails}

In many cases, if a guardrail can reduce the severity of potential crashes depends largely on engineering judgment, in particular at candidate locations considering possible installation of guardrails. For a specific vehicle-guardrail crash, the crash severity relies not only on vehicle speed and crash angle, but also on the position of the guardrail impacted by the vehicle. A crashworthy end treatment is required at the end of a roadside guardrail because an untreated end of a guardrail usually tends to result in more serious consequences. Even for a guardrail system with an appropriate end treatment, the consequence of a crash at the guardrail face may be significantly different from that at the end treatment. Presented in Table 4-7 are the consequences of the vehicle-guardrail crashes in terms of the impact positions, i.e., guardrail face and guardrail terminals or end treatments in both 2004 and 2006.

Table 4-7 Consequences of Vehicle-Guardrail Crashes

\begin{tabular}{|c|c|c|c|c|c|c|c|}
\hline Highway & \multirow{2}{*}{$\begin{array}{c}\text { Total } \\
\text { Class }\end{array}$} & Crashes & \multicolumn{2}{|c|}{ Crashes, \% } & \multicolumn{2}{c|}{ Injured, \% } & \multicolumn{2}{c|}{ Fatalities, \% } \\
\cline { 3 - 8 } & & Face & Terminal & Face & Terminal & Face & $\begin{array}{c}\text { Termina } \\
\text { I }\end{array}$ \\
\hline Interstate & 219 & 63.5 & 36.5 & 28.8 & 41.3 & 2.2 & 2.5 \\
\hline Multi-Lane & 85 & 60.0 & 40.0 & 21.6 & 50.0 & 2.0 & 8.8 \\
\hline 2-lane & 189 & 56.1 & 43.9 & 27.4 & 45.8 & 0.0 & 3.6 \\
\hline
\end{tabular}

Of the total 219 vehicle-guardrail crashes on Interstates, 63.5\% involved vehicles impacting on guardrail faces, and $36.5 \%$ involved vehicles impacting on guardrail terminals. The percentage of the crashes involving injuries was $28.8 \%$ when vehicles impacting on guardrail faces, and $41.3 \%$ when vehicles impacting on guardrail terminals. $2.2 \%$ of the crashes on guardrail faces caused fatalities, and $2.5 \%$ of the crashes on guardrail terminals caused fatalities. On multi-lane highways, there were 85 vehicle-guardrail crashes. $60.0 \%$ of the crashes involved vehicles impacting on guardrail faces, and $40.0 \%$ of the crashes involved vehicles impacting on guardrail terminals. For the crashes on guardrail faces, $21.6 \%$ caused injuries, and $2.0 \%$ caused fatalities. For the crashes on guardrail terminals, $50.0 \%$ caused injuries, and $8.8 \%$ caused fatalities. On 2-lane highways, $56.1 \%$ of the total 189 crashes impacted on guardrail faces, and $43.9 \%$ impacted on guardrail terminals. $27.4 \%$ of the crashes on guardrail faces caused injuries, 
and $0.0 \%$ caused fatalities. For the crashes on guardrail terminals, $45.8 \%$ caused injuries, and $3.6 \%$ caused fatalities.

Two conclusions can be made from the above observations. First, the potential for errant vehicles to impact guardrail terminals is very high. More than $35 \%$ of the vehicle-guardrail crashes involved vehicles impacting on guardrail terminals. The lower the highway class, the more the vehicle-guardrail crashes impacting on guardrail terminals. Second, the crashes impacting on guardrail terminals tend to result in more serious consequences. The percentage of the crashes on guardrail terminals involving injuries was approximately twice as much as that on guardrail faces, regardless of highway classes. In addition, there were more crashes on guardrail terminals that caused fatalities than crashes on guardrail faces, in particular on multi-lane and 2lane highways. 
Chapter 5

COSTS OF RUN-OFF-ROAD CRASHES

\subsection{Guardrail Economic Analysis}

As pointed out in Chapter 2, the AASHTO procedure for guardrail economic analysis are Monte Carlo stochastic procedures and consists of four modules, including encroachment module, crash prediction module, severity prediction module, and benefit/cost analysis module below $(1,4)$ :

\section{Encroachment Module}

For a specific highway segment, the encroachment frequency is estimated below:

$$
\text { Expected encroachment frequency }=\mathrm{V} \times \mathrm{P}(\mathrm{E})
$$

where $\mathrm{V}=$ average daily traffic, and $\mathrm{P}(\mathrm{E})=$ probability of an encroachment.

\section{Crash Prediction Module}

When one or more roadside obstacles are identified in the path of errant vehicle, the corresponding probability is expressed as follows:

$$
\text { Probability of a crash given an encroachment }=\mathrm{P}(\mathrm{A} / \mathrm{E})
$$

\section{Severity Prediction Module}

Crash severity depends on the speed, angle and orientation when a vehicle impacts the roadside obstacle and is expressed as follows:

$$
\text { Probability of injury severity leveli }=\mathrm{P}(\mathrm{Ii} / \mathrm{A})
$$




\section{Benefit/Cost Module}

Considering crash costs, installation costs, maintenance costs, and repair costs, the incremental benefit/cost ratios are computed as follows:

$$
\mathrm{B} / \text { CRatio }_{2-1}=\frac{\mathrm{AC}_{1}-\mathrm{AC}_{2}}{\mathrm{DC}_{2}-\mathrm{DC}_{1}}
$$

where $\mathrm{AC}_{\bullet}=$ annualized crash cost for alternative "•"; DC• = annualized agency cost for alternative "•"; and B/C Ratio $2-1=$ incremental benefit/cost ratio of Alternative 2 compared to Alternative 1.

The salvage value is assumed to be zero for all alternatives. The crash cost is obtained from the predicted severity and is computed as follows:

$$
\mathrm{AC}=\sum_{\mathrm{i}=1}^{\mathrm{n}} \mathrm{P}\left(\mathrm{I}_{\mathrm{i}}\right) \times \mathrm{C}\left(\mathrm{I}_{\mathrm{i}}\right)
$$

where $\mathrm{AC}=$ crash cost; $\mathrm{n}=$ total number of injury severity levels; $\mathrm{P}\left(\mathrm{I}_{\mathrm{i}}\right)=$ probability of injury level I; and $\mathrm{C}\left(\mathrm{I}_{\mathrm{i}}\right)=$ cost for injury severity level $\mathrm{i}$.

The above procedure is based on the Monte Carlo simulation instead of deterministic models and has the capability and flexibility in handling multiple needs, revision whenever necessary, non-tracking impacts, and impact from either both sides or both directions. To provide a realistic guardrail economic analysis, it is necessary to provide an accurate estimate of the encroachment rate, crash probability, crash severity and costs associated with the installation, repair, and maintenance of the guardrail.

\subsection{ROR Crash Costs}

\section{Encroachment Rates}

Currently, the encroachment rates are predicted on the basis of a single study conducted by Cooper 30 years ago in British Columbia, Canada (13). The Cooper study was accomplished through the observation of the tire tracks in the medians or on the shoulders. The Cooper studies 
have two main limitations (4). First, the data was collected during summer months on highways with speed limit varying from 80 to $100 \mathrm{~km} / \mathrm{h}$. Therefore, adverse weathers and high-speed interstate highways were not well represented. Second, the Cooper study was accomplished by observing the tire tracks in the medians or on the shoulders. As a result, the encroachments by errant vehicles and the encroachments by vehicles intentionally leaving roadways were not separated. It was also noted that the Cooper study only included roadways with AADT not greater than 25000. In Indiana, however, the majority of interstates have witnessed AADT values greater than 25000. Therefore, additional effort is needed to reexamine the encroachment rates based on the Indiana data.

In order to simplify the problem, the ROR crash data was grouped in terms of three highway categories, such as 2-lane, 4-lane and 6-lane (including more than 6 lanes) highways. In the process of data analysis, each road was first divided into segments, and the corresponding AADT values and reference posts were identified. Next, the reference post for each ROR crash site was determined through the GPS coordinates provided in the crash report. The number of ROR crashes and AADT were identified for each segment in light of the reference posts. The ROR rate for each segment was computed by dividing the number of ROR crashes over the segment by the segment length. Finally, the encroachment rates were determined by multiplying the ROR rates by an adjustment factor for each road to take into account those ROR crashes without GPS coordinates. The adjustment factor is defined as the ratio of the total number ROR crashes to the number of ROR crashes with GPS coordinates.

Figure 5-1 shows the encroachment rates and the corresponding AADT values. It is shown that the encroachment rates generally tend to increase as traffic volume increases, in particular on multi-lane highways. In addition, the encroachment ROR rates exhibit great dispersions regardless of highway class. The encroachment rates vary from 0.084 to 10.268 , 0.067 to 2.828 and 0.333 to 4.065 on 2-lane, 4-lane, and 6-lane (or more) highways, respectively. One of the main reasons is the effect of segment lengths. In general, the segments with short lengths tend to have great encroachment rates. Table 5-1 presents the recommended encroachment rates after eliminating those extreme cases. For other AADT values, the encroachment rates can be determined by either interpolation or extrapolation. Overall, the encroachment rates obtained by this study are less than those by the Cooper study. This is probably due in part to that the ROR crashes onto the medians were not included. 

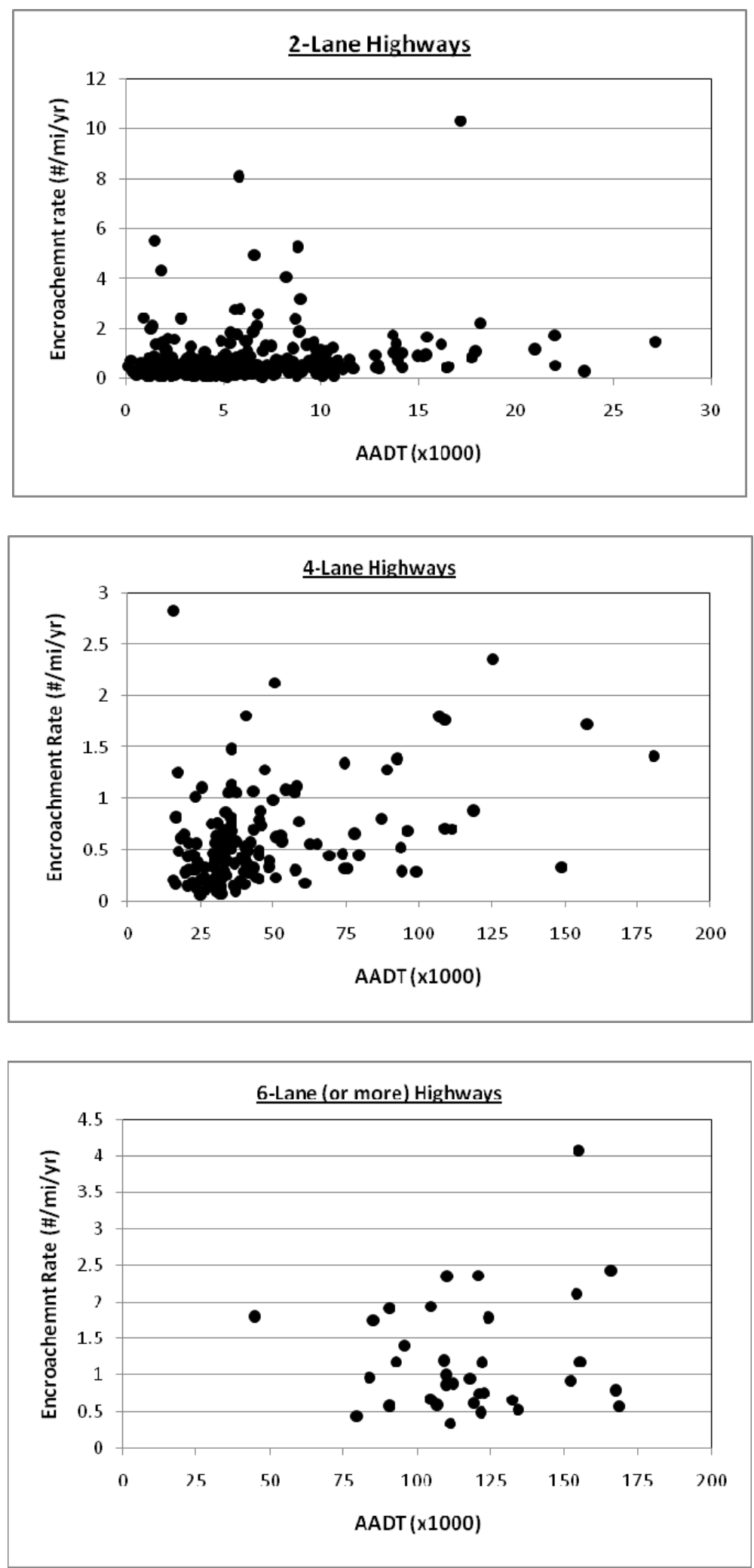

Figure 5-1Variations of ROR Rates with AADT 
Table 5-1 Recommended Encroachment Rate

\begin{tabular}{|c|c|c|c|c|c|c|c|}
\hline \multicolumn{7}{|c|}{ 2-Lane Highways } \\
\hline AADT & $\begin{array}{c}\text { Encroach. } \\
\text { Rate }\end{array}$ & AADT & $\begin{array}{c}\text { Encroach. } \\
\text { Rate }\end{array}$ & AADT & $\begin{array}{c}\text { Encroach. } \\
\text { Rate }\end{array}$ & AADT & $\begin{array}{c}\text { Encroach. } \\
\text { Rate }\end{array}$ \\
\hline 500 & 0.364 & 6500 & 0.624 & 12500 & 0.884 & 18500 & 1.144 \\
\hline 1500 & 0.407 & 7500 & 0.667 & 13500 & 0.927 & 20500 & 1.230 \\
\hline 2500 & 0.450 & 8500 & 0.710 & 14500 & 0.970 & 21500 & 1.273 \\
\hline 3500 & 0.494 & 9500 & 0.754 & 15500 & 1.014 & 22500 & 1.317 \\
\hline 4500 & 0.537 & 10500 & 0.797 & 16500 & 1.057 & 25500 & 1.447 \\
\hline 5500 & 0.580 & 11500 & 0.840 & 17500 & 1.100 & & \\
\hline \multicolumn{7}{|c|}{ 4-Lane Highways } \\
\hline AADT & $\begin{array}{c}\text { Encroach. } \\
\text { Rate }\end{array}$ & AADT & $\begin{array}{c}\text { Encroach. } \\
\text { Rate }\end{array}$ & AADT & $\begin{array}{c}\text { Encroach. } \\
\text { Rate }\end{array}$ & AADT & $\begin{array}{c}\text { Encroach. } \\
\text { Rate }\end{array}$ \\
\hline 15000 & 0.310 & 60000 & 0.642 & 105000 & 0.974 & 150000 & 1.307 \\
\hline 20000 & 0.347 & 65000 & 0.679 & 110000 & 1.011 & 155000 & 1.344 \\
\hline 25000 & 0.384 & 70000 & 0.716 & 115000 & 1.048 & 160000 & 1.380 \\
\hline 30000 & 0.421 & 75000 & 0.753 & 120000 & 1.085 & 165000 & 1.417 \\
\hline 35000 & 0.458 & 80000 & 0.790 & 125000 & 1.122 & 170000 & 1.454 \\
\hline 40000 & 0.495 & 85000 & 0.827 & 130000 & 1.159 & 175000 & 1.491 \\
\hline 45000 & 0.531 & 90000 & 0.864 & 135000 & 1.196 & 180000 & 1.528 \\
\hline 50000 & 0.568 & 95000 & 0.901 & 140000 & 1.233 & 185000 & 1.565 \\
\hline 55000 & 0.605 & 100000 & 0.937 & 145000 & 1.270 & 190000 & 1.602 \\
\hline \multicolumn{7}{|c|}{ 6-Lane (or more) Highways } \\
\hline AADT & $\begin{array}{c}\text { Encroach. } \\
\text { Rate }\end{array}$ & AADT & \multicolumn{2}{|c|}{$\begin{array}{c}\text { Encroach. } \\
\text { Rate }\end{array}$} & AADT & Encroach. \\
Rate & AADT & Encroach. \\
Rate
\end{tabular}

\section{Crash Probabilities}

It is indicated that in Chapter 4, not all ROR accidents resulted in crashes. This is because in the ROR accidents, some errant vehicles could slow down and stop safely. Whether a ROR accident can result in crash solely depends on the roadside physical features, including the width of clear zone, presence of roadside obstacles, and highway subgrade slope. In order to determine 
the probability for a ROR accident to result in crash, the ROR accident data was divided into two groups, one including the ROR accidents with crash and the other without crash. The probability was computed as the ratio of the number of ROR accidents with crash to the number of total ROR accidents. Presented in Table 5-2 are those probabilities estimated from the ROR accident data in both 2004 and 2006. It is shown that the probabilities estimated in 2004 and 2006 are quite consistent for these three highway categories, respectively. 2-lane highways witnessed the greatest probability in 2004 and multi-lane highways in 2006. Overall, multi-lane highways experienced the greatest crash probability, and interstate highways experienced the smallest probability.

Table 5-2 ROR Crash Probabilities by Highway Category

\begin{tabular}{|c|c|c|c|}
\hline \multirow{2}{*}{ Year } & \multicolumn{3}{|c|}{ Highway Category } \\
\cline { 2 - 4 } & 2-lane & Multi-Lane & Interstate \\
\hline 2004 & 0.934 & 0.928 & 0.901 \\
\hline 2006 & 0.922 & 0.934 & 0.885 \\
\hline Combined & 0.928 & 0.931 & 0.893 \\
\hline
\end{tabular}

\section{Severity Probabilities}

In the original vehicle crash database, the damage associated with each crash was categorized as one of the nine damage levels. The estimate of total damage for each ROR crash at Level 1 is under $\$ 750$, and over $\$ 100000$ at Level 9. At the damage levels of 2 to 8 , the total estimated damage for each ROR crash is $\$ 750 \sim \$ 1000, \quad \$ 1001 \sim 2500, \$ 2501 \sim 5000$, \$5001 \$10000, \$10001 \$25000, \$25001 \$50000, and \$50001 \$100000, respectively. Presented in Figure 5-2 are the numbers of the ROR crashes at these nine damage levels. It is demonstrated that the distributions of the ROR crashes in 2004 and 2006 follow a similar trend. For 2-lane highways, the majority of the ROR crashes are those of Level 4, followed by Level 3, Level 5, and Level 6. For multi-lane highways, the majority of the ROR crashes are those of Level 3, followed by Level 4, Level 5, and Level 6. For interstate highways, the majority of the ROR crashes are those of Level 4 in 2004 and those of Level 5 in 2006. Overall, the ROR crashes at Levels 3 to 5 occurred most frequently and accounted for approximately $85 \%$ of the total ROR crashes. 

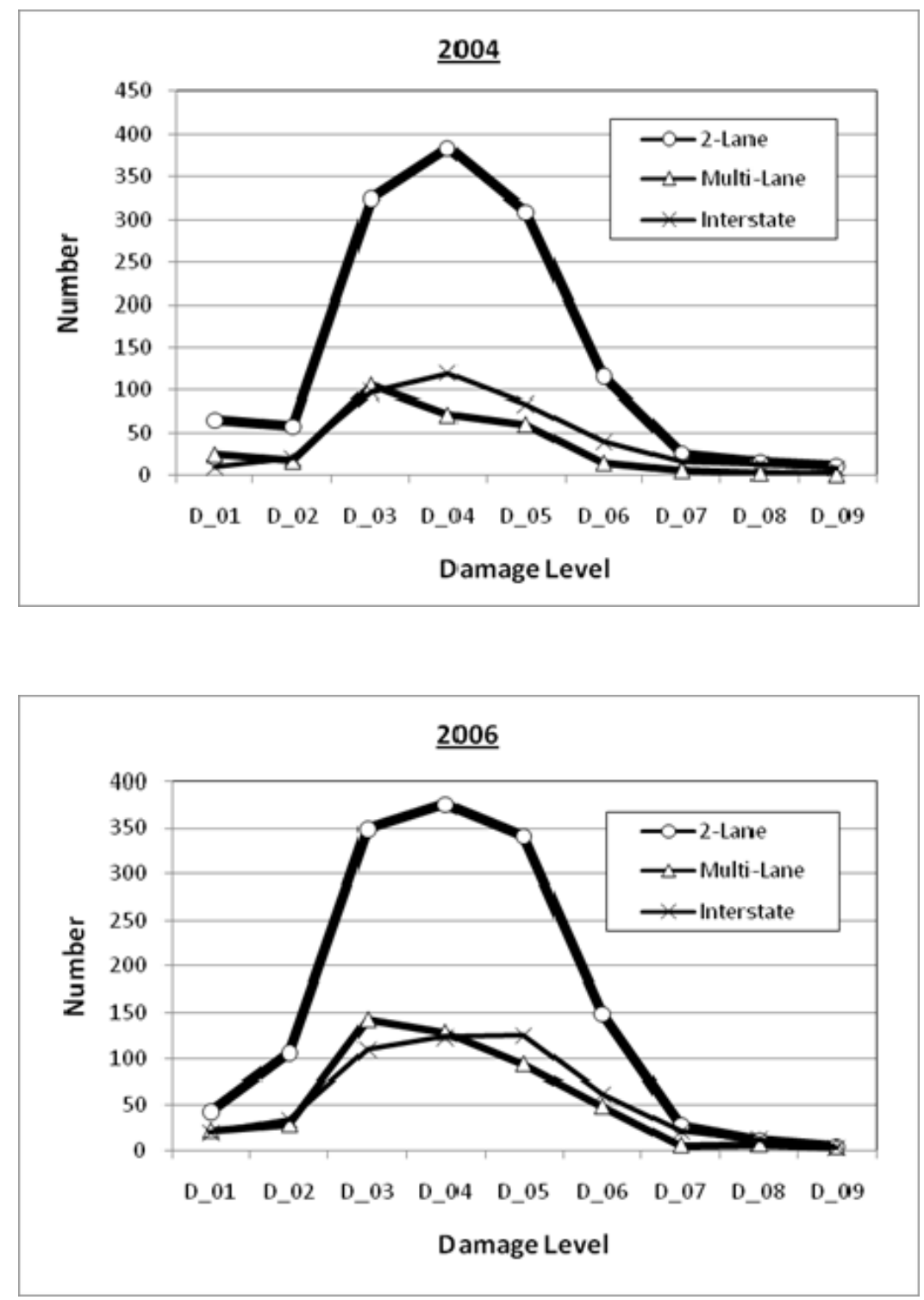

Figure 5-2 Numbers of ROR Crashes by Damage Level

Plotted in Figure 5-3 are the total losses of the ROR crashes at these nine damage levels, respectively. The losses were estimated using the midpoint values of the loss intervals at different damage levels except at Level 9. At level 9, the total losses were calculated using $\$ 100000$ for each ROR crash. In general, 2-lane highways accounted for about $57.6 \%$, multi-lane highways for $15.6 \%$, and freeways for $26.8 \%$ of the total losses associated with all ROR crashes. As shown in Figure 4, all curves become skewed left, i.e., with tails on the left. The ROR crashes with the greatest losses are those at Levels 5 and 6 for 2-lane highways. Similar observation was made for the class of multi-lane highway. However, the top two losses are those at Levels 8 and 
9 in 2004, and Levels 5 and 6 in 2006 for Freeways. This indicates that the losses are very sensitive to the damage levels of 8 and 9. Summarized in Table 5-3 are the probabilities that a ROR crash may result in damages at different levels. In reality, these probabilities were calculated as the rates of the ROR crashes with respect to the damage levels. The greatest probabilities arise in relation to a ROR crash at Level 4 for 2-lane highways and interstate highways. For multi-lane highways, the greatest probability occurs at Level 3.
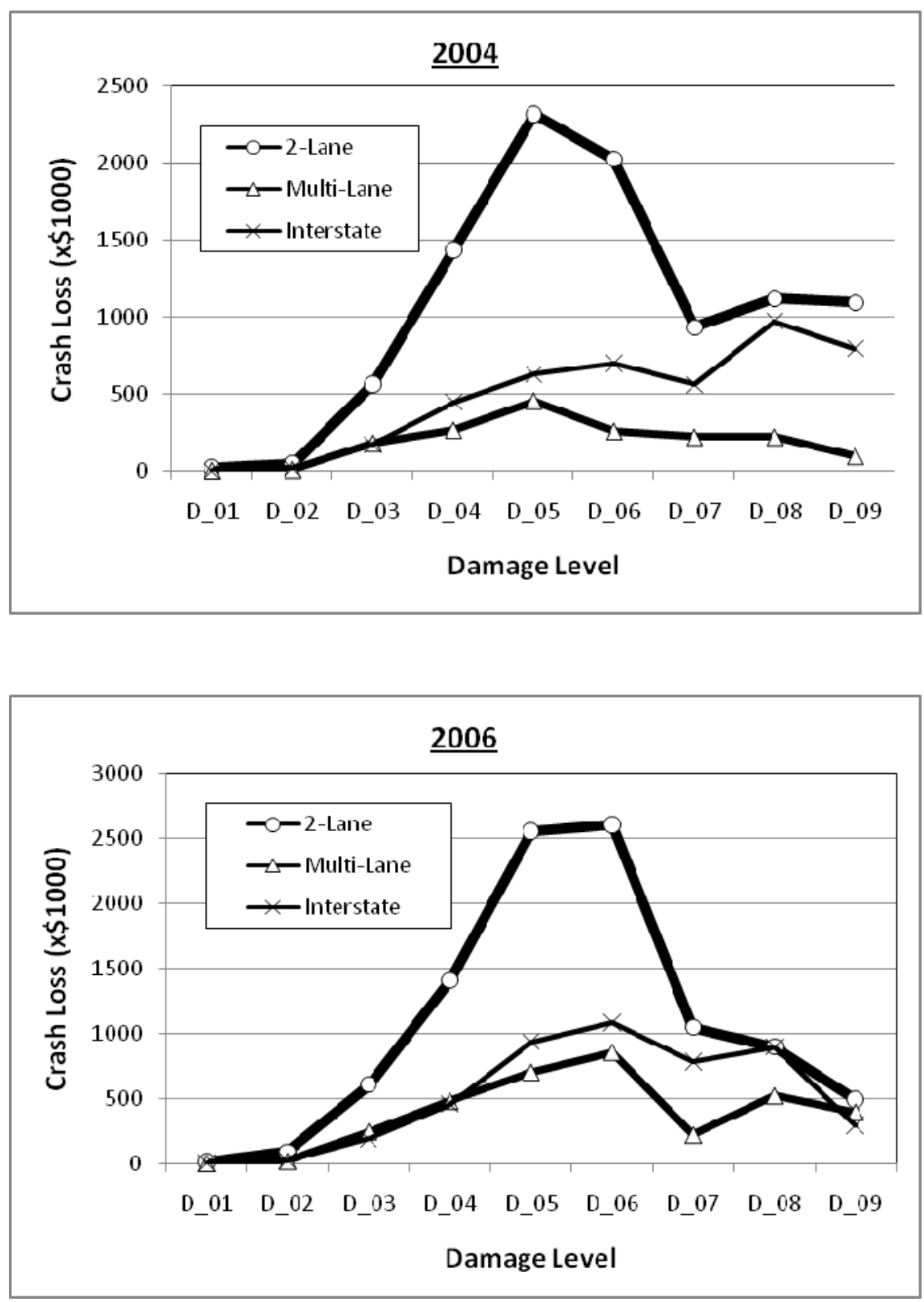

Figure 5-3 Losses of ROR Crashes by Damage Levels 
Table 5-3 ROR Crash Damage Probabilities by Damage Level

\begin{tabular}{|c|c|c|c|c|c|c|c|c|c|}
\hline \multirow{2}{*}{$\begin{array}{c}\text { Highway } \\
\text { Class }\end{array}$} & \multicolumn{9}{|c|}{ Damage Level } \\
\hline & 1 & 2 & 3 & 4 & 5 & 6 & 7 & 8 & 9 \\
\hline 2-lane & 0.0397 & 0.0603 & 0.2480 & 0.2796 & 0.2395 & 0.0975 & 0.0195 & 0.0099 & 0.0059 \\
\hline Multi-Lane & 0.0596 & 0.0583 & 0.3156 & 0.2548 & 0.1965 & 0.0811 & 0.0152 & 0.0127 & 0.0063 \\
\hline Interstate & 0.0316 & 0.0589 & 0.2268 & 0.2650 & 0.2279 & 0.1112 & 0.0393 & 0.0273 & 0.0120 \\
\hline
\end{tabular}

\subsection{Guardrail Repair and Maintenance Costs}

\section{Prices for Guardrail Crash Repairs}

The impact of guardrail by an errant vehicle usually causes damage to the guardrail. Once the damage is reported to the Sub-Districts, necessary repair will be undertaken within 24-72 hours. This study examined the guardrail repair records from five INDOT Sub Districts, including Frankfort, Fowler, Rensselaer, Evansville and Tell City. In general, the repair cost consists of three components, i.e., parts, labor, and equipment. Accordingly, one of the main factors that affect guardrail repair costs is the prices for parts, labor, and equipment. In reality, the Sub Districts order all parts at the prices listed in the Quantity Purchase Award (QPA) agreements. Presented in Tables 5-4 to 5-10 are the QPA prices for both shoulder guardrail end treatments and median crash cushions, respectively. Though there are still some Buried-In end treatments on INDOT roadways, they will be replaced by other shoulder end treatments once they are damaged.

Table 5-4 QPA Prices for CAT

\begin{tabular}{|c|c|c|c|c|c|c|}
\hline Parts & $\begin{array}{c}\text { Nose } \\
\text { Assembly } \\
\text { (Stage 1) }\end{array}$ & $\begin{array}{c}\text { GA Slotted } \\
\text { Rail } \\
\text { (Stage 2) }\end{array}$ & $\begin{array}{c}\text { GA Slotted } \\
\text { Rail } \\
\text { (Stage 3) }\end{array}$ & $\begin{array}{c}\text { Front } \\
\text { Anchorage } \\
\text { System }\end{array}$ & $\begin{array}{c}\text { Foundation } \\
\text { Tube } \\
\text { Assembly }\end{array}$ & Transition \\
\hline 2005 & 548.20 & 941.32 & 1407.42 & 693.80 & 351.00 & 621.00 \\
\hline 2009 & 591.60 & 1083.33 & 6141.66 & 758.00 & 1500.00 & 683.33 \\
\hline
\end{tabular}

Table 5-5 QPA Prices for SKT 350

\begin{tabular}{|c|c|c|c|c|c|}
\hline Parts & Head & End Section & $\begin{array}{c}\text { Anchor } \\
\text { cable }\end{array}$ & $\begin{array}{c}\text { Foundation } \\
\text { Soil Tube }\end{array}$ & $\begin{array}{c}\text { Complete } \\
\text { Unit }\end{array}$ \\
\hline 2005 & $\$ 777.50$ & $\$ 203.00$ & 51.00 & 115.00 & 2295.00 \\
\hline 2007 & $\$ 885.00$ & $\$ 225.00$ & 67.00 & 149.00 & 2825.00 \\
\hline $2008 / 2009$ & $\$ 885.00$ & $\$ 225.00$ & 67.00 & 149.00 & 2825.00 \\
\hline
\end{tabular}


Table 5-6 QPA Prices for ET 2000 Plus

\begin{tabular}{|c|c|c|c|c|}
\hline Parts & Extrude Head & Cable Anchor & Soil Plate & Complete Unit \\
\hline $2004-2005$ & 945.00 & 123.50 & 25.00 & 2145.00 \\
\hline 2006 & 900.00 & 162.00 & 26.00 & 2200.00 \\
\hline $2007-2009$ & 1033.00 & 212.00 & 34.00 & 2970.00 \\
\hline
\end{tabular}

Table 5-7 QPA Prices for Impact Barrel

\begin{tabular}{|c|c|c|c|c|c|c|c|c|}
\hline Parts & \multicolumn{4}{|c|}{ Module } & \multicolumn{4}{c|}{ Container } \\
\hline & $200 \mathrm{lb}$. & $400 \mathrm{lb}$. & $700 \mathrm{lb}$. & $1400 \mathrm{lb}$. & $200 \mathrm{lb}$. & $400 \mathrm{lb}$. & $700 \mathrm{lb}$. & $1400 \mathrm{lb}$. \\
\hline 2005 & 185.00 & 185.00 & 185.00 & 170.00 & 210.00 & 210.00 & 210.00 & 190.00 \\
\hline 2007 & 185.00 & 185.00 & 185.00 & 170.00 & 240.00 & 240.00 & 240.00 & 190.00 \\
\hline 2009 & 168.00 & 168.00 & 168.00 & 161.00 & 193.78 & 193.78 & 193.78 & 172.52 \\
\hline
\end{tabular}

Table 5-8 QPA Prices for QUADGUARD

\begin{tabular}{|c|c|c|c|c|c|c|c|}
\hline Parts & $\begin{array}{c}\text { Plastic } \\
\text { Nose } \\
\text { Assembly }\end{array}$ & Cartridge & $\begin{array}{c}\text { Diaphragm } \\
\text { Assembly } \\
\text { (24”) }\end{array}$ & $\begin{array}{c}\text { Fender } \\
\text { Panel } \\
\text { Assembly }\end{array}$ & $\begin{array}{c}\text { Transition } \\
\text { Panel } \\
\text { Assembly }\end{array}$ & $\begin{array}{c}\text { Side } \\
\text { Panel }\end{array}$ & $\begin{array}{c}\text { Complete } \\
\text { Unit }\end{array}$ \\
\hline 2005 & 600.00 & 649.00 & 836.00 & 539.00 & 841.00 & 81.00 & 18843.00 \\
\hline 2006 & 612.00 & 673.00 & 861.00 & 550.00 & 849.00 & 82.00 & 20179.00 \\
\hline 2007 & 612.00 & 673.00 & 861.00 & 550.00 & 849.00 & 82.00 & 20179.00 \\
\hline 2008 & 650.00 & 725.00 & 804.00 & 581.00 & 648.00 & 78.00 & 15132.00 \\
\hline 2009 & 530.00 & 580.00 & 876.00 & 600.00 & 966.00 & 86.00 & 15163.00 \\
\hline
\end{tabular}

Table 5-9 QPA Prices for GREAT

\begin{tabular}{|c|c|c|c|c|c|c|}
\hline Parts & $\begin{array}{c}\text { Nose } \\
\text { Assembly }\end{array}$ & Cartridge & $\begin{array}{c}\text { Diaphragm } \\
\text { Assembly } \\
\text { (30”) }\end{array}$ & $\begin{array}{c}\text { Cable } \\
\text { Anchor } \\
\text { (6-Bay) }\end{array}$ & $\begin{array}{c}\text { Cable } \\
\text { (6-Bay) }\end{array}$ & $\begin{array}{c}\text { Transition } \\
\text { Panel } \\
\text { (Bi-Direction) }\end{array}$ \\
\hline 2005 & 661.00 & 771.00 & 1126.00 & 1922.00 & 967.00 & 882.00 \\
\hline $2006 / 2007$ & 648.00 & 756.00 & 1164.00 & 1980.00 & 996.00 & 912.00 \\
\hline 2008 & 696.00 & 804.00 & 1248.00 & 2196.00 & 1104.00 & 984.00 \\
\hline 2009 & 840.00 & 936.00 & 1500.00 & 2635.00 & 1338.00 & 1104.00 \\
\hline
\end{tabular}

Table 5-10 QPA Prices for Hex-Foam Sandwich

\begin{tabular}{|c|c|c|c|c|c|}
\hline Parts & $\begin{array}{c}\text { Anchor } \\
\text { Assembly }\end{array}$ & $\begin{array}{c}\text { Nose } \\
\text { Assembly }\end{array}$ & $\begin{array}{c}\text { Cable } \\
\text { Assembly }\end{array}$ & Cartridge & $\begin{array}{c}\text { Fender } \\
\text { Panel }\end{array}$ \\
\hline 2005 & 648.00 & 1308.00 & 1104.00 & 612.00 & 1020.00 \\
\hline $2006 / 2007$ & 684.00 & 1776.00 & 1176.00 & 600.00 & 1080.00 \\
\hline 2008 & 732.00 & 1908.00 & 1260.00 & 648.00 & 1164.00 \\
\hline 2009 & 876.00 & 2298.00 & 1512.00 & 792.00 & 1398.00 \\
\hline
\end{tabular}


Apparently, the QPA prices for guardrail end treatments and crash cushions varied noticeably in the past years. The prices for all parts except for QUADGUARD and Impart Barrel increased dramatically, in particular those steel parts such as CAT. From 2005 to 2009, the prices for those parts listed in Tables 5-4 to 5-5 approximately increased by $135.8 \%, 23.1 \%, 38.5 \%$, $32.0 \%$ and $46.5 \%$ for CAT, SKT 350, ET 2000 Plus, GREAT and Hex-Foam Sandwich, respectively. In the meantime, the labor prices have also increased in the past years. As an illustration, Figure 5-4 shows the pay rates for a typical Maintenance Worker III between 2002 and 2006. The average annual increase in pay rate is $8.74 \%$. It should be noted that in addition to the parts, labor, and equipment prices, the repair costs for guardrail crash repairs depend to a large extent on the severity of guardrail damage.

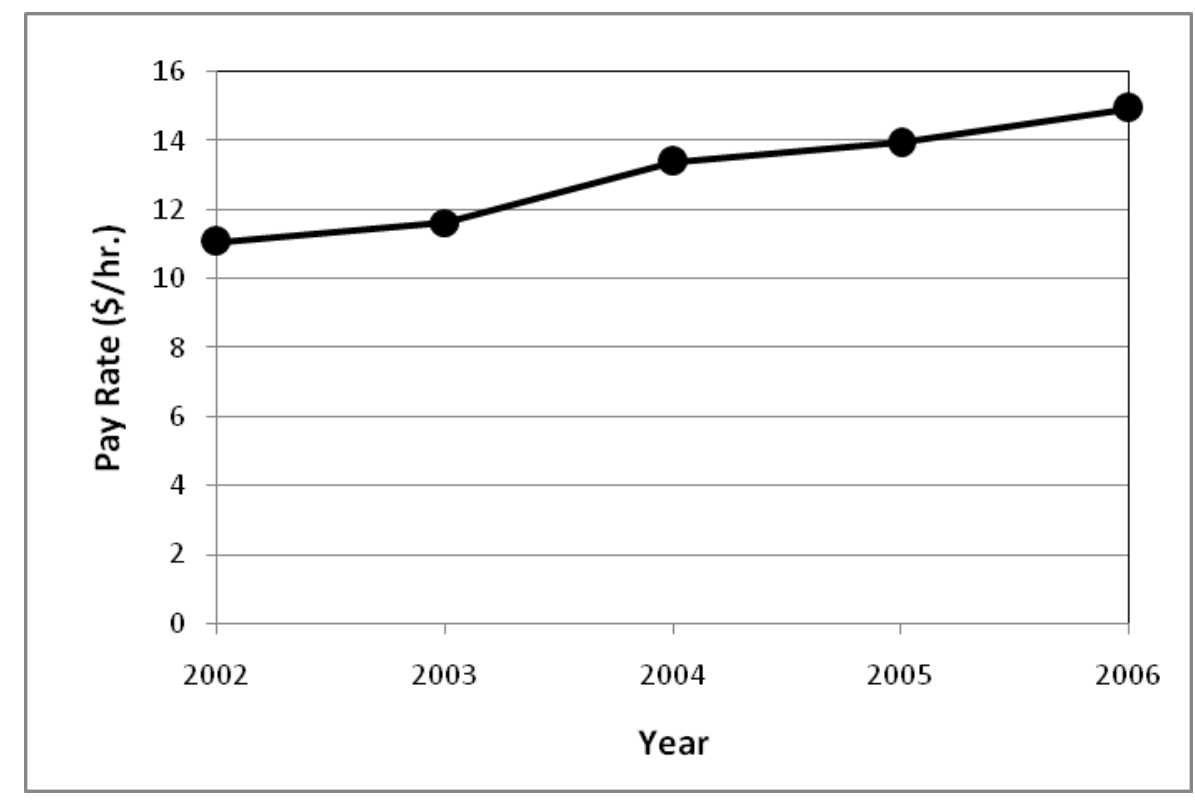

Figure 5-4 Labor Rates

\section{Repair Costs for End Treatments and Crash Cushions}

In the past years, most of the repairs of the damaged end treatments were done by the Sub District work forces. Figure 5-5 shows the repair costs for each repair of CAT crash cushion. For all 73 CAT crash repairs, the repair costs varied greatly in the past years. As illustrated in Figure $5-5$, the lowest repair cost is approximately $\$ 200$, and the greatest repair cost is $\$ 5000$. The greatest amount of repair costs was spent on parts, followed by the costs on labors. The equipment costs accounted for the smallest part of the repair costs. Similar observations were 
made on all other types of end treatments and crash cushions, in particular those widely used in the medians as shown in Table 5-11. For crash cushions used in the medians, the parts costs accounted for more than $85 \%$ of the repair costs. However, the equipment costs are insignificant, except for Impact Barrel. For shoulder guardrail end treatments and crash cushions, however, the parts costs decreased dramatically to less than $58 \%$. The labor costs accounted for $30 \%$ to $44 \%$, and the equipment costs for $10 \%$ to $15 \%$.

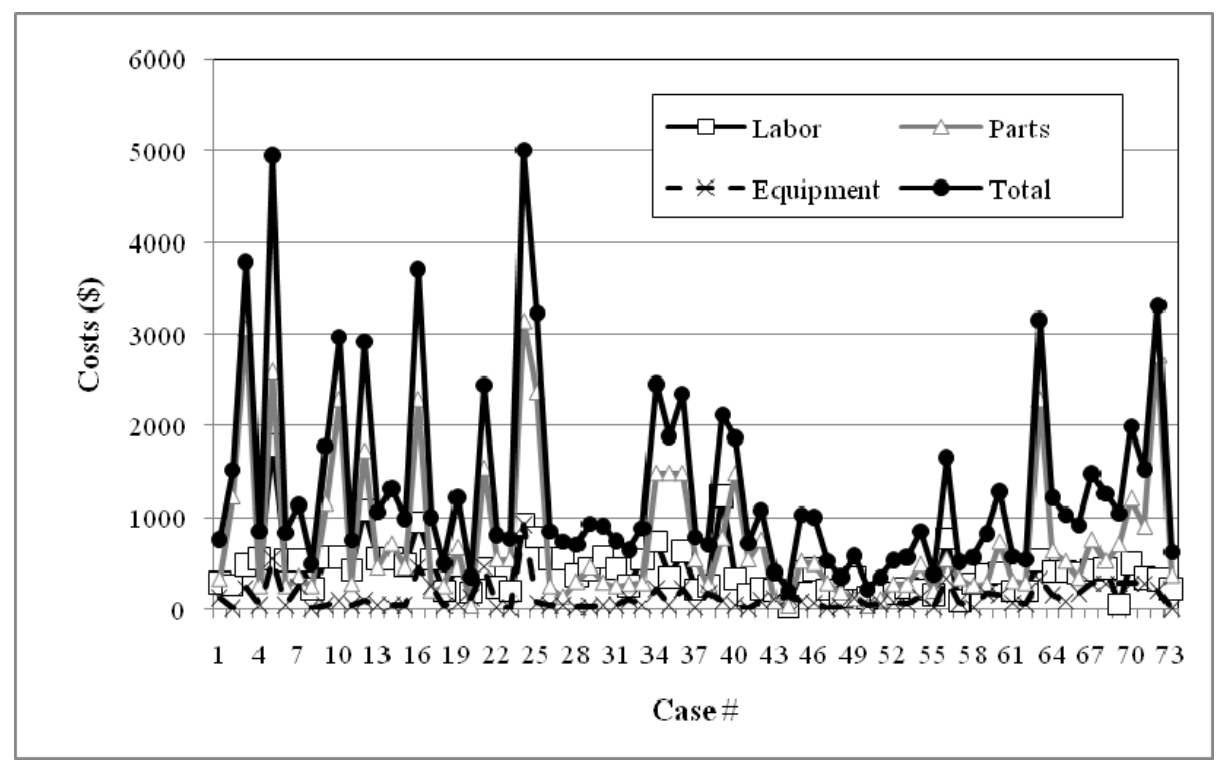

Figure 5-5 Repair Costs for CAT End Treatments

Table 5-11 Breakdowns of End Treatment Repair Costs

\begin{tabular}{|c|c|c|c|}
\hline \multirow{2}{*}{ Type } & \multicolumn{3}{|c|}{ Costs (\%) } \\
\cline { 2 - 4 } & Parts & Labor & Equipment \\
\hline CAT & 57.2 & 32.1 & 10.7 \\
\hline ET 2000 Plus & 53.4 & 31.9 & 14.8 \\
\hline SKT 350 & 44.3 & 43.3 & 12.4 \\
\hline ADIEM & 89.4 & 3.8 & 6.8 \\
\hline Impact Barrel & 57.5 & 28.1 & 14.4 \\
\hline GREAT & 88.2 & 7.5 & 4.4 \\
\hline Hex-Foam Sandwich & 96.2 & 3.7 & 0.1 \\
\hline QUADGUARD & 88.3 & 8.5 & 3.2 \\
\hline Tau II & 85.7 & 10.3 & 4.0 \\
\hline
\end{tabular}


Presented in Table 5-12 are the summary statistics of the repair costs, including means and standard deviations, and confidence bounds of the repair costs. The confidence bounds were computed in terms of a confidence level of $95 \%$. It is shown that the repair costs for crash cushions are much greater than those for shoulder end treatments. Hex-Foam Sandwich demonstrated the greatest repair cost per crash, followed by ADIEM, TAU II, GREAT, and QUADGUARD, which are much greater than those for Impact barrel. For shoulder guardrail end treatments and crash cushions, ET 2000 Plus demonstrated the lowest repair cost per crash, followed by SKT 350 and CAT. Obviously, the repair cost per crash used in the current INDOT Design Manual has been greatly overestimated for CAT, ET 2000 Plus, SKT 350, and Impact Barrel, but underestimated for all other crash cushions.

Table 5-12 Summary Statistics of Repair Costs per Crash for End Treatments and Crash Cushions (\$)

\begin{tabular}{|c|c|c|c|c|}
\hline Type & Mean & Standard Deviation & Lower Bound & Upper Bound \\
\hline CAT & 1325 & 1057 & 1082 & 1567 \\
\hline ET 2000 Plus & 995 & 687 & 647 & 1343 \\
\hline SKT 350 & 1064 & 873 & 460 & 1669 \\
\hline ADIEM & 5371 & 1069 & 4811 & 5931 \\
\hline Impact Barrel & 1465 & 1138 & 1150 & 1780 \\
\hline GREAT & 5020 & 3875 & 4143 & 5897 \\
\hline Hex-Foam Sandwich & 5571 & - & 5571 & - \\
\hline QUADGUARD & 4255 & 2554 & 3040 & 5469 \\
\hline Tau II & 5114 & - & 5114 & - \\
\hline
\end{tabular}

\section{Repair Costs for Guardrails}

Different from end treatment and crash cushion repairs, most guardrail repairs, in particular those guardrail repairs involving posts, were done by contractors mainly due to the equipment issues. It was estimated that only $10 \%$ of the guardrail repairs were done by the Sub District work forces. Similar to the end treatment or crash cushion repairs, the guardrail repair costs also include parts, labor, and equipment costs. However, the labor rather than the parts consumed a large portion of the repair costs. On average, the labor, equipment, and parts costs respectively accounted for $62.1 \%, 31.5 \%$ and $6.3 \%$ of the total repair costs. The average guardrail repair cost is $\$ 722$ per crash with a confidence bound between $\$ 506$ and $\$ 937$. Again, it 
appears that the guardrail repair cost used in the current INDOT Design Manual is greater than the guardrail repair cost identified in this study.

\section{Guardrail Maintenance Costs}

Each year, the annual guardrail maintenance is awarded to contractors by each district. The contract dollar amount usually covers not only the costs for direct maintenance work, but also the costs for mobilization and demobilization, traffic control, and communications. However, the cost on the direct maintenance work is usually the solely primary component of the total cost. As an illustration, the total guardrail maintenance cost was $\$ 319,200$ for the Crawfordsville District in 2005. The direct maintenance cost was \$310,398, accounting approximately for $97 \%$ of the total maintenance cost. For the Crawfordsville District, its total guardrail length is approximately 1,373,645 linear feet, and the annual maintenance costs are $\$ 319,200, \$ 499.494$, and $\$ 439,859$ in 2005,2008 and 2009, respectively. The annual average guardrail maintenance cost is $\$ 0.305$ per linear foot. 
Chapter 6

GIS-INTERFACED SOFTWARE FOR ROR CRASH AND GUARDRAIL ANALYSIS

\subsection{Software Introduction}

To effectively manage and analyze the guardrails and related ROR crash data, a software interface has been developed with Geographic Information System (GIS) technology. The interface is based on ArcMap, a GIS software produced by ESRI (14). ArcMap is an application that allows the viewing, editing and querying of geo-referenced data. A snap-shot of the interface is shown in Figure 6-1.

As can be seen from Figure 6.1, the ArcMap software interface consists of two main parts. On the right is the map component which allows the user to visualize all data in a geographic context. Information is displayed on the map as layers, where each layer represents a particular type of feature. On the left is the "Table of Content" component where all the data features are listed. Each feature has an attribute table that represents the underlying database associated the specific feature. Although the software interface does not display the attribute table directly, it does provide tools for a user to access the table and execute query against the table. A user can selectively display any of the features listed in the Table of Content by using the check boxes in front of the each content list.

\subsection{Core Contents and Underlying Database of the Software Interface}

\section{Base Map}

The ArcMap interface includes several features. The first feature is the base map that contains all interstate, state and US routes. This is designated as the "Route_layer" in the Table of Content. The attribute table of the "Route_layer" has 14 attributes. A snapshot of the table is shown in Figure 6-2. Of relevance are the road names (designated as "NE_UNIQUE"), road class (designated as "ROUTE_DESI") and route number (designated as ROUTE_NUMB). Examples of road names are "I65" for Interstate 65, "SR26" for State Road 26 and "US52" for 
U.S. Road 52. Examples of road classes are "I" for interstate, "SR" for state route and "US" for U.S. route.

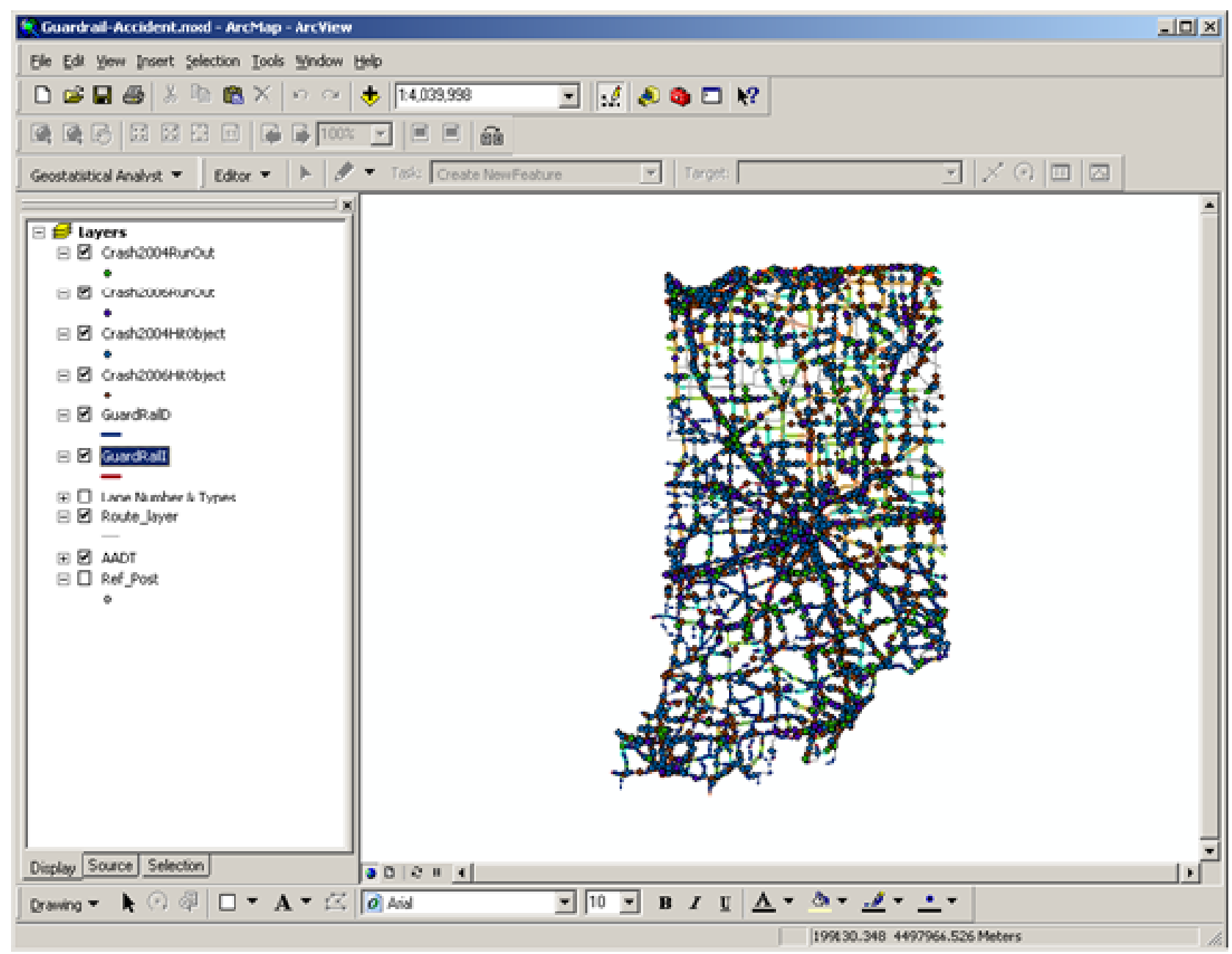

Figure 6-1 A Snap-Shot of the ArcMap Software Interface

\section{Reference Posts}

The second feature in the ArcMap interface contains the reference posts location points along the routes. This is designated as "Ref_Post" in the Table of Content. The attribute table of the "Ref_Post" feature contains 12 attributes. As shown in Figure 6-3 is a snapshot of a segment of the table. Relevant information includes route type (designated as "TYPE"), route number (designated as "ROUTE"), county number (designated as "CO"), county log (designated as "CO_LOG"), reference post number (designated as "POST"), road name (designated as "RteName"). 


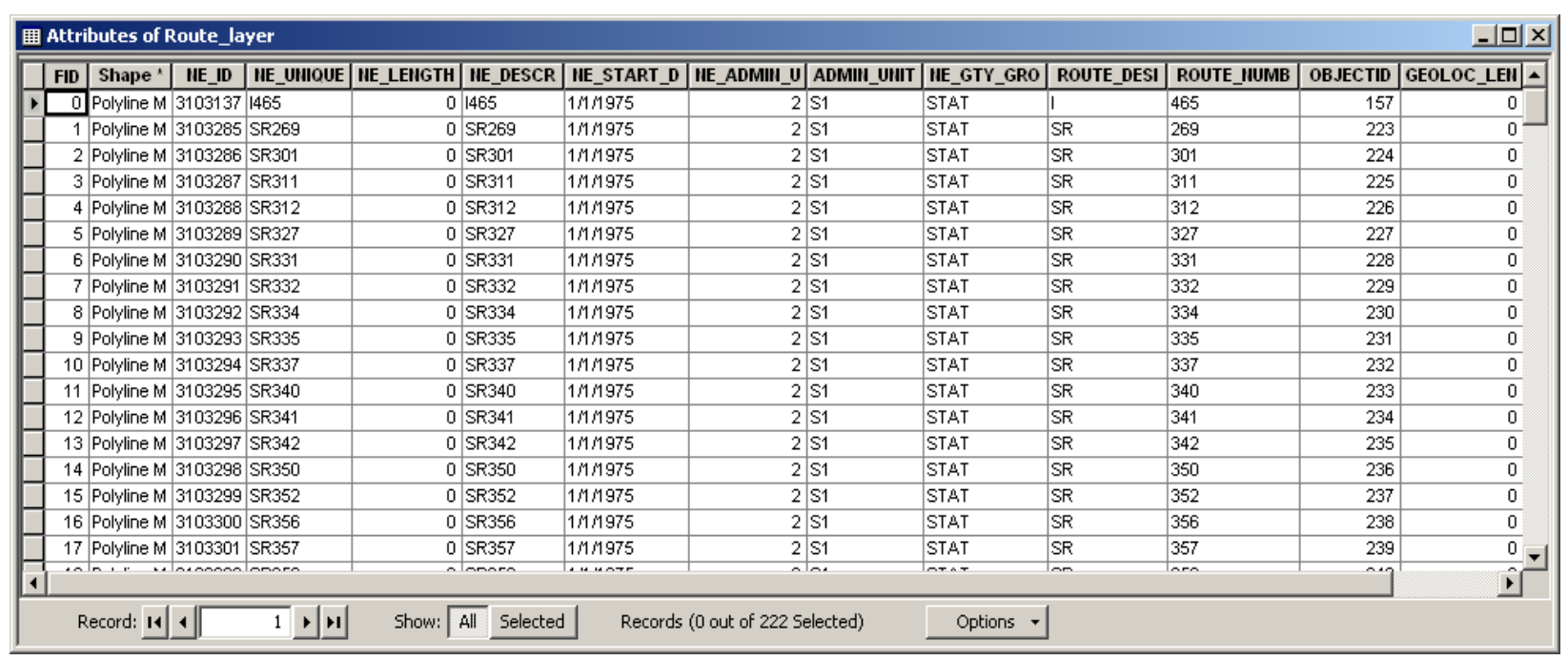

Figure 6-2 Attribute table of the "Route_layer" feature

\begin{tabular}{|c|c|c|c|c|c|c|c|c|c|c|c|c|c|c|c|c|}
\hline \multicolumn{15}{|c|}{ 囲 Attributes of Ref_Post } & \multicolumn{2}{|c|}{$-x$} \\
\hline & FID & Shape & & OBJECTID & & ID & LRS_ID & TYPE & ROUTE & $\mathrm{Co}$ & CO_LOG & POST & Rtellame & Postlnt & & $\Delta$ \\
\hline & 12 & Point & & 0 & 0 & 0 & & 1 & 64 & 65 & 12.04 & 12 & 164 & 12 & & \\
\hline & 13 & Point & & 0 & 0 & 0 & & I & 64 & 65 & 12.99 & 13 & 164 & 13 & & \\
\hline & 14 & Point & & 0 & 0 & 0 & & I & 64 & 65 & 14.04 & 14 & 164 & 14 & & \\
\hline & 15 & Point & & 0 & 0 & 0 & & I & 64 & 65 & 15.02 & 15 & 164 & 15 & & \\
\hline & 16 & Point & & 0 & 0 & 0 & & I & 64 & 65 & 16.02 & 16 & 164 & 16 & & \\
\hline & 17 & Point & & 0 & 0 & 0 & & 1 & 64 & 65 & 17.02 & 17 & 164 & 17 & & \\
\hline & 18 & Point & & 0 & 0 & 0 & & I & 64 & 82 & 0.58 & 18 & 164 & 18 & & \\
\hline & 19 & Point & & 0 & 0 & 0 & & I & 64 & 82 & 1.58 & 19 & 164 & 19 & & \\
\hline & 20 & Point & & 0 & 0 & 0 & & I & 64 & 82 & 2.58 & 20 & 164 & 20 & & \\
\hline & 21 & Point & & 0 & 0 & 0 & & I & 64 & 82 & 3.58 & 21 & 164 & 21 & & \\
\hline & 22 & Point & & 0 & 0 & 0 & & 1 & 64 & 82 & 4.58 & 22 & 164 & 22 & & \\
\hline & 23 & Point & & 0 & 0 & 0 & & 1 & 64 & 82 & 5.57 & 23 & 164 & 23 & & \\
\hline & 24 & Point & & 0 & 0 & 0 & & I & 64 & 26 & 0.52 & 24 & I 64 & 24 & & \\
\hline & 25 & Point & & 0 & 0 & 0 & & I & 64 & 26 & 1.52 & 25 & 164 & 25 & & \\
\hline & 26 & Point & & 0 & 0 & 0 & & I & 64 & 26 & 2.51 & 26 & 164 & 26 & & \\
\hline & 27 & Point & & 0 & 0 & 0 & & I & 64 & 82 & 0.66 & 27 & 164 & 27 & & \\
\hline & 28 & Point & & 0 & 0 & 0 & & I & 64 & 26 & 0.56 & 28 & 164 & 28 & & \\
\hline & 29 & Point & & 0 & 0 & 0 & & I & 64 & 26 & 1.51 & 29 & I 64 & 29 & & \\
\hline & 30 & Point & & 0 & 0 & 0 & & I & 64 & 87 & 0.65 & 30 & 164 & 30 & & \\
\hline & 31 & Point & & 0 & 0 & 0 & & 1 & 64 & 87 & 1.65 & 31 & 164 & 31 & & \\
\hline & 32 & Point & & 0 & 0 & 0 & & 1 & 64 & 87 & 2.66 & 32 & 164 & 32 & & $\nabla$ \\
\hline & & cord: 14 & 4 & 1 & $\bullet$ & 1 & Show: & All & Selected & & ecords (0 ou & ut of 112 & 13 Selected) & Optio & 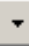 & \\
\hline
\end{tabular}

Figure 6-3 Attribute table of the reference post feature

\section{ROR Crash Data}

The ArcMap interface also includes ROR crash data. As mentioned in Chapter 4, this study examined ROR accidents occurred during 2004 and 2006. All crash data was extracted 
from the Indiana State Police (ISP) accident database. The 2004 database has a total accident count of 208591. Among these, 49089 accidents happened on interstate, state and US routes. Of interest to us are 2218 of those classified as ROR accidents, which are further divided into two categories. Those accidents with errant vehicles running off road and impacting one of more roadside objects are classified as ROR Crash and designated as "Crash2004HitObject" in the Table of Content. Those with vehicles running off road without hitting any roadside objects are classified as ROR Only and designated as "Crash2004RunOut" in the Table of Content.

The 2006 database has 182922 accidents, including 98535 accidents that happened on interstate, state and US routes. The total number of ROR accidents is 2411. Similarly, the ROR Crash is designated as "Crash2006HitObject" while the ROR Only accidents are designated as "Crash2006RunOut" in the Table of Content. As shown in Figure 6-4 is the attribute table of the "Crash2004RunOut" feature. The important attributes in the table include road names ("RdwyNumber" and "RdwyIDTxt"), primary factor(s) causing the accident ("PrimaryFac"), number of vehicles involved in the accident ("MotorVehIn"), number of people injured ("InjuredNm"), number of people dead ("DeadNmb"), types of object that the errant vehicles collided with ("EventCollw"), and the X, Y coordinate of the accident location on the map. For the primary factor, "16" represents run-off-road right, and "17" run-off-road left. For the "EventCollw" attribute, "20" represents ROR crashes without hitting any object.

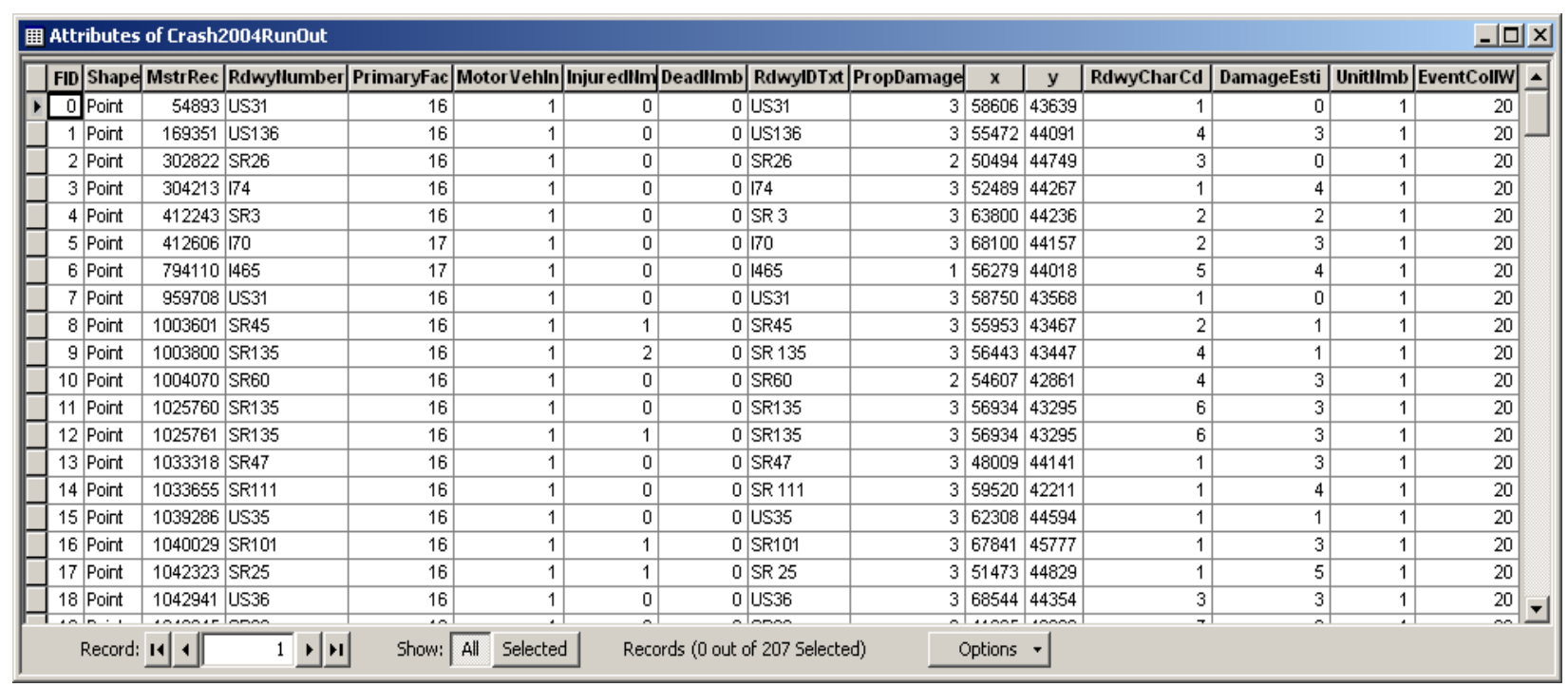

Figure 6-4 Attribute Table of the "Crash2004RunOut" Feature 
Figure 6-5 shows the attribute table of the "Crash2004HitObject" feature. The attributes included in the table are exactly the same as those in "Crash2004RunOut" feature. A notable difference between the two tables lies in the value of the attribute "EventCollw". While in the "Crash2004RunOut" table all the "EventCollw" values are 20, in the "Crash2004HitObject" table, the number varies, representing a range of different roadside objects. Figure 6-6 provides a list of the number with corresponding roadside objects.

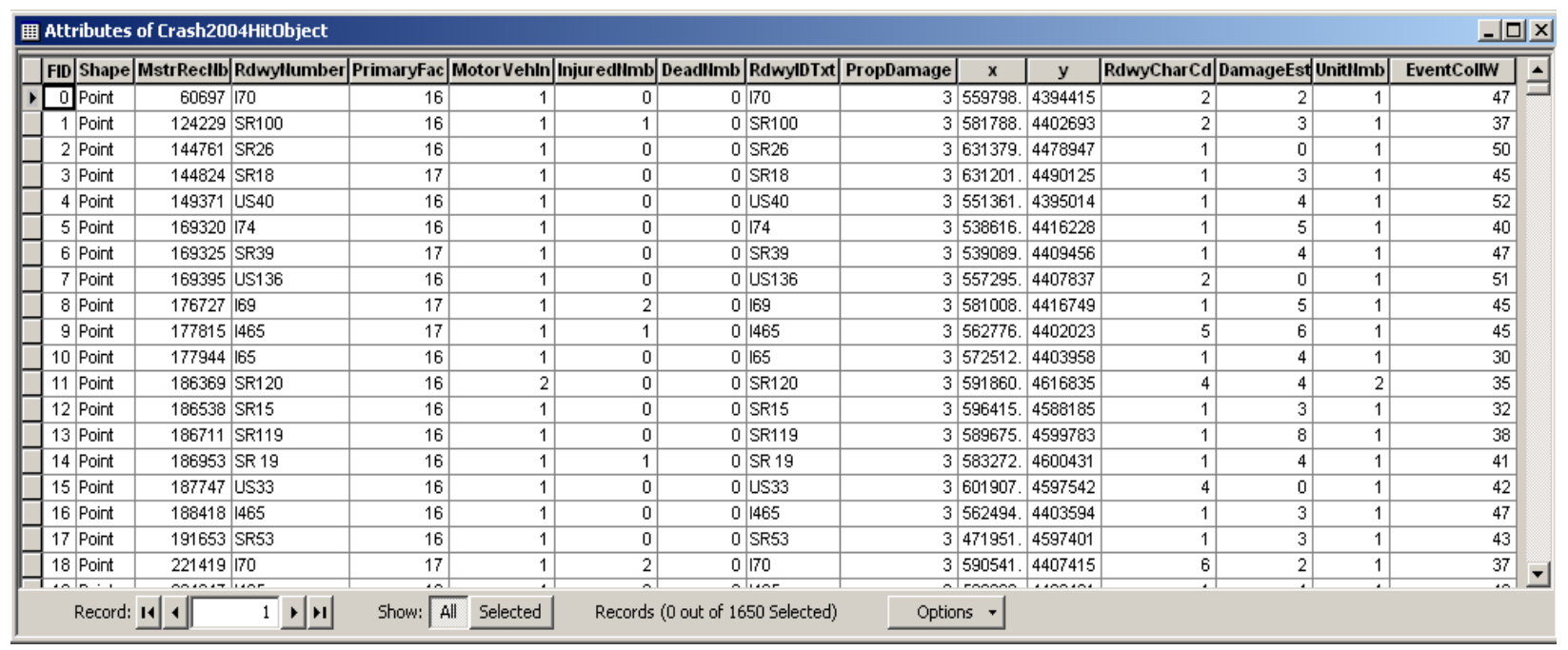

Figure 6-5 Attribute Table of “Crash2004HitObject” Feature

The attribute tables of the 2006 ROR accidents are similar to their 2004 counterparts.

\section{Guardrails along the Routes}

Guardrails along different directions are designated as "GuardrailD" for those in the south or west direction and "Guardraill" for those in the east of north direction. Each guardrail is displayed as a line on the map. Figure 6-7 shows the attribute table of "GuardRailD" feature. The attributes include district number (designated as "District"), road name ("Road"), direction of the road ("Direction"), starting mile post ("MPfrom"), ending mile post ("MPto"), starting reference post ("RPfrom"), ending reference post ("RPto"), guard rail front end type ("FrontEndTy"), back end type ("EndType"), the length of the guardrail ("Length"), relative standing of the guardrail (“Environment”). 


\begin{tabular}{|c|c|}
\hline Collision Involved Key & Collision Involved \\
\hline 30 & Impact Attenuator/Crash Cushion \\
\hline 31 & Bridge Overhead Structure \\
\hline 32 & Bridge Pier or Abutment \\
\hline 33 & Bridge Parapet End \\
\hline 34 & Bridge Rail \\
\hline 35 & Guardrail Face \\
\hline 36 & Guardrail End \\
\hline 37 & Median Barrier \\
\hline 38 & Highway Traffic Sign Post \\
\hline 39 & Overhead Sign Post \\
\hline 40 & Light/Luminaire Support \\
\hline 41 & Utility Pole \\
\hline 42 & Other Post/Pole or Support \\
\hline 43 & Wall/Building/Tunnel \\
\hline 44 & Work Zone Maintenance Equipment \\
\hline 45 & Embankment \\
\hline 46 & Curb \\
\hline 47 & Ditch \\
\hline 48 & Culvert \\
\hline 49 & Fence \\
\hline 50 & Mailbox \\
\hline 51 & Tree \\
\hline
\end{tabular}

\section{Figure 6-6 Roadside Objects with Corresponding Key Numbers}

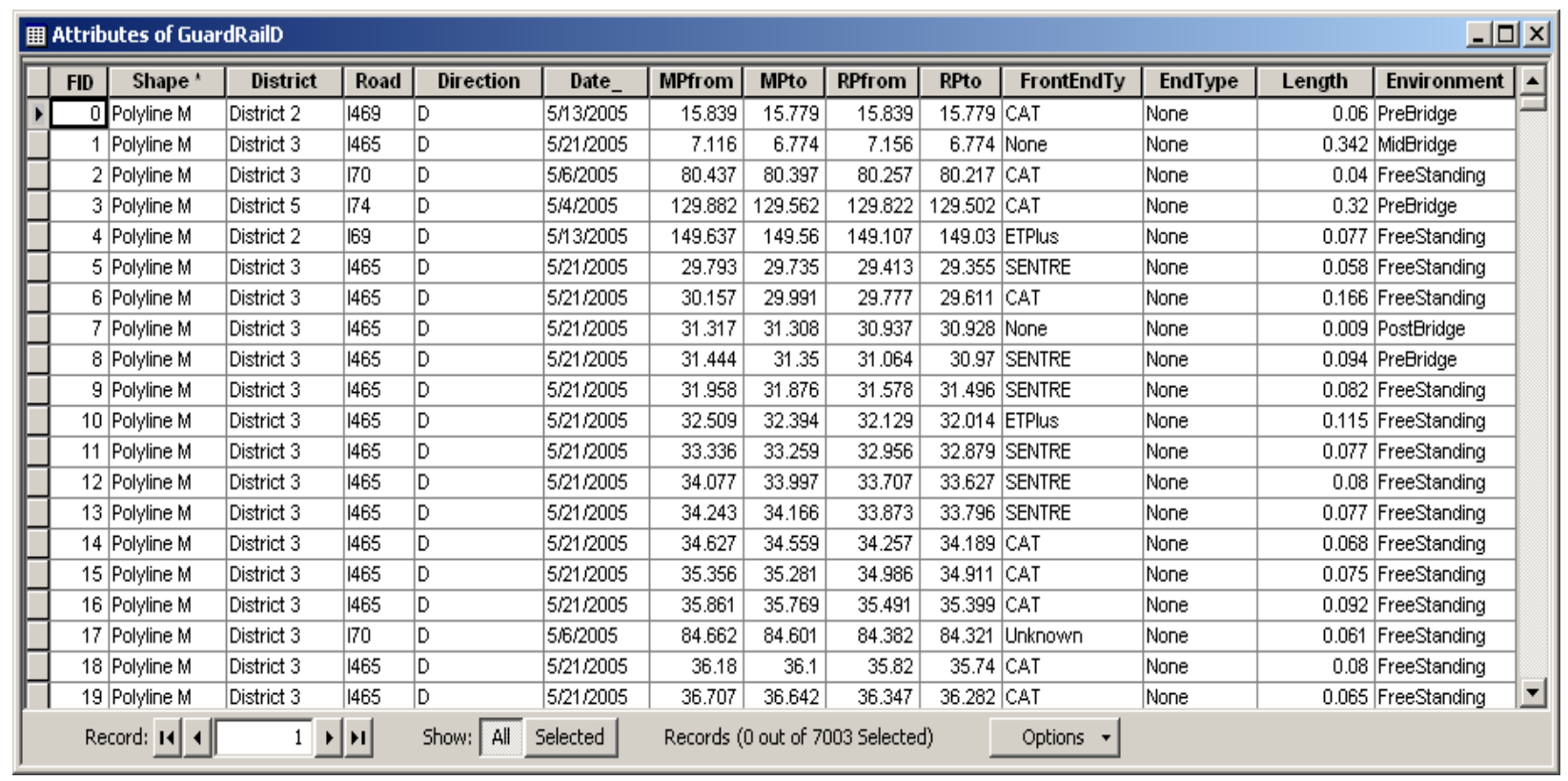

Figure 6-7 Attribute Table of the “GuardRailD” Feature 


\section{AADT Distributions along the Routes}

AADT is displayed as lines on the map. Depending on the AADT value, the line is displayed in different colors. As can be seen from the Table of Content in Figure 6.8, the AADT display is divided into 10 data ranges: those below 1000, between 1000 and 2000, between 2000 and 3000, between 3000 and 4000, between 4000 and 5000, between 5000 and 10000, between 10000 and 20000, between 20000 and 30000, between 30000 and 60000, and between 60000 and 100000. Different data ranges are distinguished by different line color and line width. The most important attribute in the attribute table is the AADT value ("AADT_COUNT"). Notice that the AADT ranges were determined in light of the needs of this study, and can be easily changes by users.

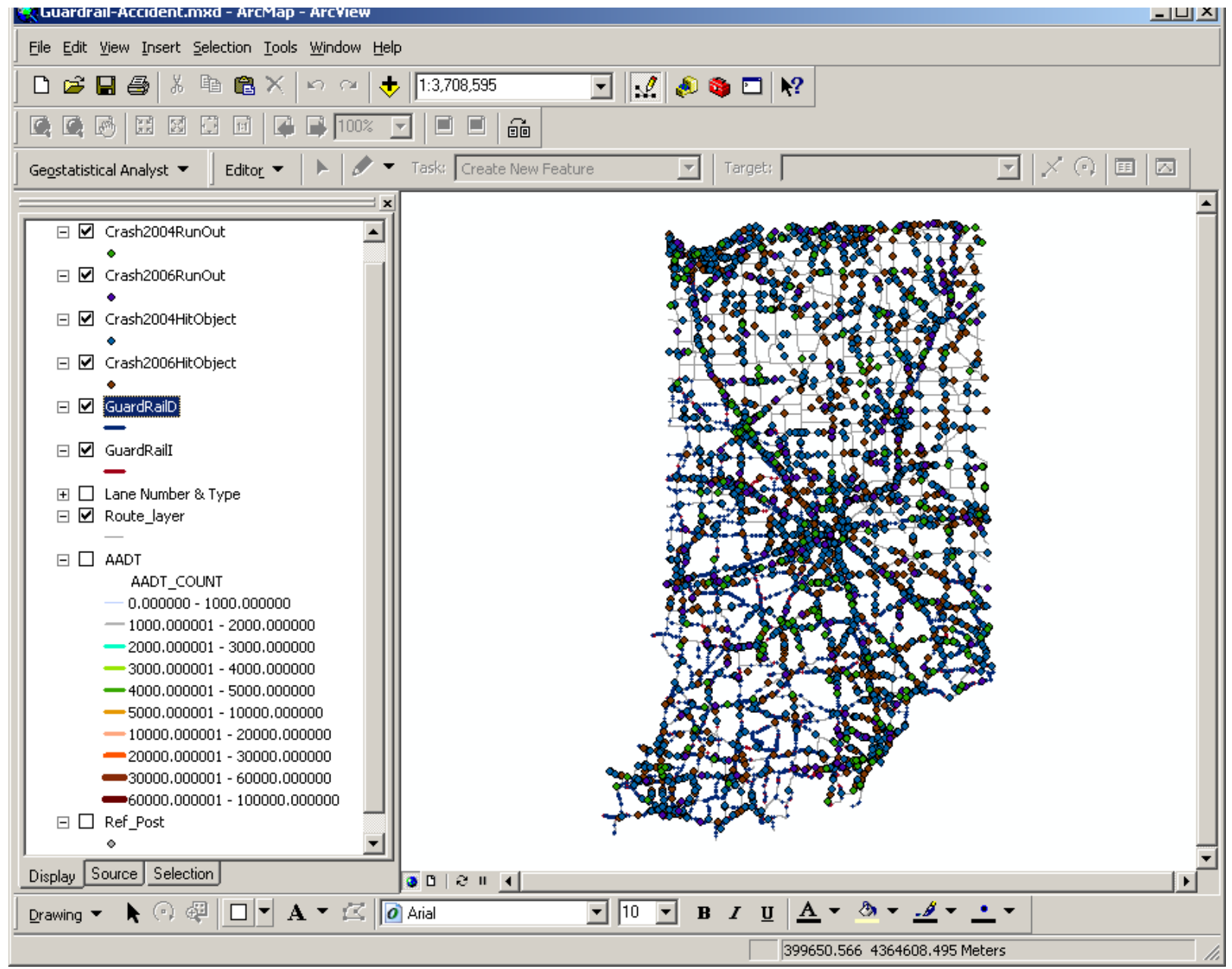

Figure 6-8 ArcMap Interface with the Table of Content Showing AADT Classifications 


\section{Number of Lanes and Highway Type (Divided or Undivided)}

Roads with different number of lanes are displayed with different symbols. As can be seen in Figure 6-9, the "Line Number \& Type" entry in the Table of Content is divided into 10 categories depending on the combination of the number of lanes and highway type for a road segment. Each category is represented by two numbers. The first number varies from 1 to 7 , indicating the total number of lane in both directions. The second number is either 0 or 1 , indicating the type of road (or road segment). " 0 " represents the type of undivided highway, and " 1 " represents the type of divided highway. With this feature, it becomes easier for users to examine the effects of the number of lanes and highway type.

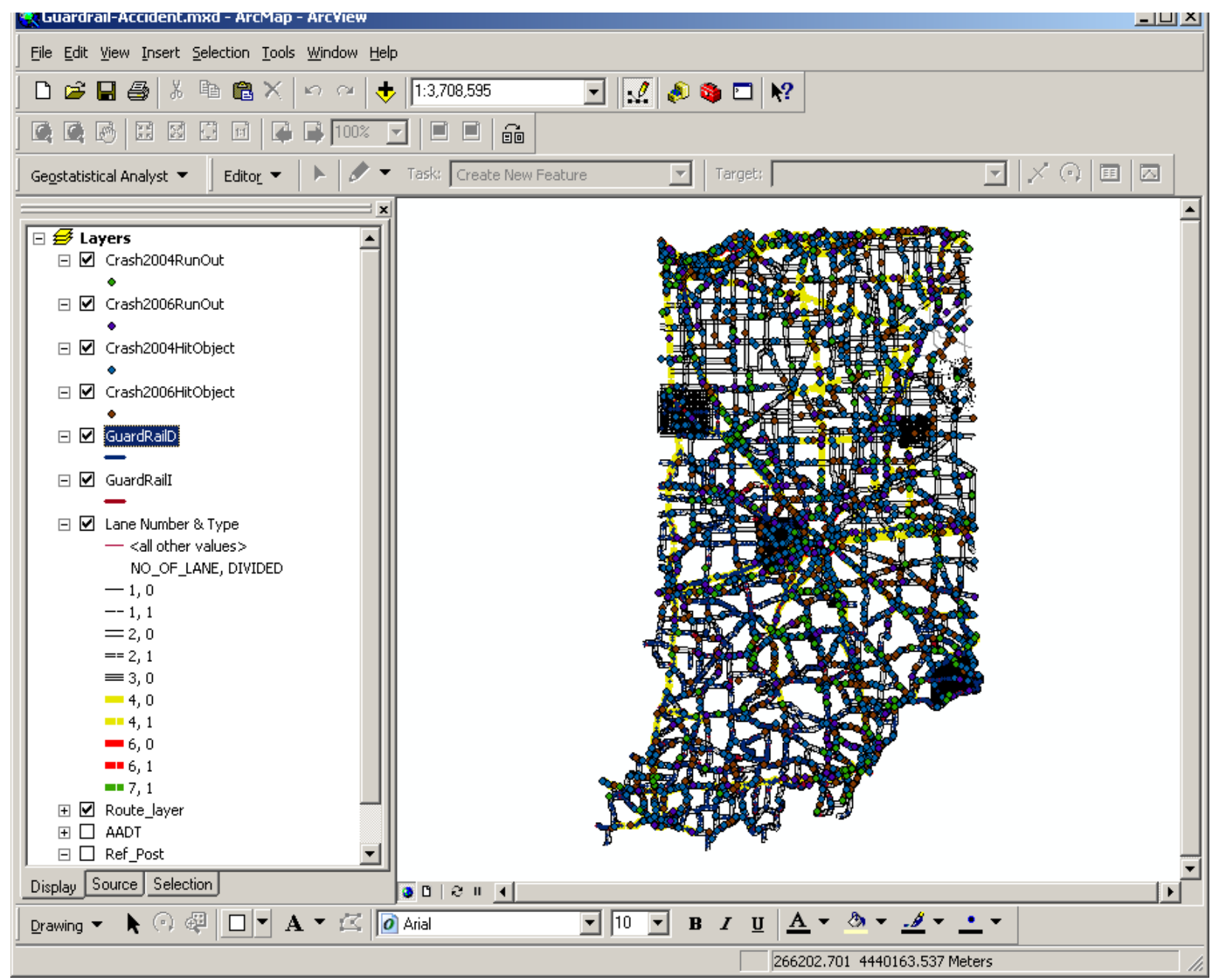

Figure 6-9 ArcMap Interface with the Table of Content Showing Highway Types and Number of Lanes 


\subsection{Functions of the Software Interface}

\section{Examine the Geographical Distribution of Features}

The ArcMap software interface allows users to visualize the geographical distribution of any features of interest. For example, a user can selectively display all 2004 ROR accidents by turning on the check marks in front of the "Crash2004RunOut" and "Crash2004HitObject" features, as shown in Figure 6-10. The ROR Only accident sites are depicted as green dots while the ROR Crash accident sites are depicted in blue. From the map, a user can view the geographical distribution of the ROR accidents and pick out areas with higher accident rates for further analysis.

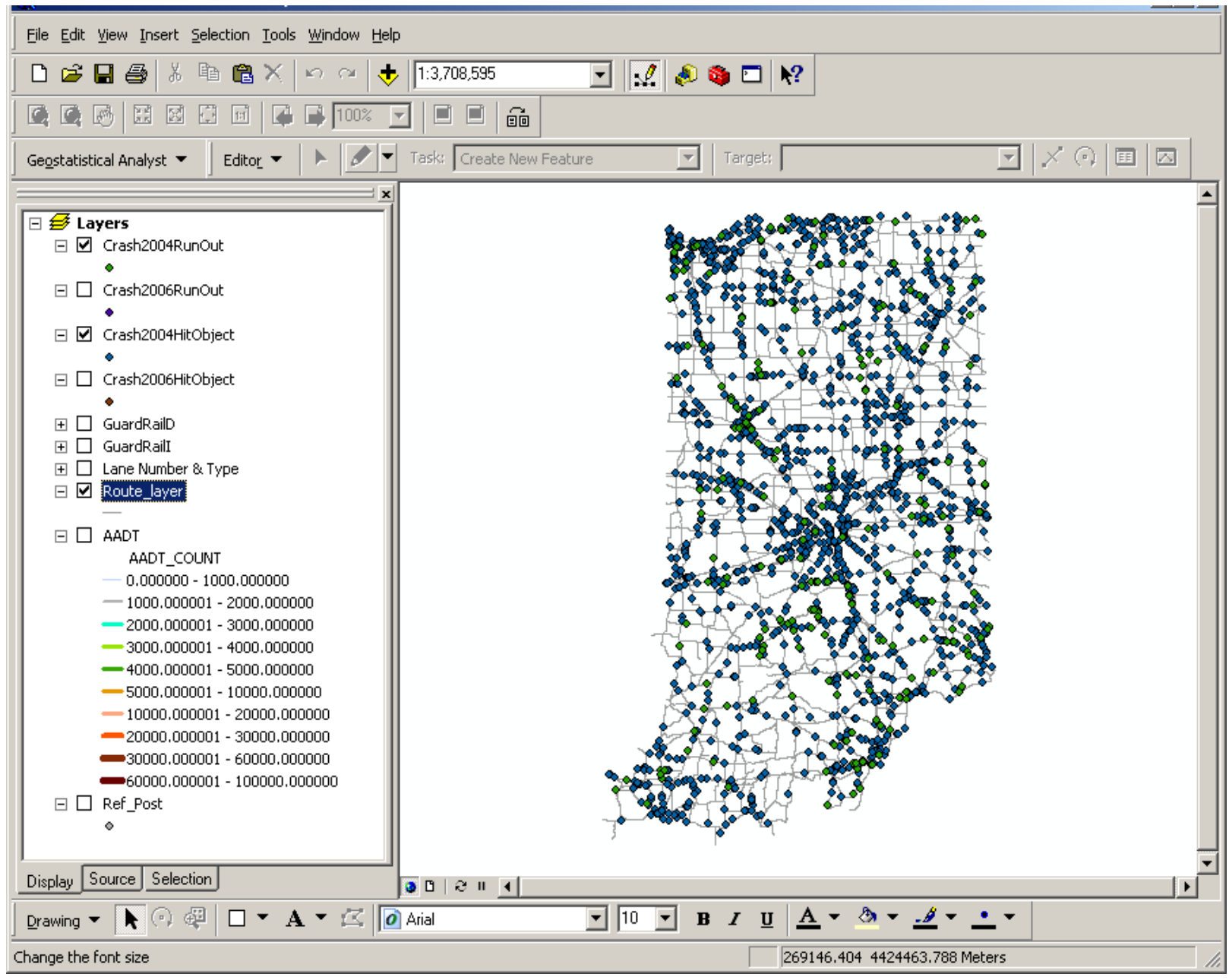

Figure 6-10 Distribution of 2004 ROR Crashes on Indiana Highways 
Figure 6-11 shows a zoomed-in area of the 2004 ROR accident sites. The user can then turns on the display of the 2006 accident sites and make comparisons between the two year data. Similarly, a user can look at the distribution of other features such as guardrails and AADTs.

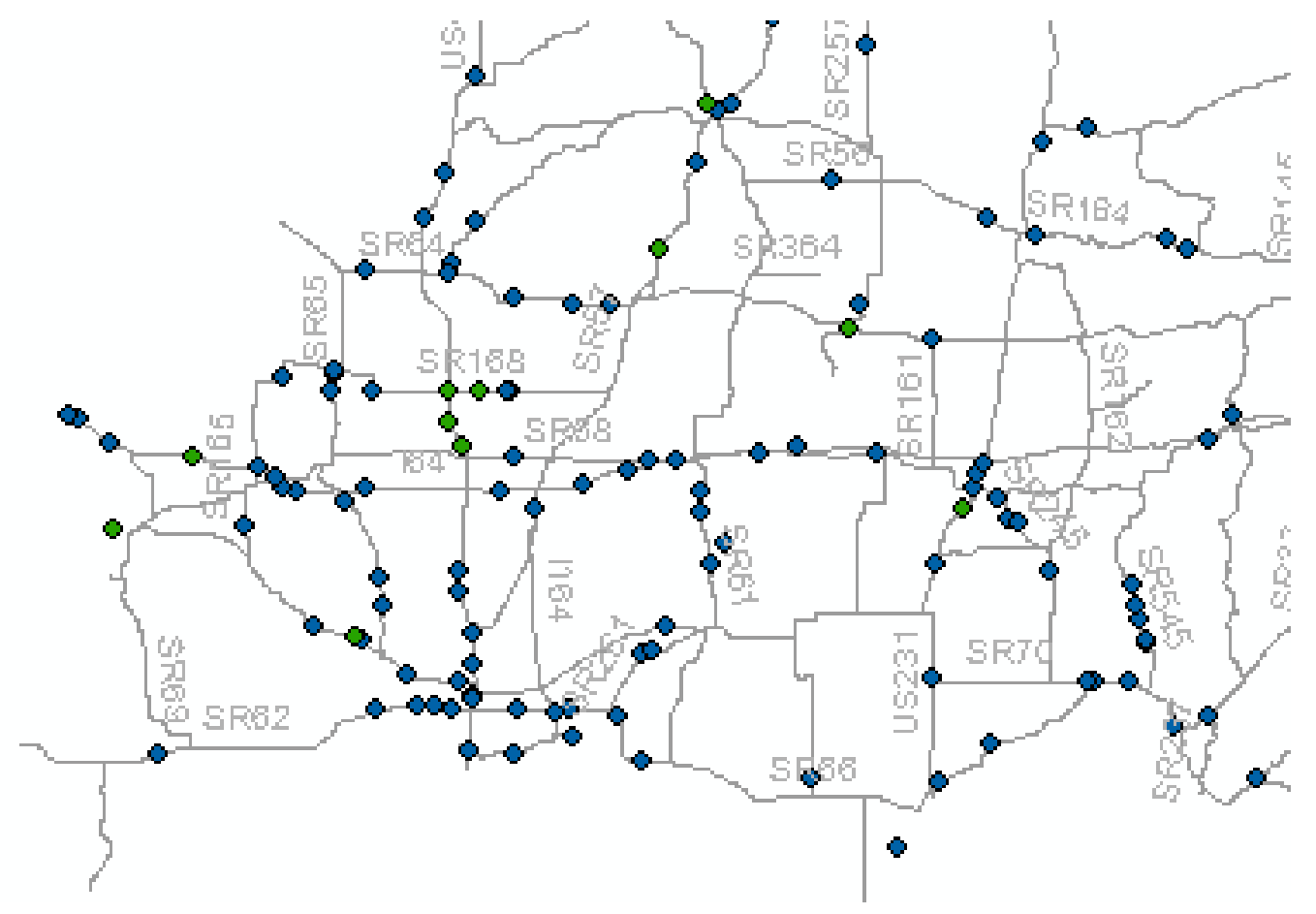

Figure 6-11 A Zoomed-In Area of the 2004 ROR Crash Sites

\section{Query of Individual Features}

Since all features are associated with attribute tables. Users can perform queries to search for features with specific criteria. As an example, the following five basic steps are utilized for users to query the "Crash2006HitObject" feature to find out accident sites with fatalities:

- Step 1. Make sure the check mark in front of the feature is present. Then use the mouse, right click the feature name to bring out the pop-up menu, as shown in Figure 6-12.

- Step 2. Select Properties... in the pop-up menu, this brings up another window. Select the Definition Query tab, as shown in Figure 6-13.

- Step 3. Click the Query Builder... button to bring out the "Query Builder" window as shown in Figure 6-14 
- Step 4. In the top section of the the "Query Builder" window, scroll down until the "DeadNmb" shows up, double click on it, then click the ">" button in the middle section. Now in the bottom section, the following text shows up “DeadNmb" >. Enter 0 at the end of the text. The text becomes "DeadNmb" $>0$. This is the query string, as shown in Figure 6-15.

- Step 5. Click the OK button. The Query Builder window will be closed and the query string will be executed. Since the query string “DeadNmb" $>0$ looks for the ROR accidents with the number of fatalities greater than 1, only those accidents meeting the criteria are displayed in the map interface now, as shown in Figure 6-16.

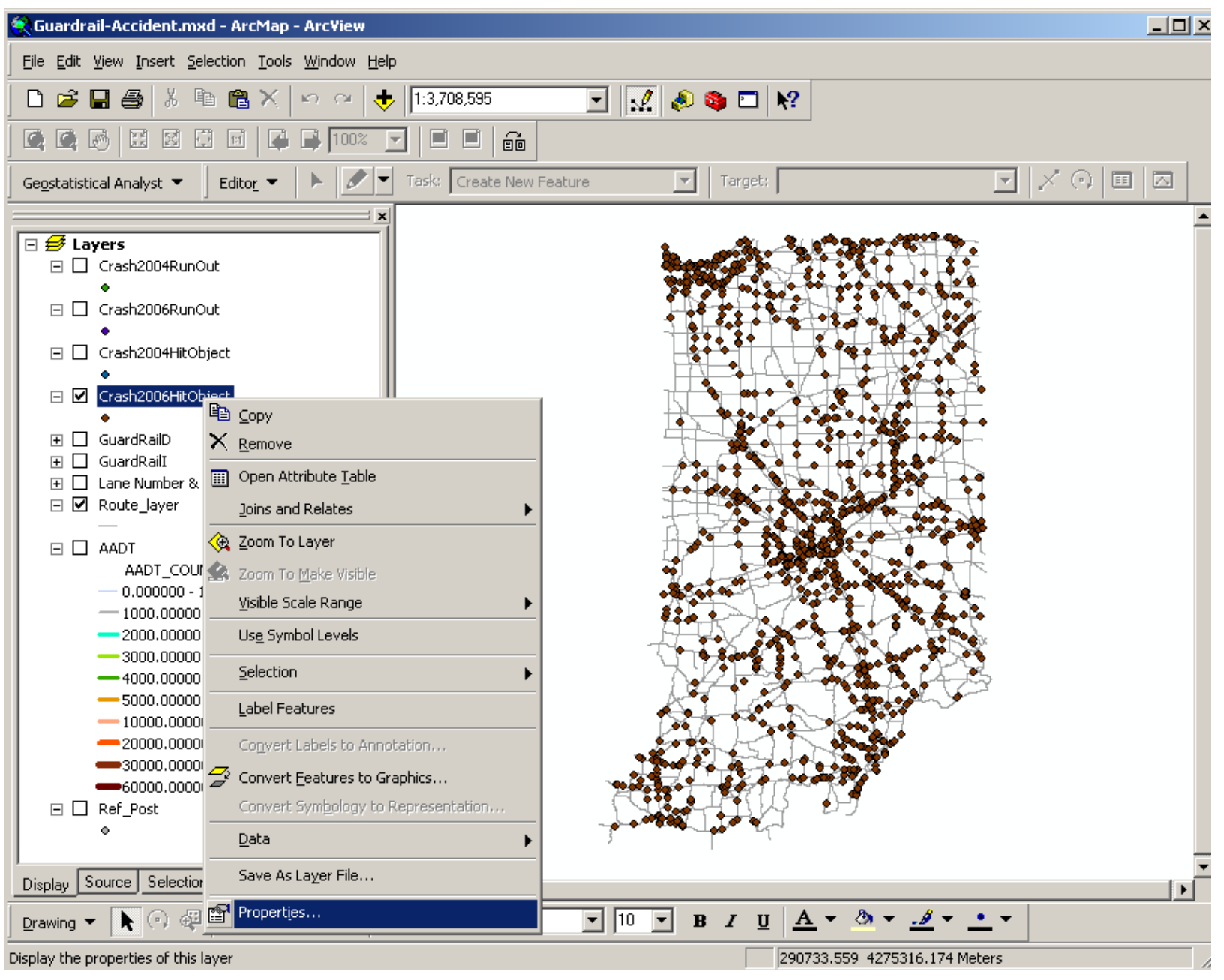

Figure 6-12 Step 1 of the Query Example 


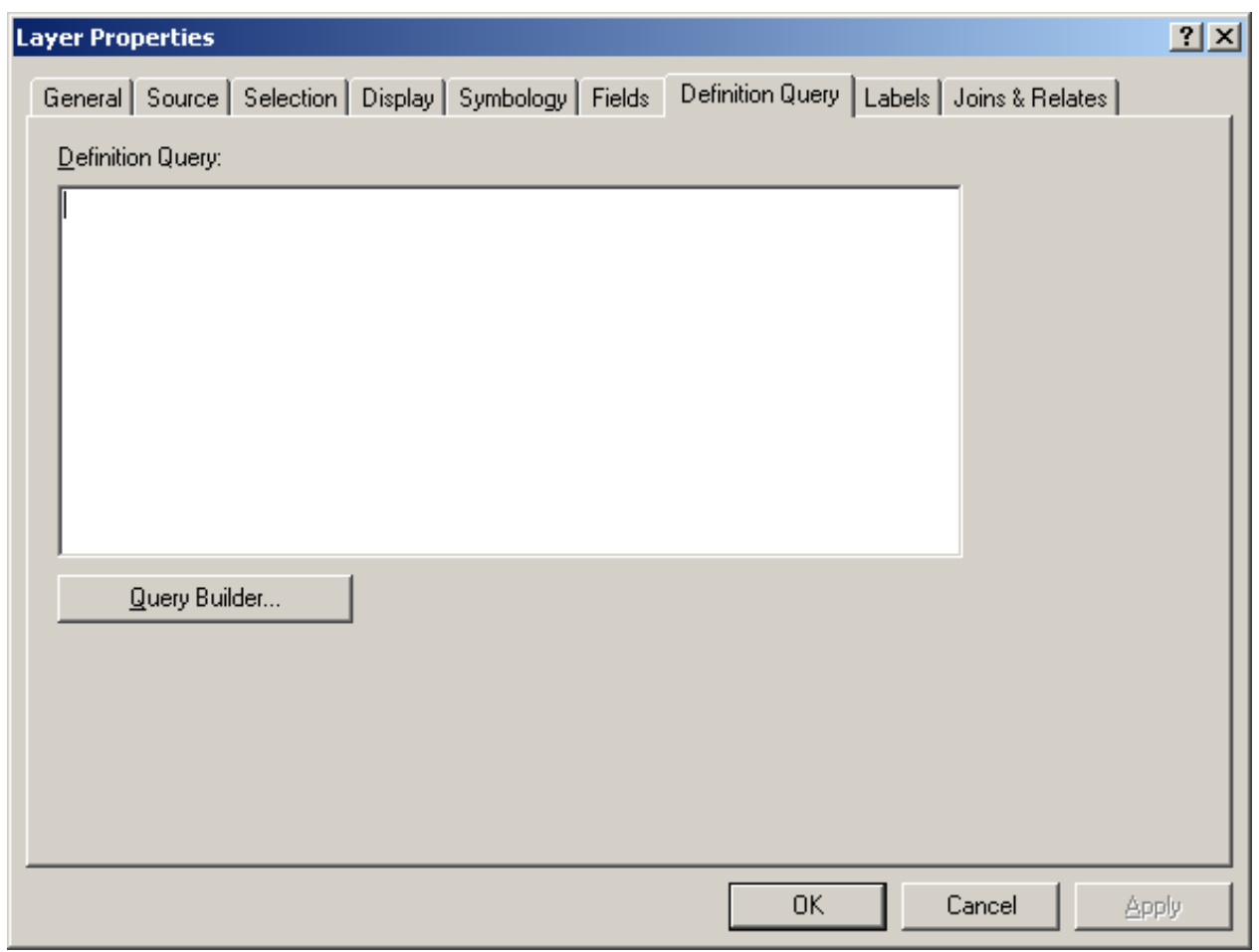

Figure 6-13 Step 2 of the Query Example

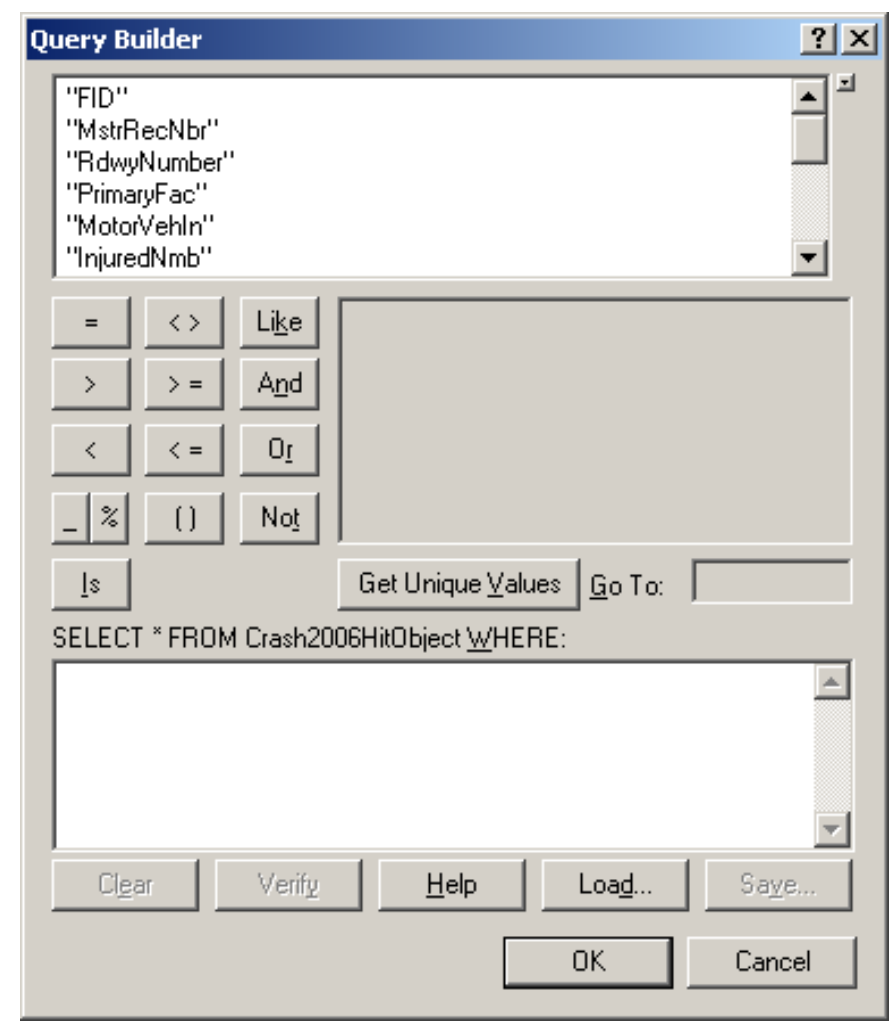

Figure 6-14 Step 3 of the Query Example 


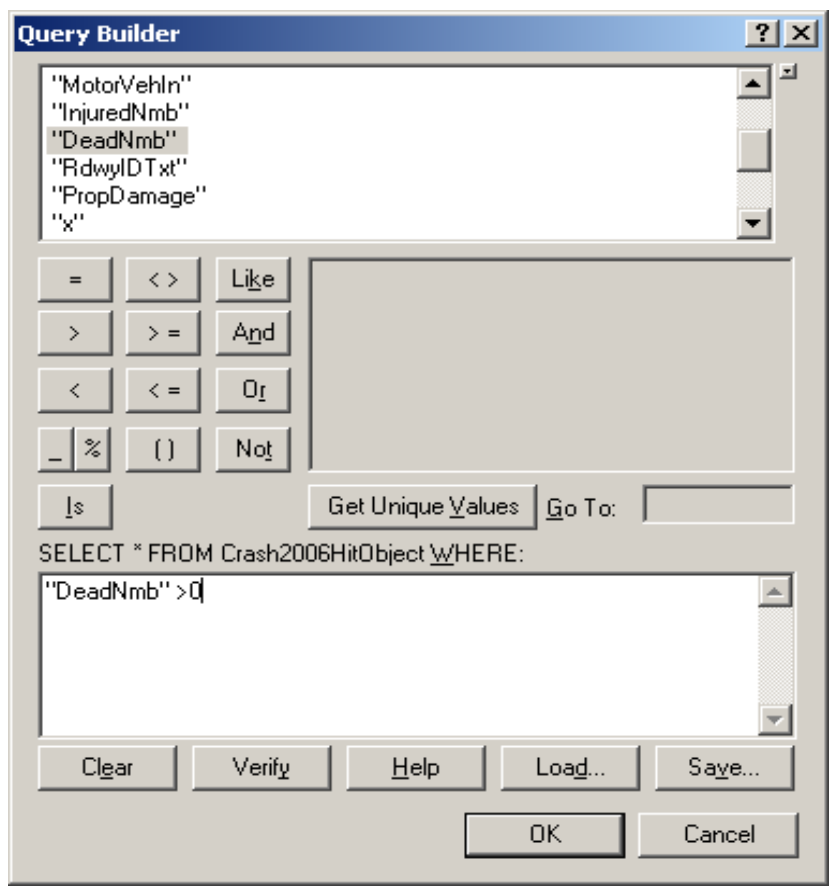

Figure 6-15 Step 4 of the Query Example

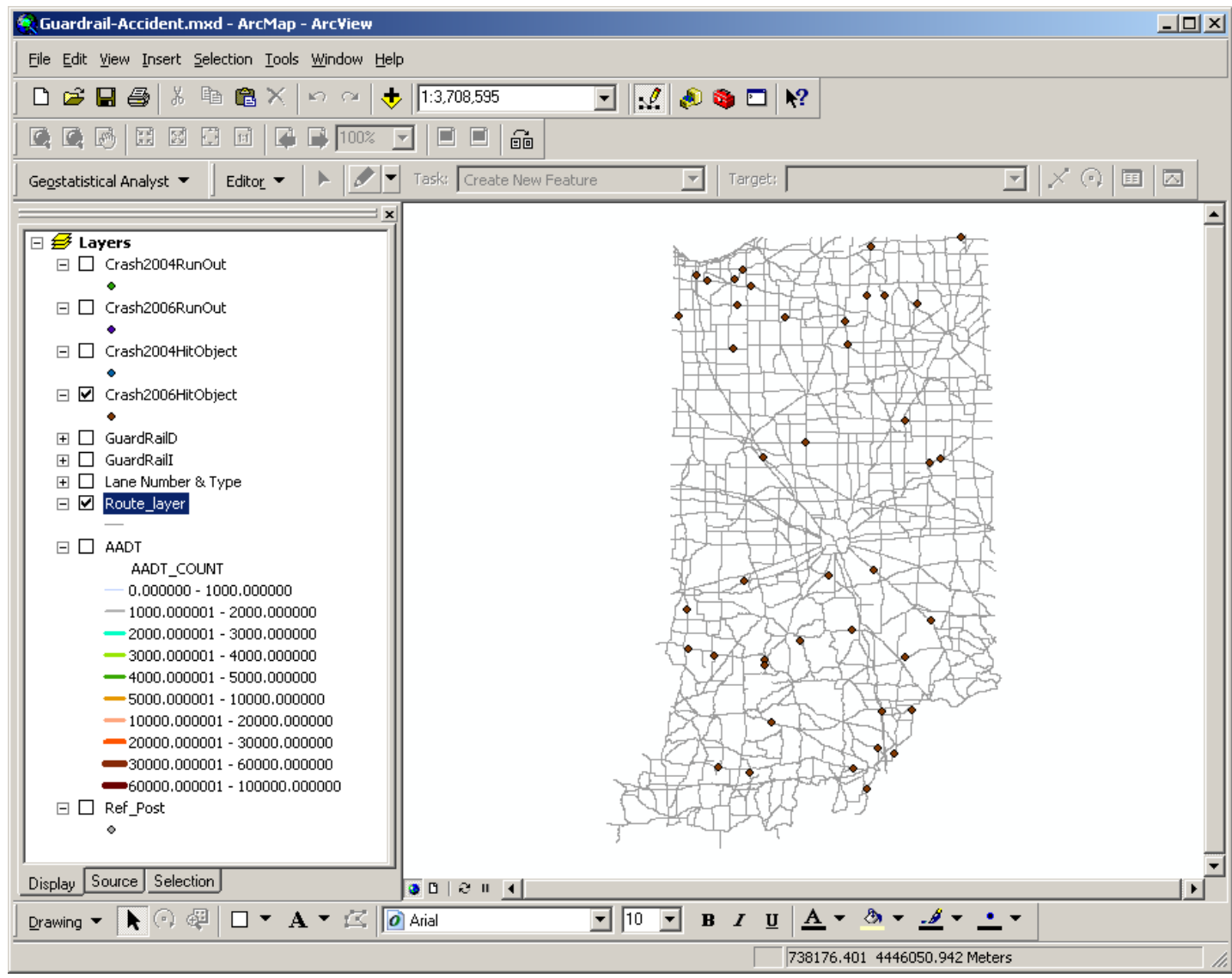

Figure 6-16 ArcMap Interface with the Map Showing 2006 ROR Fatal Crashes 
By following the steps listed above, users can query any of the features according to userspecified criteria. For example, to display all the guardrails with the "SKT-350" type of end treatment in the Crawfordsville district, user needs to perform a query on both the "GuardRailD" and "GuardRaill" features using steps outlined above. At step 4, build the query so that the string becomes "District" = 'District 1' AND "FrontEndTy" = 'SKT350'. Once the query string is executed, only the guardrails meeting the set criteria will be displayed.

\section{Data Analysis}

When geographically related features are grouped together, valuable information can be derived. As shown in Figure 6-17 is an example of the analysis of a fatal ROR accident in 2006. The red dot in the map is the location of the accident, the pop-up window with "Identify" label lists detailed information associated with the accident. From the map, we can tell that the accident site is on SR-54 between reference post 38 and 39, the road has a sharp turn at the site and there is no guardrail present. We can also tell that the road is two-lane, undivided and the AADT is between 5000 and 10000. All these are valuable information that can help provide insight in the accident analysis. Other analysis includes examination of the relationship between ROR crashes and roadway geometrics such as horizontal curves and effect of traffic volumes on the ROR crashes.

\subsection{Expansion of the Software Interface}

The core contents of the ArcMap software interface can be expanded easily. Currently only 2004 and 2006 ROR crash data is included. When new data become available, they can be added to the interface by using <Tools $>$ and $<$ Add XY Data...> in ArcMap. For any accident data to be compatible with other features in the software interface, each accident record should present the $\mathrm{X}$ and $\mathrm{Y}$ coordinates in the Universal Transverse Mercator (UTM) system. Since most accident sites are initially identified in terms of longitude and latitude, a process called map projection is necessary. The projection process can be found in the Handbook for Transformation

of Datum, Projects, Grids and Common Coordinates Systems Published by the Topographic Engineering Center of U.S. Army Corps of Engineers (14). 


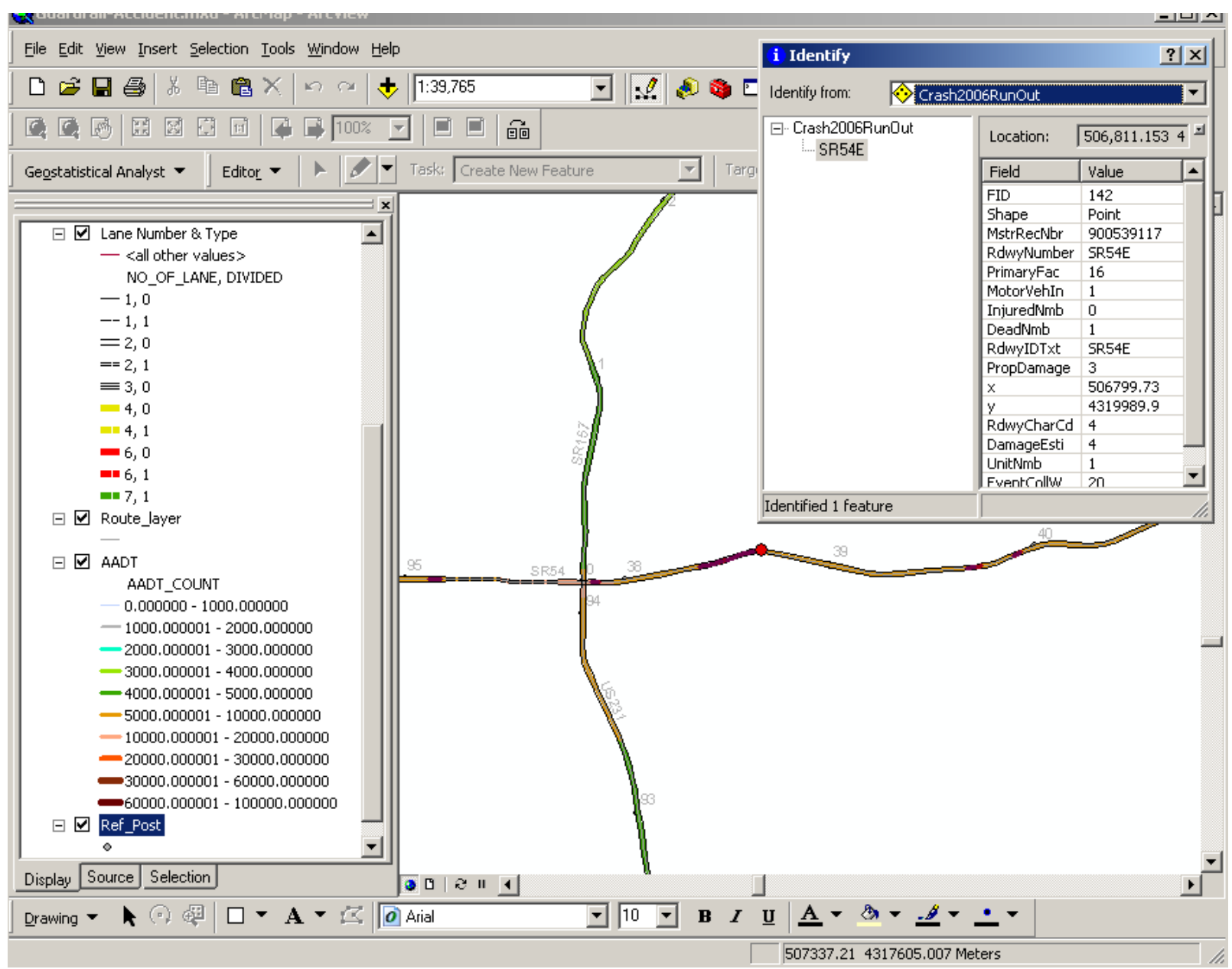

Figure 6-17 Analysis of a 2006 Fatal ROR Crash 
Chapter 7

FINDINGS, RECOMMENDATIONS, AND IMPLEMENTATION

\subsection{Main Findings}

Most right shoulder guardrails on INDOT roadways are W-beam guardrails with strong posts. Some guardrails consist of a steel rubrail below the W-beams. The post spacing includes $1.905 \mathrm{~m}$ (deflection $>1.30 \mathrm{~m}), 0.955 \mathrm{~m}$ (deflection $<1.30 \mathrm{~m})$, and $0.475 \mathrm{~m}(0.84 \mathrm{~m}<$ deflection $<1.0$ $\mathrm{m})$. Most guardrails are placed with post spacing of $1.905 \mathrm{~m}$. The guardrails adjoining bridge ends account for $37.7 \%$ of the total guardrail on interstates, $31.4 \%$ on US highways, and $30.6 \%$ on State highways.

The end treatments or crash cushions widely used for shoulder guardrails are Buried-In, CAT, ET 2000 Plus, and SKT 350 terminals. Buried-In terminals account for the significant portion of the unknown terminals which constitute $58.0 \%$ of the total number of terminals, followed by CAT (21.7\%), SKT 350 (9.9\%), and ET 2000 Plus (8.8\%). 57.9\% of the terminals are placed on State highways, $23.1 \%$ on US highways, and $19 \%$ on interstates. On interstates, CAT accounts for about $69 \%$ of the total terminals, followed by ET 2000 Plus (12\%) and SKT $350(10 \%)$. On State highways, the dominant terminals are those unknown terminals which account for $77 \%$ of the total terminals, followed by SKT 350 (8.7\%), ET 2000 Plus (7.2\%), and CAT (6.6\%). On US highways, the unknown terminals constitute $54.7 \%$ of the total terminals, followed by CAT (20.4\%), SKT 350 (12.6\%), and ET 2000 Plus (10.3\%).

ROR crashes increased from 2004 to 2006 in terms of the number, injury and fatality. Most ROR crashes occurred on the right side of highway. By average, the percentages of ROR crashes on the right side are $96.0 \%, 95.5 \%$ and $90.2 \%$ on 2-lane, multi-lane, and interstate highways, respectively. Most ROR crashes involved a single vehicle, accounting for $96.0 \%$ of the total ROR crashes. In addition, more than $85 \%$ of the fatal ROR crashes involved one person. Therefore, the majority of persons injured or killed in the ROS crashes were drivers. The majority of ROR crashes occurred on 2-lane highways, accounting for $60.9 \%$ of the total ROR crashes. Interstates and US highways respectively witnessed $20.9 \%$ and $18.2 \%$ of the total ROR crashes. $71.5 \%$ of the fatal ROR crashes occurred on 2-lane highways, $15.5 \%$ on interstates, and 
$13.0 \%$ on US highways. The ROR crashes involving three or more fatalities all occurred on 2lane highways. ROR accidents were more severe on 2-lane highways.

Highway geometric features affect ROR crashes. When horizontal curves were involved, the frequencies of ROR crashes increased in all aspects. For 2-lane and multi-lane highways, the effects of curves were noticeable, in particular on Curve-Level segments. For interstates, the effect of Curve-Grade was greater than that of Curve-Level. However, most fatalities occurred on Straight-Level segments, accounting for $84 \%$ of total fatalities. Vertical curves had some effects on crashes, injuries and fatalities.

On 2-lane highways, the greatest number of ROR crashes was recorded in June, accounting for about $9.3 \%$ of the total ROR crashes. On multi-lane highways, the greatest number of ROR crashes was recorded in October, accounting for $10 \%$ of the total ROR crashes. On interstate highways, the greatest number of ROR crashes occurred in January, accounting for $10.7 \%$ of the total ROR crashes. Monthly distributions of the ROR crashes varied more significantly on 2-lane highways than on other highways. More injuries and fatalities occurred in warm seasons regardless of highway categories. In general, ROR crashes increased as AADT increased. The greatest ROR crash rates occurred at locations with high AADT and curves.

The potential for errant vehicles to impact with guardrail terminals is very high, and tends to result in more serious consequences. On interstates, $63.5 \%$ of the vehicle-guardrail crashes impacted with guardrail faces, and $36.5 \%$ with terminals. $28.8 \%$ of the crashes on the guardrail faces caused injuries. However, $41.3 \%$ of the crashes on terminals caused injuries. The percentage of the crashes caused fatalities was $2.2 \%$ when impacting with guardrail faces and $2.5 \%$ when impacting with terminals. On multi-lane highways, $60.0 \%$ of the crashes impacted with guardrail faces, and $40.0 \%$ with terminals. For the crashes on guardrail faces, $21.6 \%$ caused injuries and $2.0 \%$ caused fatalities. For the crashes on terminals, $50.0 \%$ caused injuries and $8.8 \%$ caused fatalities. On 2-lane highways, $56.1 \%$ of the crashes impacted with guardrail faces, and $43.9 \%$ with terminals. Also, $27.4 \%$ of the crashes on guardrail faces caused injuries and no fatal crashes were observed. For the crashes on terminals, $45.8 \%$ caused injuries and $3.6 \%$ caused fatalities.

ROR encroachment increased as traffic volume increased and exhibited considerable dispersions. The encroachment rates varied from 0.084 to $10.268,0.067$ to 2.828 and 0.333 to 4.065 on 2-lane, 4-lane, and 6-lane (or more) highways, respectively. The encroachment rates 
obtained by this study are less than those in the AASHTO Roadside Design Guide. Multi-lane highways experienced the greatest crash probability and interstates the smallest probability. The majority of the ROR crashes caused damages of Level 4 for 2-lane highways, Level 3 for multilane highways, and Level 4 or Level 5 for interstates. Overall, the ROR crashes at Levels 3, 4 and 5 accounted for $85 \%$ of the total ROR crashes. The crash losses were very sensitive to the damages of Levels 8 and 9.

Steel guardrail parts prices increased dramatically. From 2005 to 2009, the parts prices increased by $23.1 \%$ to $135.8 \%$, depending the terminal type. In the meantime, the labor price increased $8.74 \%$ each year. For median crash cushions, the majority of the repair costs were spent on parts, which accounted for more than $85 \%$ of the repair costs. Hex-Foam Sandwich demonstrated the greatest repair cost per crash, followed by ADIEM, TAU II, GREAT, and QUADGUARD. For should guardrail terminals, the parts costs accounted for $58 \%$ or less. The labor costs accounted for $30 \%$ to $44 \%$, and the equipment costs for $10 \%$ to $15 \%$. ET 2000 Plus demonstrated the lowest repair cost per crash, followed by SKT 350. The repair costs are overestimated for CAT, ET 2000 Plus, SKT 350 and Impact Barrel, but underestimated for other crash cushions in the INDOT Design Manual,

For regular guardrail repairs, however, the labor rather than the parts consumed the majority of the repair costs. On average, the labor, equipment, and parts costs respectively accounted for $62.1 \%, 31.5 \%$ and $6.3 \%$ of the total repair costs. The average guardrail repair cost is $\$ 722$ per crash with a confidence bound between \$506 and \$937. Again, the guardrail repair cost is overestimated in the INDOT Design Manual. The annual average guardrail maintenance cost is $\$ 0.305$ per linear foot.

\subsection{Recommendations}

The unknown terminals account for $57.7 \%$ of the total guardrail terminals on roadways under INDOT's jurisdiction. In particular on State highways, the unknown terminals account for $77 \%$ of the total terminals. On US highways, the unknown terminals constitute $54.7 \%$ of the total terminals. Based on the results of field surveys conducted by this study, the major portion of the unknown terminals are Buried-In terminals. When an errant vehicle impact a Buried-In terminal, 
the errant vehicle may override the guardrail, get behind the guardrail or become airborne. Therefore, the use of Buried-In terminals requires special cares and is discouraged.

The majority of the fatal ROR crashes involved one person. Therefore, an efficient way to reduce ROR crash fatalities is to take proactive countermeasures, such as shoulder rumble strips, speed management, and public education.

The majority of ROR crashes occurred on 2-lane highways. In order to enhance roadway safety performance effectively, further effort, such as shielding of roadside obstacles and installation of guardrails on steep grade, should be made to improve 2-lane highway roadside safety.

The encroachment rates obtained by this study are less than those in the AASHTO Roadside Design Guide, which was identified 30 years ago in British Columbia, Canada. It is worthy to make further effort to upgrade the encroachment rates for guardrail design and engineering analysis.

Steel guardrail parts prices have increased dramatically in the past years. It appears that the default guardrail repair cost data is outdated and should be updated.

The ArcMap interface developed by this study integrates ROR crashes with road map and roadside safety facilities and provides the unique visualization benefit, and can be utilized to enhance the analysis and management of roadside safety and guardrail data.

\subsection{Implementation}

In general, the findings can be implemented by INDOT to upgrade the current practices, polices, and design manuals associated with guardrail engineering analysis and design. The findings on the characteristics and contribution factors of the ROR crashes can be utilized by INDOT planning to make more informed decisions on guardrail installations. The ArcMap interface can be utilized to enhance the analysis and management of roadside safety and guardrail data.

A detailed implementation plan will be developed by PIs together with the INDOT Traffic Safety Office personnel. The focus will be on three immediate issues. First, the ArcMap interface will be fine-tuned and used by the Traffic Safety Office to determine if a low cost safety improvement program of providing guardrail at unprotected locations can be developed 
and if the ArcMap application is able to identify candidate routes and projects. Second, the outdated or substandard roadside guardrails, in particular the Buried-In end treatments on NHS highways, will be identified for upgrading. Third, specific needs for improving the roadside safety at those fatal ROR crash sites, such as installation of roadside guardrails, will be determined. 


\section{REFERENCES}

(1) Roadside Design Guide, American Association of State Highway and Transportation Officials (AASHTO), Washington D. C., 2002.

(2) Ross H. E., D. L. Sicking, R. A. Zimmer, and J. D. Michie, Recommended Procedures for the Safety Performance Evaluation of Highway Features, NCHRP Report 350, Transportation Research Board, Washington, D. C., 1993.

(3) Design Manual, Indiana Department of Transportation. 2006.

(4) Mak K. K., and Sicking D. L., Roadside Safety Analysis Program (RSAP)-Engineer's Manual, NCHRP Report 492, Transportation Research Board, Washington, D. C., 2003.

(5) M. H. Ray, J. Weir, and J. Hopp, Roadside In-Service Performance of Traffic Barriers, NCHRP Report 490, Transportation Research Board, Washington, D. C., 2003.

(6) Collision Data, Automated Reporting Information Exchange System (ARIES), Indiana State Police.

(7) Michie J. D., Recommended Procedures for the Safety Performance Evaluation of Highway Features, NCHRP Report 230, Transportation Research Board, Washington, D. C., 1981.

(8) Technical Advisory $T$ 7570.1, Motor Vehicle Accident Costs, Federal Highway Administration (FHWA), U.S. Department of Transportation, June 30, 1988.

(9) Technical Advisory $\mathrm{T}$ 7570.2, Motor Vehicle Accident Costs, Federal Highway Administration (FHWA), U.S. Department of Transportation, October 31, 1994.

(10) Shuo Li, Scott Newbolds, Karen Zhu, and Holly Menne, Field Evaluation of Brifen WRSF on Indiana Freeways: Phase I Safety Performance and Economic Issues, Final Report, Part 2, Office of Research and Development, Indiana Department of Transportation, 2009.

(11) Design Alternatives for Rural Roads, Franklin Regional Council of Governments, Greenfield, MA 01301, 2002.

(12) ArcGIS 9: ArcMap Tutorial, ESRI, USA, 2006.

(13) Cooper P., Analysis of Roadside Encroachments-Single Vehicle Run-Off-Road Accident Data Analysis for Five Provinces, B. C. Research, Vancouver, British Columbia, Canada, 1980. 
(14) Handbook for Transformation of Datums, Projections, Grids and Common Coordinate Systems. TEC-SR-7. US Army Corps of Engineers, Topographic Engineering Center, 1996. 